\author{
UNIVERSIDADE DE SÅO PAULO \\ FACULDADE DE MEDICINA DE RIBEIRÃO PRETO
}

\title{
EXCREC̄̃O URINÁRIa DE HIDROXIPROLINA NA DEFICIENCIA PROTÉICa EXPERIMENTAL EM RATOS DE IDADES DIFERENTES
}

\author{
Aparecida Yooko Outa Angeleli
}

Oriontador: Prof. Or. J. E. DUTRA DE OLIVEIRA

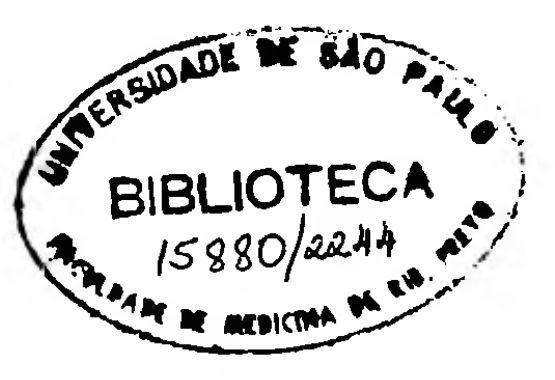
Dissertaçāo de Mestrado apresentado so Curso de Pós-Graduação em Bioquimica da Faculdade de Medicina de Ribeiräo Preto.

- RIBEIRAO PRETO -

1982 
Data de Delesa

Con:

कysio: 713081 
Dedicada a

WALTER ANTONIO ANGELELI

Por considerar que ainda este simples ato the é devido, a ele e aos que o amaram, agora, quando para ele jā não há mais retorno. 
Por meus filhos

Omir Francisco

e

Camila

\author{
em cujas "ternuras" busco \\ coragem e esperança
}

Reconheço com gratidão o amparo amigo que recebi de meus familiares, principalmente nas pessoas das mães Tomie ota e Jacyra Setten Angeleli. 
Ao Prof.Dr. J.E. Dutra de Oliveira, amigo e orientador deste trabalho, de quem procuro assimilar a grande capacidade em conciliar ciência e familia e que me propiciou condições para o desenvolvimento da pes quisa. 


\section{AGRADECIMENTOS}

o experimento piloto foi realizado no Departamento de Clínica Médica da Faculdade de Medicina de Ribeirão Pre to. A fase experimental definitiva foi realizada no Laboratório de Pesquisas Bioquímicas do Departamento de Clínica Médica da Fa culdade de Medicina de Botucatu - UNESP.

Muitos participaram deste trabalho e meus agra decimentos se estendem a todos que tiveram envolvimento direto ou indireto, particularmente:

- Ao Prof.Dr. Alvaro Oscar Campana, responsável pelo meu ingresso na carreira científica, de quem procurei absorver a seriedade e o rigor científicos;

- Ao Prof.Dr. Roberto Carlos Burini, pelo companheirismo e constante presença científica, responsável imediato pelo grande impulso das pesquisas do grupo, coordenando, orientando e criticando construtivamente em prol do desenvolvimento científico;

- Ao Prof.Dr. João Lauro Viana de Camargo, parceiro dinâmico desta pesquisa, pela revisão crítica do testo e pela análise histológica do fígado;

- Ao Prof.Dr. Paulo Roberto Curi, por tornar compreensível o intrincado processo de análise estatística dos dados obtidos;

- A Professora Maria Aparecida M. Rodrigues Kobayasi, pelo co leguismo e auxilio no tratamento dos animais;

- A Bibliotecāria Elza Numata, pelas sugestões apresentadas pạ ra a disposição dos dados bibliográficos;

- A Professora Miriam Celi P. Porto Foresti, do Departamento de Pedagogia, pela pronta disponibilidade na revisão ortográfica e gramatical do texto;

- Aos colegas da Disciplina de Laboratório Clínico que tornaram viável meu afastamento para realização do Curso de Pós-Graduação;

- Aos funcionários do Departamento de Clínica Médica da Facul dade de Medicina de Ribeirão Preto, pela manutenção cotidia 
na de um bom clima de trabalho, em especial a Telma Regina Rodrigues, Antonio Luis de Cário e Miltom Domingues Pateiro;

- Aos funcionários ligados ao Laboratório de Pesquisas Bioquí micas do Departamento de Clínica Médica da Faculdade de Medicina de Botucatu, nas pessoas de Adércio Ferreira, Amando de Assis Laperuta, Darci Severo, Hēlio João Listoni, José Antonio Grassi e Silvio Antunes, que auxiliaram e não negaram esforços em sacrificar seus feriados para a realização deste trabalho;

- Ao Sr. Alcides Aparecido Corvino pelo carinho na confecção das figuras;

- Ao Sr. Nivalde A. Basso pelo capricho nos serviços datilográficos;

- Ao Sr. Modesto Bovolenta, Diretor do Biotério Central e aos funcionários da Oficina Gráfica do Campus de Botucatu;

Finalmente expresso meus agradecimentos à Maria Thereza Rodrigues e aos colegas de Pós-Graduação que conviveram comigo no triênio 76-78. Tornaram bastante agradável nosso convívio; a eles sou grata e todos sabem porque. 
MATERIAL E METODOS ........................ 5

1. Animais, Ambiente e Delineamento Experimental ... 5

2. Agua e Dietas ........................ 7

3. Peso dos Animais ........................ 8

4. Ingestão Alimentar .................... 9

5. Coleta da Urina e Preparo das Amostras para Dosa-

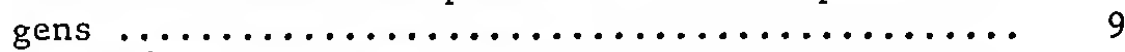

6. Sacrifício dos Animais, Coleta de Sangue e Obtenção do Fragmento de Fígado .................. 11

7. Métodos de Dosagem ...................... 11

8. Bases de Referência .................... 12

9. Anālise Histológica do Fígado .............. 12

10. Análise Estatística - Anālise Multivariada de Per

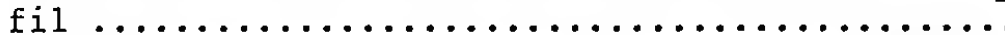

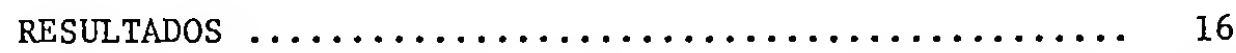

1. Peso dos Animais ....................... 16

2. Ingestão Al imentar ...................... 19

3. Excreção Urinária de Nitrogênio Uréico ......... 24

4. Proteînas Plasmáticas .................... 29

5. Análise Histológica do Fígado .............. 30

6. Excreção Urinária de Creatinina ............... 31

7. Excreção Urināria de Hidroxiprolina Total ...... 36

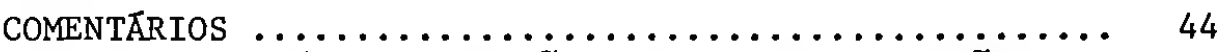

1. Peso Corpóreo, Ingestão Alimentar e Excreção de Nitrogênio Urêico ........................ 44

2. Excreção Urinária de Creatinina ............ 48

3. Avaliação do Estado Nutricional ............ 49

4. Hidroxiprolina Urinária e Metabolismo do Colägeno 59

5. Influência da Idade Sobre o Metabolismo do Coláge

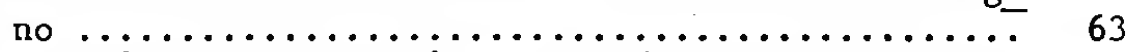

6. Influência da Deficiência Protéica Sobre a Excreção de Hidroxiprolina .................... 64

CONCLUSÕES $\ldots \ldots \ldots \ldots \ldots \ldots \ldots \ldots \ldots \ldots \ldots \ldots \ldots \ldots \ldots \ldots \ldots \ldots \ldots \ldots$

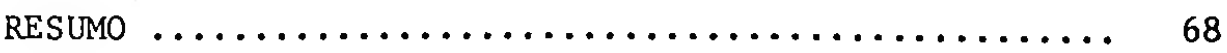

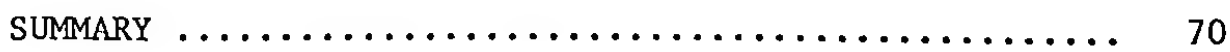

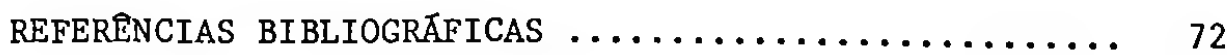

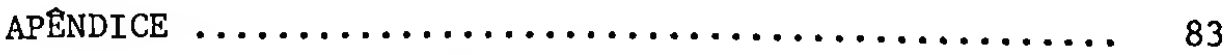


Pāg.

1. Esquematização do delineamento experimental ......... 6

2. Gaiola metabólica .......................... 10

3. Peso médio (em gramas) dos animais durante o período experimental ................................ 17

4. Ingestão alimentar diāria média ( $g / d i a)$ dos animais durante o periodo experimental .................. 20

5. Ingestão alimentar diária média ( $\mathrm{g} / \mathrm{l} 00 \mathrm{~g}$ rato/dia) dos animais durante o periodo experimental ..............

6. Excreção urinária de nitrogênio uréico (mg/dia) dos animais durante o periodo experimental ...............

7. Excreção urināria de nitrogênio uréico (mg/loog rato/dia) dos animais durante o período experimental ...........

8. Excreção urināria de creatinina (mg/dia) dos animais du-

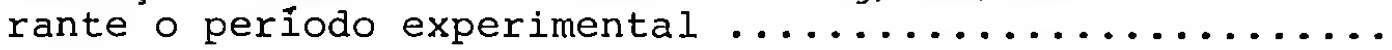

9. Excreção urinária de creatinina (mg/lo0g rato/dia) dos a nimais durante o periodo experimental .............

10. Excreção urināria de hidroxiprolina total ( $\mu \mathrm{g} / \mathrm{dia}$ ) dos a nimais durante o periodo experimental ..............

11. Excreção urinária de hidroxiprolina total ( $\mu \mathrm{g} / 100 \mathrm{~g}$ rato/ /dia) dos animais durante o período experimental ......

12. Excreção urinária de hidroxiprolina total $(\mu \mathrm{g} / \mathrm{mg}$ creatinina/dia) dos animais durante o periodo experimental ...

13. Biossintese da uréia e de pirimidinas ............ 57

14. Degradação de colágeno até hidroxiprolina urinária ....

\section{RELAÇÃO DAS TABELAS}

1. Peso médio (em gramas) dos animais dos grupos controlese hipoprotéicos durante o período experimental ..........

2. Ingestão alimentar diāria média ( $/$ /dia) dos animais dos grupos controles e hipoprotêicos durante o período expe-

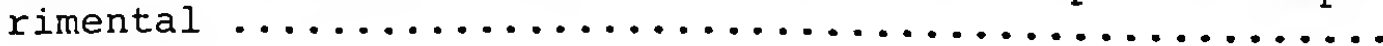

3. Ingestão alimentar diāria média ( $/ 100 \mathrm{~g}$ rato/dia) dos animais dos grupos controles e hipoprotéicos durante o pe riodo experimental 
4. Excreção urināria de nitrogênio uréico (mg/dia) dos ani. mais dos grupos controles e hipoprotéicos durante o periodo experimental ....................... 26

5. Excreção urināria de nitrogênio uréico (mg/100g rato/dia) dos animais dos grupos controles e hipoprotéicos durante 28

6. Valores estatisticos das proteínas plasmáticas ........

7. Frequência de esteatose hepática segundo sua intensidade nos animais tratados com dieta hipoprotéica, após 42 dias de periodo experimental ..................... 30

8. Excreção urināria de creatinina (mg/dia) dos animais dos grupos contioles e hipoprotéicos durante o período expe-

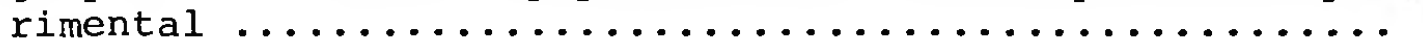

9. Excreção urinária de creatinina (mg/lo0g rato/dia) dos a nimais dos grupos controles e hipoprotéicos durante o pe

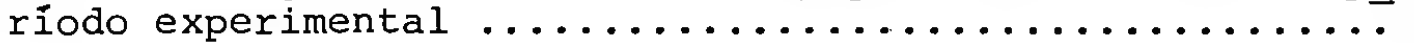

10. Excreção urināria de hidroxiprolina total ( $\mu \mathrm{g} / \mathrm{dia}$ ) dos a nimais dos grupos controles e hipoprotéicos durante o pe riodo experimental ........................

11. Excreção urinária de hidroxiprolina total ( $\mu \mathrm{g} / 100 \mathrm{~g}$ rato/ /dia) dos animais dos grupos controles e hipoprotêicos du rante o periodo experimental ...................

12. Excreção urináxia de hidroxiprolina total ( $\mu \mathrm{g} / \mathrm{mg}$ creatinina/dia) dos animais dos grupos controles e hipoprotéico durante o período experimental .................

13. Ingestão alimentar e ganho de peso observados em ratos da linhagem Wistar, alimentados com dietas controle prepa-

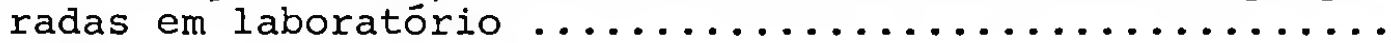

14. Peso semanal (em gramas) dos animais dos grupos controles durante o período experimental ...............

15. Peso semanal (em gramas) dos animais dos grupos hipoprotéicos durante o período experimental ...............

16. Ingestão alimentar diāria média (g/dia) dos animais dos grupos controles durante o período experimental .......8 8

17. Ingestão alimentar diāria média (g/dia) dos animais dos grupos hipoprotéicos durante o período experimental ....

18. Ingestão alimentar diāria média (g/l00g rato/dia) dos animais dos grupos controles durante o periodo experimen-

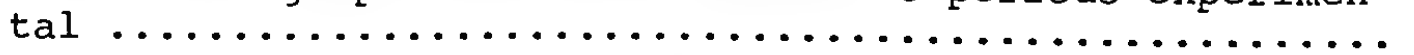

19. Ingestão alimentar diāria média ( $g / 100 \mathrm{~g}$ rato/dia) dos animais dos grupos hipoprotéicos durante o período experi mental 
20. Excreção urināria de nitrogênio uréico (mg/dia) dos animais dos grupos controles durante o período experimental

21. Excreção urinária de nitrogênio uréico (mg/dia) dos animais dos grupos hipoprotéicos durante o período experimental

22. Excreção urināria de nitrogênio uréico (mg/100g rato/dia) dos animais dos grupos controles durante o período expe-

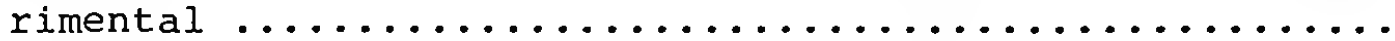

23. Excreção urināria de nitrogênio uréico (mg/lo0g rato/dia) dos animais dos grupos hipoprotéicos durante o periodo

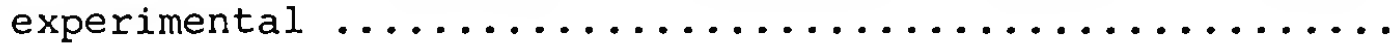

24. Concentração plasmática de proteínas totais e frações (al bumina e globulina), em go dos animais dos grupos contrō les e hipoprotéicos após 42 dias de período experimental

25. Excreção urināria de creatinina (mg/dia) dos animais dos grupos controles durante o período experimental .......

26. Excreção urināria de creatinina (mg/dia) dos animais dos grupos hipoprotéicos durante o período experimental ....

27. Excreção urinária de creatinina (mg/100g rato/dia) dos a nimais dos grupos controles durante o periodo experimental

28. Excreção urinäria de creatinina (mg/100g rato/dia) dos a nimais dos grupos hipoprotéicos durante o período experi

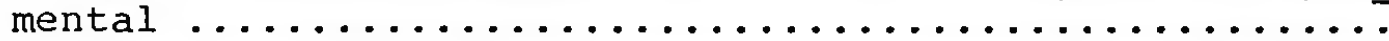

29. Excreção urināxia de hidroxiprolina total ( $\mu \mathrm{g} / \mathrm{dia}$ ) dos a nimais dos grupos controles durante o período experimen= tal

30. Excreção urināria de hidroxiprolina total ( $\mu \mathrm{g} / \mathrm{dia}$ ) dos a nimais dos grupos hipoprotéicos durante o periodo experi

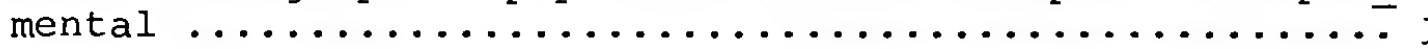

31. Excreção urināria de hidroxiprolina total ( $\mu \mathrm{g} / \mathrm{l00g}$ rato/ /dia) dos animais dos grupos controles durante o período experimental ............................ 101

32. Excreção urinária de hidroxiprolina total ( $\mu \mathrm{g} / 100 \mathrm{~g}$ rato/ /dia) dos animais dos grupos hipoprotéicos durante o periodo experimental ......................... 102

33. Excreção urināria de hidroxiprolina total ( $\mu \mathrm{g} / \mathrm{mg}$ creatinina/dia) dos animais dos grupos controles durante o pe-

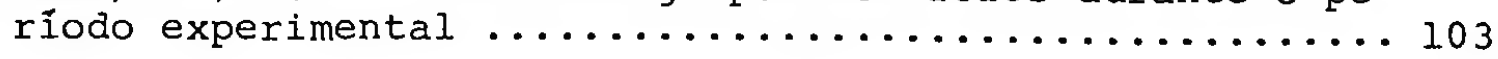

34. Excreção urināria de hidroxiprolina total ( $\mu \mathrm{g} / \mathrm{mg}$ creatinina/dia) dos animais dos grupos hipoprotéicos durante o

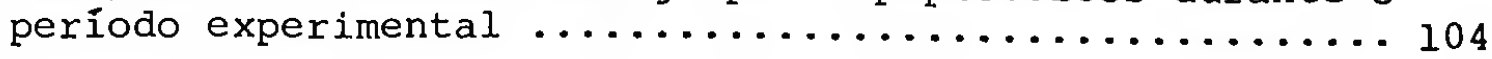


INTRODUÇÃO

Os dados existentes na literatura demonstram a elevada frequência de várias deficiências nutricionais a nível internacional e reforçam o interesse, a oportunidade e a atualidade da realização de estudos na área de nutrição. No início da década de 70, iniciou-se neste Laboratório (Laboratório de Pesquisas Bioquímicas do Departamento de Clínica Médica da Faculdade de Medicina de Botucatu), grupo multiprofissional interessado no estudo dos mecanismos de adaptação do organismo às deficiências nutricionais.

A preocupação básica inicial foi o estudo das alterações metabólicas decorrentes da deficiência específica de proteínas. Considerando a quase inviabilidade deste estudo em hu manos, uma vez que a desnutrição humana é multifatorial, optou-se pelo emprego de modelo experimental.

o modelo escolhido utilizou o rato como animal e a deficiência nutricional foi induzida pelo uso de dietas experimentais de composições definidas (REZENDE, 1973; ACHILLES, 1974; BURINI, 1974; BURINI et alii, 1976a e b; CAMARGO, 1981).

A caracterização da deficiência protēica tem sido consubstanciada nas seguintes evidências: perda de peso dos animais, balanço nutrogenado negativo, hipoproteinemia, hipoalbu minemia e esteatose hepática (CAMPANA et alii, 1975). Estes resultados têm sido sistematicamente reproduzidos nos estudos sobre deficiência protéica realizados por BURINI et alii, 1972; $\underline{R E}$ ZENDE, 1973; ACHILLES, 1974; OUTA et alii, 1975; ANGELELI et alii, 1978; MAFFEI et alii, 1980; BURINI et alii, 1981; CAMPANA \& BURINI, 1982 . 
o tecido muscular desses animais adaptou-se à condição dietética, com redução do teor nitrogenado, particularmente o nitrogênio não colágeno, sem alteração dos níveis de DNA, sugerindo existência de retração citoplasmática sem alteração da celularidade (BURINI et alii, 1981a). Um dado que despertou a atenção desde os primeiros experimentos realizados(BURINI et alii, 1972 ) foi o comportamento peculiar do nitrogênio colágeno, o qual se encontrava elevado, contrariamente ao nitrogênio total e fração não colāgena (BURINI et alii, 1981a).

Em outro estudo (ANGELELI et alii, 1978) foi demonstrado que a elevação da concentração do nitrogênio colágeno ocorreu também em outros órgãos como fígado, pele e carcaça, não sendo o aumento devido ao acúmulo ocorrido durante o período de carência protéica mas sim à diminuição seletiva das outras frações nitrogenadas. Nas condições do estudo, o colágeno mostrou-se mais resistente à degradação do que as proteínas não colāgenas.

O colágeno constitui 20-25\% do total de proteí nas do organismo de mamíferos (NEUBERGER et alii, 1951;NEUBERGER \& RICHARDS, 1964), onde desempenha funções físicas, físico-quími cas e biológicas como: estabilidade estrutural mecânica; interações dinâmicas e formação de depōsitos, mecanismos básicos para a homeostase do metabolismo de água e eletrólitos nos tecidos; re paro de lesões e defesa orgânica, respectivamente (CHVAPIL, 1967). Sendo o maior componente do tecido conectivo, o colágeno constitui elemento essencial para sustentação de órgãos e de tecidos (DAWSON \& MILNE, 1978). E uma proteina típica, que apresenta alteração da sua estrutura molecular com a idade. Produzida pelos fibroblastos, imersos na substância fundamental do conectivo, aparece inicialmente na forma imatura de tropocolágeno, caracte- 
rística dos tecidos em formação. As unidades de tropocolágeno se polimerizam em fibrilas, constituindo o protocolágeno. Com o envelhecimento, estas formas vão se polimerizando gradativamente em moléculas maiores, atingindo a forma adulta ou madura de fibras colāgenas (CHAPMAN, 1962; WIDDOWSON, 1969; VUUST \& PIEZ, 1972 ; PROCKOP \& GUZMAN, 1977).

A maior preservação do conteúdo colágeno referida para a situação de deficiência protéica não encontra amparo no valor nutricional desta proteína. Tem sido demonstrado que o colágeno, pela composição desbalanceada de seus aminoácidos cons tituintes, é incapaz de promover crescimento de animais; assim sendo, é improvável que o colágeno do corpo seja preservado com a finalidade de servir como reserva protéica disponível nos períodos de privação protēica (DAWSON \& MILNE, 1978). Entretanto, isso não exclui a possibilidade desta proteína ser utilizada em outras situações adversas como a carência energética (BURINI, 1980) uma vez que apresenta aminoácidos glicogênicos em sua molé cula (wolf et alii, 1956).

Com o objetivo de explorar o padrão de excreção urinária de hidroxiprolina na situação de deficiência protéi ca, propôs-se o estudo "in vivo" de ratos alimentados com dieta hipoprotéica normocalórica.

Para melhor conhecimento da influência do enve lhecimento sobre o processo, o experimento foi realizado com an mais jovens, adultos e velhos. A hidroxiprolina urinária foi utí lizada como índice do metabolismo do colágeno total do corpo(LAI TINEN et alii, 1966; NUSGENS \& LAPIERI, 1973), o nitrogênio uréi co urinário, como índice do aproveitamento do nitrogênio alimentar e do metabolismo protéico global do organismo (GOLDEN et alii, 1977a e b; UAUY et alii, 1978) e a creatinina urināria co- 
mo base de referência para expressar resultados de hidroxiprolina (WATERLOW, 1977; BURINI, 1980). 


\section{MATERIAL E METODOS}

\section{Animais, Ambiente e Delineamento Experimental}

Utilizaram-se 30 ratos machos da linhagem wistar, fornecidos pelo Biotério Central do Campus de Botucatu UNESP. Foram selecionados animais de três idades diferentes, os quais constituíram três grupos etários, assim distribuídos:

Grupo Jovem : dez ratos com pesos aproximados de $80 \mathrm{~g}$ e idades de 30 dias;

Grupo Adulto : dez ratos com pesos aproximados de 200 g e idades de 60 dias;

Grupo Velho : dez ratos com pesos aproximados de 450 $g$ e idades superiores a um ano.

Os animais foram mantidos em gaiolas metabólicas individuais, em ambiente fechado com controle de luze de tem peratura. Todos os ratos receberam dieta controle (208 de proteí na) por um período de cinco a dez dias, para adaptação às condições da gaiola e ao tipo de dieta.

Terminado o período de adaptação, cada grupo etário foi dividido em dois subgrupos de pesos semelhantes. A se guir, os subgrupos foram sorteados para a identificação daqueles que continuaram a receber dieta contendo $20 \%$ de proteínas (dieta controle = animais controles) e daqueles que passaram a receber dieta deficiente em proteínas (dieta hipoprotēica = animais hipo protéicos). 
ta, foram constituídos os seguintes grupos de animais:

$$
\begin{aligned}
& \mathrm{Gl}=\text { ratos jovens controles } \\
& \mathrm{G} 2 \text { = ratos jovens hipoprotéicos } \\
& \mathrm{G} 3=\text { ratos adultos controles } \\
& \mathrm{G} 4=\text { ratos adultos hipoprotéicos } \\
& \mathrm{G} 5=\text { ratos velhos controles } \\
& \mathrm{G} 6=\text { ratos velhos hipoprotéicos }
\end{aligned}
$$

o periodo experimental compreendeu a fase que se seguiu imediatamente ao final da adaptação e se estendeu por 42 dias para todos os animais. O delineamento experimental está esquematizado na Figura 1.

FIGURA 1. Esquematizaçdo do dolineomento experimentol
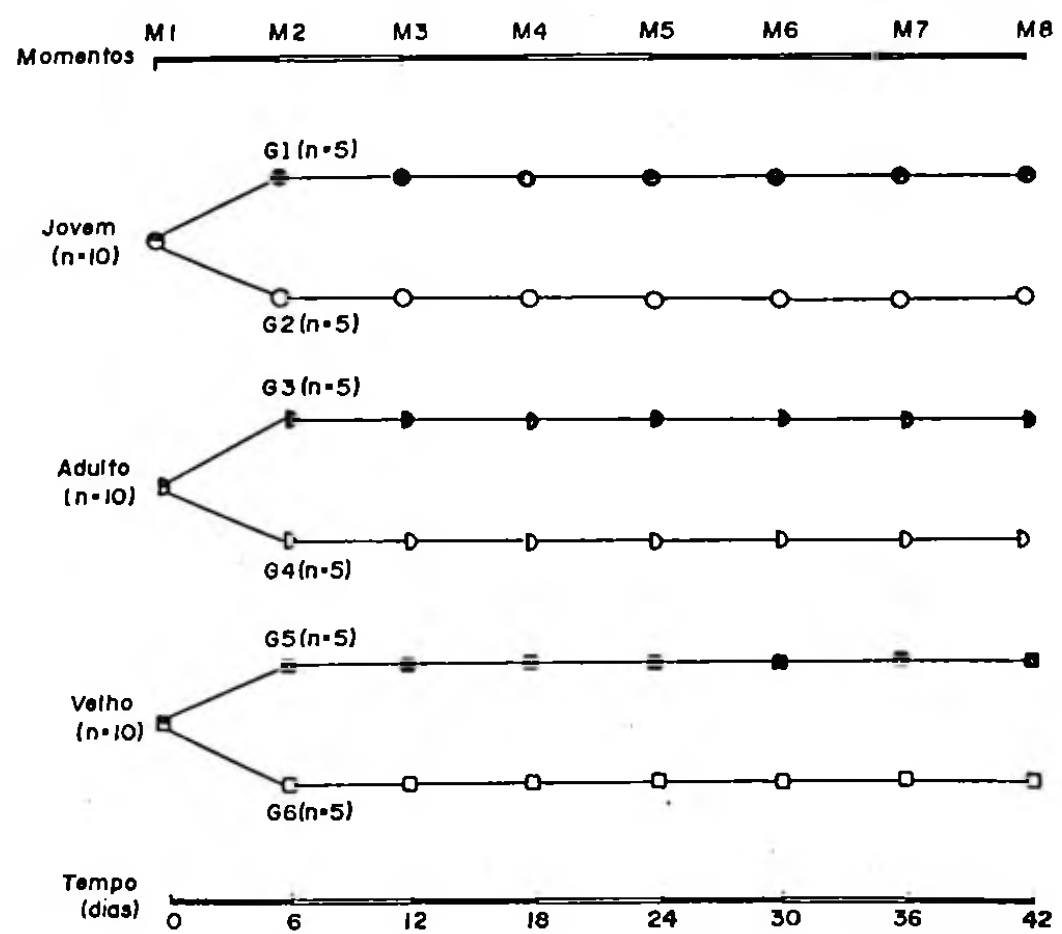

M1 - Inicio do experimento: ME - Final do experimento; $M 2$... M7 - Poriodos informediórios de 6 dias: $01(\div-0)$ - Jovens controles : $62(0-0)$ - Jovens hipoprotéicos; $63(1-D)$ - Adultos controles: $64(D-O) \cdot$ Adultos hipopro. toico; G5(1)—a) - Vethos controlos; G6(0-O) - Velhos hipoprotéicos ; $n$ número de onimais constifuintes do grupo. 


\section{Agua e Dietas}

Os animais receberam diariamente ,"ad libitum", água natural potável oferecida em dois tubos de ensaio.

As dietas oferecidas foram isocalóricas $(4,2$ ca lorias/g de dieta), preparadas em laboratório e armazenadas em "freezer" a -109C. A concentração protéica das dietas, determina da pelo seu teor de nitrogênio, multiplicado pelo fator de conversão de 6,25, mostrou os seguintes valores: $20,05 \pm 1,07 \mathrm{~g} / 100 \therefore \mathrm{g}$ de dieta controle e 2,08 $\pm 0,29 \mathrm{~g} / 100 \mathrm{~g}$ de dieta hipoprotéica. Ambas as dietas foram fornecidas diariamente, "ad libitum".

\subsection{Composição das Dietas}

As dietas obedeceram à seguinte composição:

\begin{tabular}{lcc}
\hline & Dieta Controle & Dieta Hipoprotéica \\
\hline Proteina (caseina) & $20 \%$ & 28 \\
Mistura de sais minerais & $4 \%$ & $4 \%$ \\
Mistura de vitaminas & $1 \%$ & $1 \%$ \\
Oleo de algodão & $8 \%$ & $8 \%$ \\
Maizena q.s.p. & $100 \%$ & $100 \%$ \\
\hline
\end{tabular}

\subsection{Composição da Mistura de Vitaminas}

Um quilograma de mistura de vitaminas* apresen tou a seguinte composição:

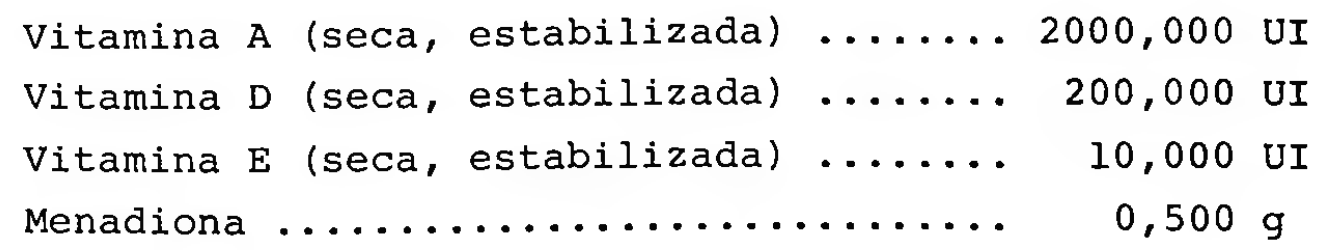

In: Official Methods of Analysis of the Association of Official Agricultural Chemists. Washington, D.C., AOAC, 10th Edition, 1965. 
Colina* ..................... 200,000 g

PABA (ácido p-amino benzóico)......... 10,000 g

Inositol ..................... 10,000 g

Niacina .................... 4,000 g

D-pantotenato de cálcio ........... 4,000 g

Riboflavina ..................... $0,800 \mathrm{~g}$

Tiamina-HCl .................. $0,500 \mathrm{~g}$

Piridoxina-HCl ................. $0,500 \mathrm{~g}$

Ácido Fólico .................... 0,200 g

Biotina .............................. $0,040 \mathrm{~g}$

Vitamina $\mathrm{Bl} 2 \ldots \ldots \ldots \ldots \ldots \ldots \ldots \ldots \ldots . \ldots \ldots, 0 \ldots \ldots$

Dextrose q.s.p. ...............1000,000 g

\subsection{Composição da Mistura de Sais Minerais}

Um quilograma da mistura de sais minerais** apresentou a seguinte composição:

\begin{tabular}{|c|c|c|}
\hline SAIS & $\mathrm{g} / \mathrm{kg}$ de & mistura \\
\hline $\mathrm{NaCl} \ldots \ldots$ & $\ldots \ldots \ldots \ldots$ & 139,300 \\
\hline $\mathrm{KI} \ldots \ldots \ldots$ & $\ldots \ldots \ldots \ldots \ldots$ & 0,790 \\
\hline $\mathrm{KH} 2 \mathrm{PO} 4 \ldots$ & $\ldots \ldots \ldots \ldots \ldots$ & 389,000 \\
\hline $\mathrm{MgSO} 4.7 \mathrm{H} 20$ & $\ldots \ldots \ldots \ldots$ & 57,300 \\
\hline $\mathrm{CaCO} 3 \ldots$. & $\ldots \ldots \ldots \ldots \ldots$ & 381,400 \\
\hline $\mathrm{FeSO} 4.7 \mathrm{H} 2 \mathrm{O}$ & $\ldots \ldots \ldots \ldots$ & 27,000 \\
\hline MnSO $4 . \mathrm{H} 20$ & $\ldots \ldots \ldots \ldots$ & 4,010 \\
\hline $\mathrm{ZnSO} 4.7 \mathrm{H} 2 \mathrm{O}$ & $\ldots \ldots \ldots \ldots$ & 0,548 \\
\hline CuSO $4.5 \mathrm{H} 2 \mathrm{O}$ & $\ldots \ldots \ldots \ldots \ldots$ & 0,477 \\
\hline $\mathrm{CoCl} .6 \mathrm{H} 2 \mathrm{O}$ & $\ldots \ldots \ldots \ldots$ & 0,023 \\
\hline
\end{tabular}

\section{Peso dos Animais}

Os animais foram pesados em balança graduada $(0, \mathrm{lg})$ no inicio da fase experimental (ML) e a cada seis dias (M2

${ }^{*}$ Como cloreto de colina, na forma de solução aquosa a $20 \%$.

${ }^{\star *}$. In: Official Methods of Analysis of the Association of Official Agricultural Chemists. Washington D.C., AOAC, 10th Edition, 1965. 
a M8) até o final do experimento. Para os cálculos, foram utilizados os valores individuais dos animais de cada grupo para cada uma das faixas etárias.

\section{Ingestão Alimentar}

A quantidade de dieta consumida foi controlada diariamente, no mesmo horário, mediante cálculo da diferença entre o peso da dieta oferecida e o peso do restante no comedouro.

\section{Coleta da Urina e Preparo das Amostras para Dosagens}

A urina foi coletada em um sistema constituido de funil amplo justaposto a um funil menor contendo pérolas de vidro, acoplado a cilindro graduado contendo ácido clorídrico concentrado e toluol como preservativos (Fig. 2).

No final de cada período de três dias, o siste ma coletor de urina de cada uma das gaiolas foi lavado com água destilada para assegurar coleta de toda a urina eliminada. o líquido resultante foi adicionado à urina do animal. Portanto, a coleta de urina foi feita em períodos consecutivos de três dias (volume total de três dias).

o volume coletado foi medido e, a seguir centrifugado e fracionado em alíquotas, as quais foram armazenadas em "freezer" a -109C até o momento de serem analisadas. Este esque ma foi repetido durante todo o experimento. 


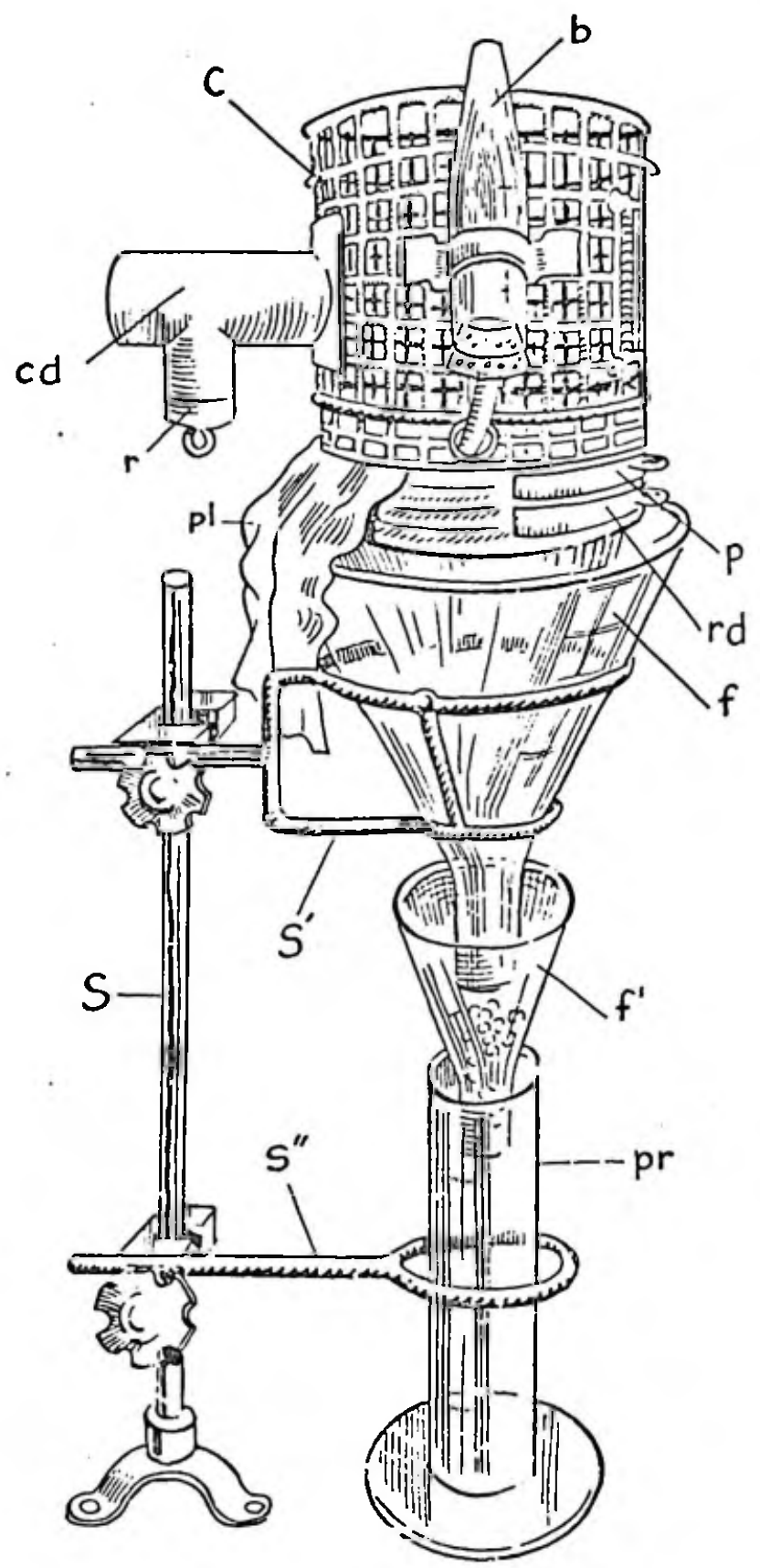

Figura 2: Gaiola para estudo de balanço metabólico.

c) corpo da gaiola

b) bebedouro (tubo de vidro)

cd) comedouro metálico cilíndrico

r) recipiente móvel para dieta

p) piso da gaiola (rede de metal que permite passagem de fezes e urina)

rd) rede de malhas finas que permite passagem de urina e retém fezes

f) funil de vidro para coleta de urina

$\left.f^{\prime}\right)$ funil de vidro, de dimensão menor, contendo pérolas de vidro

pr) proveta graduada

ss's") suportes de metal para os funis

pl) plástico para proteção do funil 
6. Sacrificio dos Animais, Coleta de Sangue e Obtenção do Frag mento de Figado

Encerrada a fase experimental, os animais foram sacrificados por decapitação, após período de jejum de uma a quatro horas. O sangue proveniente do pescoço foi recolhido em frasco contendo heparina* como anticoagulante, centrifugado e o plasma separado e armazenado: em "freezer" (-10.C) para dosagens posteriores de proteínas totais e de albumina. Imediatamente após a decapitação e exsanguinação procedeu-se ã dissecção do fĩgado e ã remoção do lobo caudado, utilizado para análise histopa tológica.

7. Métodos de Dosagem

\section{7.l. Nitrogênio Urēico Urinārio}

A quantificação do nitrogênio uréico foi feita pelo método da diacetilmonoxima, segundo FOSTER \& HOCHHOLZER(1971).

\subsection{Creatinina Urināria}

A determinação da creatinina urinária foi feita colorimetricamente segundo o método de CLARK \& THOMPSON(1949).

\subsection{Hidroxiprolina Urinäria}

A quantificação da hidroxiprolina total foi fei ta segundo adaptação da metodologia proposta por BERGMAN \& LOXLEY (1970) .

\footnotetext{
*Liquémine "Roche" - Produtos Roche - R. de Janeiro, GB.
} 


\subsection{Proteínas Plasmáticias}

o plasma de cada um dos animais foi utilizado na dosagem das proteínas totais (método do biureto*) e de albumi na (método do verde de bromocresol*).

\section{Bases de Referência}

Os resultados foram referidos como ingestão ou excreção observadas em 24 horas. Como ocorreu variação do peso corpóreo durante o experimento, os valores foram corrigidos para a massa corporal, ou seja, ingestão ou excreção diāria, expressa por $100 \mathrm{~g}$ de peso (BURINI, 1980).

Além destas duas bases de referência, a excreção de hidroxiprolina foi referida tambēm por miligrama de creatinina excretada no mesmo período. Esta relação é utilizada para avaliação da excreção preferencial de uma substância em relação a um metabolito de excreção bastante estável como a : creatinina (WATERLOW, 1977).

\section{Anālise Histológica do Fígado}

O fragmento do lobo caudado do fígado de todos os animais foi fixado em formol a $10 \%$, incluído em parafina, cor tado em micrótomo comum na espessura de 4 a $5 \mu \mathrm{m}$ e corado pela hematoxilina-eosina, de acordo com a técnica rotineira de proces samento histológico.

As lâminas foram misturadas e analisadas sem que o examinador soubesse a respectiva correspondência com os animais estudados.

\footnotetext{
*Kit da Labtest. Sistemas Diagnósticos Ltda., Belo Horizonte.
} 
A esteatose hepática, quando presente,foi clas sificada de acordo com sua intensidade crescente em graus I; II e III, segundo padronização anterior (CAMPANA et alii, 1975).

\section{Análise Estatística - Anālise Multivariada de Perfil}

A metodologia empregada foi a de MORRISON (1967). Esta análise foi processada no C.C.E. (Centro de Computação Eletrônica) da USP, utilizando-se o programa MGLM-102MAE.

Cada uma das variáveis experimentais foi estudada ao longo do tempo em oito momentos espaçados semanalmente (seis em seis dias), em seis grupos experimentais, assim discriminados :

$$
\begin{aligned}
& \text { Gl - Grupo Jovem Controle }(n=5) \\
& \text { G2 - Grupo Jovem Hipoprotéico }(n=5) \\
& \text { G3 - Grupo Adulto Controle }(n=5) \\
& \text { G4 - Grupo Adulto Hipoprotéico }(n=5) \\
& \text { G5 - Grupo Velho Controle }(n=5) \\
& \text { G6 - Grupo Velho Hipoprotéico }(n=5)
\end{aligned}
$$

Como cada animal foi medido em oito momentos

(Fig. 1), existe uma estrutura de dependência entre as medidas $\underline{\text { E }}$ fetuadas que foi levada em consideração na análise estatística. Portanto, a análise de perfil foi o método escolhido. Para cada uma das variáveis estudadas esta análise se apoiou no modelo matricial definido como: $\mathrm{Y}=\mathrm{X} \beta+\varepsilon$, onde:

- Y (30 x 8) é a matriz das observações (oito medidas para cada uma das unidades amostrais);

- X $(30 \times 6)$ é a matriz de planejamento, que associa cada unidade experimental ao seu respectivo grupo;

- $\beta(6 \times$ x 6 é a matriz de médias populacionais desconhecí das, onde cada linha representa as médias es- 
peradas da variável em cada um dos oito momen tos considerados, para um determinado grupo. Sua estimativa $\hat{\beta}$ contém as médias amostrais e esta matriz é básica nos testes de hipóteses efetuados;

- $\varepsilon(30 \times 8)$ é a matriz dos componentes aleatórios das observações. Cada um de seus elementos represen ta o desvio casual entre média observada e a respectiva média esperada de acordo com o modelo proposto.

As duas pressuposições bāsicas para se efetuar este tipo de análise são:

a) os grupos devem ser independentes;

b) a variável estudada deve ter distribuição normal multivariada, com matriz de covariância comum à todos os grụ pos experimentais.

Todas as hipóteses de nulidade foram formuladas matricialmente como Ho $=\hat{C} \hat{\beta} U=0$, onde $C$ é uma matriz encarregada de efetuar contrastes entre grupos e U, entre momentos.

Tendo em vista que o esquema experimental adotado era composto de dois fatores (dieta e idade), a anālise foi subdividida para comparar o efeito da dieta dentro de cada uma das faixas etārias e o efeito da idade para uma dieta prefixada. As hipōteses foram testadas segundo a existência ou não de:
a) analogia entre curvas obtidas nos grupos dietéticos;
b) igualdade entre curvas obtidas nos grupos dietēticos;
c) efeito de cada momento dentro dos grupos;
d) integração dieta $\mathrm{x}$ idade em cada um dos momentos;
e) diferença entre grupos em cada um dos momentos;

O programa computacional utilizado forneceu va lores da Estatistica $F$ multivariada e Estatisticas F Univariadas, acompanhadas de seus respectivos níveis de significância (p) para cada uma das situações estudadas. 
De acordo com o nível de significância prefixa da $(\alpha=0,05)$ foram determinadas duas situações:

a) se $\mathrm{p}>\alpha$, houve aceitação de Ho e conclusão de que, pela amostragem estudada e para $\alpha=0,05$, não foi possivel a constatação de diferença estatisticamente signifi cativa.

b) se $p \leqslant \alpha$, houve rejeição de Ho, e a conclusão de que,pela amostra estudada e para $\alpha=0,05$, constatou-se diferença estatisticamente significativa, indicado com um asterisco (*) colocado após o valor da Estatistica F calculada.

Os resultados obtidos por esta análise estatís tica são apresentados em Tabelas, conforme os estudos realizados. O tratamento estatístico empregado para avaliar os dados de proteínas totais e frações foi a análise de variância fatorial, considerando os fatores idade e dieta e a inte ração dos mesmos. A seguir, foi aplicado o teste de Tukey para contrastes entre médias, com $\alpha=0,05$, de acordo com COCHRAM \& $\operatorname{cox}(1957)$ 
16.

\section{RESULTADOS}

\section{Peso dos Animais}

\subsection{Efeito da Idade nos Animais Alimentados com Dieta Con trole}

Todos os animais alimentados com dieta controle ganharam peso durante a fase experimental (Fig. 3). A velocidade de crescimento foi inversa à idade dos animais, apresentando os seguintes valores: jovem: $4,2 \mathrm{~g} / \mathrm{dia}$; adulto: $1,8 \mathrm{~g} / \mathrm{dia}$ e velho: $1,0 \mathrm{~g} / \mathrm{dia}$. O ganho de peso observado no grupo jovem foi significativamente crescente até o 30 q dia (momento 6) do experí mento quando foi atingido o "plateau", o qual foi mantido até o 42 dia (momento 8). Para o grupo adulto o "plateau" foi atingido mais precocemente ou seja, no 249 dia (momento 5). O crescimento médio dos animais do grupo velho foi irregular (Fig. 3 e Tá bela 1).

\subsection{Efeito da Dieta}

Os animais alimentados com dieta hipoprotéica perderam peso (Fig. 3). A maior taxa de perda de peso foi verifi cada para o grupo velho: $1,5 \mathrm{~g} / \mathrm{dia}$, apresentando peso final correspondente a $85,7 \%$ do peso inicial. Para o grupo jovem a veloci dade de perda de peso foi menor, $0,5 \mathrm{~g} / \mathrm{dia}$; entretanto, o peso resultante após 42 dias de alimentação com dieta hipoprotéica correspondeu a 758 do peso inicial. O peso final do grupo adulto 


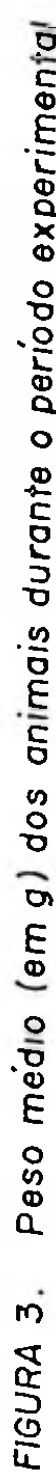

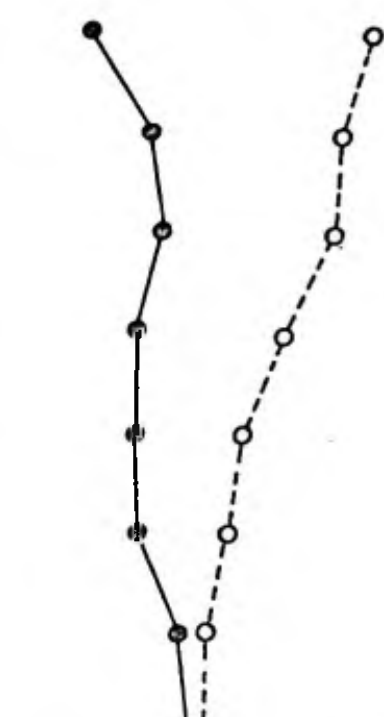

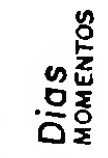

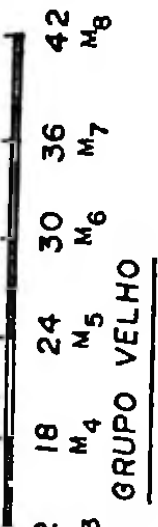

$\simeq \Sigma^{m}$

$0 \Sigma^{N}$

$0=$

$\underset{7}{2}$

品乏

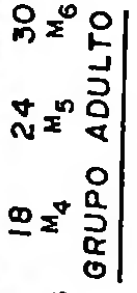

$\underline{x^{m}}$

$0 x^{N}$

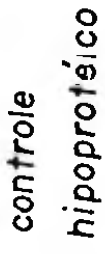

인

$\left\{\begin{array}{l}9 \\ 1 \\ 1 \\ 1\end{array}\right.$

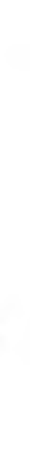

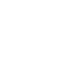

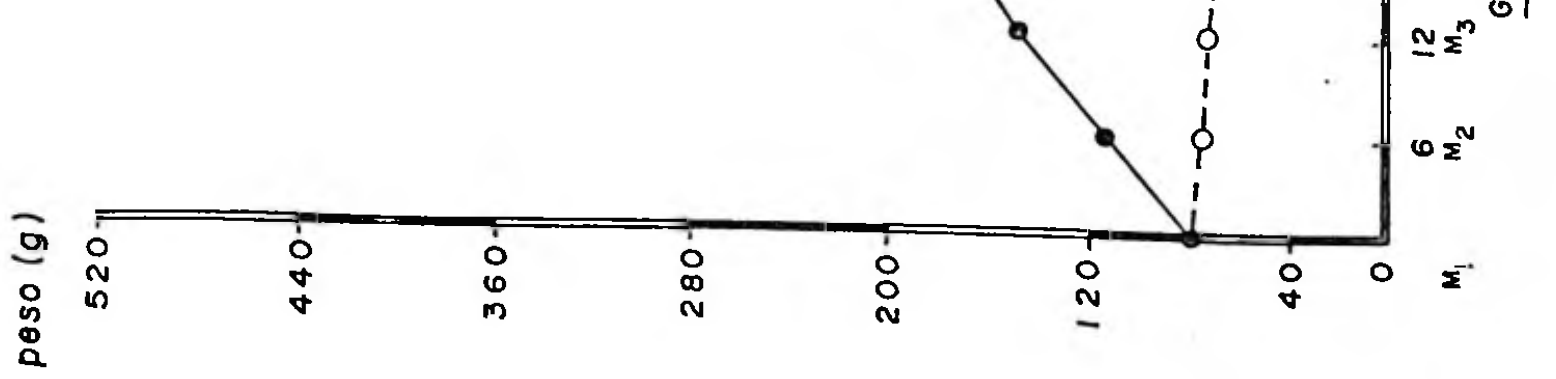


TABELA 1 - Peso méd10 (gramas) dos animals dos grupos controles e hipoprotëlcos durante o perlodo axperimental.

1a) Hipóteses testadas para analogla entre gruposi valores multivarlados de F calculado, valores criticos de $F$ e valores univarindos de $F$ acompanhados dos respectivos nivels de algnificáncia. Comentärio sobre os resultados obtidos.

\begin{tabular}{|c|c|c|c|c|c|c|c|c|}
\hline \multirow{2}{*}{$\begin{array}{l}\text { ANALOGIA } \\
\text { ENTRE }\end{array}$} & \multicolumn{7}{|c|}{$\begin{array}{lllllll}M & O & M & E & N & T & 0\end{array}$} & \multirow{2}{*}{$\begin{array}{l}\text { ESTATIS- } \\
\text { TICA MUL } \\
\text { TIVARIADA }\end{array}$} \\
\hline & $M 1$ a $M 2$ & $M 2 \triangle M 3$ & M3 a Ma & M4 a M5 & M5 a M6 & $M 6$ a $M 7$ & M7 a M8 & \\
\hline$G 1$ e $G 2$ & $\begin{array}{l}F=54,11 \\
p=0,0001\end{array}$ & $\begin{array}{l}F=82,01 * \\
p=0,0001\end{array}$ & $\begin{array}{l}F=74,00 \\
p=0,0001\end{array}$ & $\begin{array}{l}F=71,39 \\
p=0,0001\end{array}$ & $\begin{array}{l}F=22,40^{\circ} \\
p=0,0002\end{array}$ & $\begin{array}{l}F=43,69 * \\
p=0,0001\end{array}$ & $\begin{array}{l}F=2,12 \\
p=0,1554\end{array}$ & $\begin{array}{l}F=55,30 * \\
p=0,0001\end{array}$ \\
\hline
\end{tabular}

G3 e G4

$\begin{array}{ll}F=39,17^{\circ} & F=19,44^{*} \\ p=0,0001 & p=0,0004\end{array}$

$\begin{array}{ll}F=39,17^{\circ} & F=19,44^{*} \\ p=0,0001 & p=0,0004\end{array}$

$=-10,15 * \quad F=6,99$ * $p=0,0042 \quad p=0,0136$ $\begin{array}{llll}F=0,93 & F=3,25 & F=0,53 & F=14,00 \\ p=0,6544 & p=0,0807 & p=0-5195 & p=0,0001\end{array}$ $\begin{array}{llll}F=0,93 & F=3,25 & F=0,53 & F=14,00 \\ p=0,6544 & p=0,0807 & p=0-5195 & p=0,0001\end{array}$

G5 e 66

$F=1,59 \quad F=29,22$ *

$\mathrm{p}=0,2178 \quad \mathrm{p}=0,0001$

$F=2,54$

$F=17,20$ *

$F=5,37^{*}$

$F=8,63$ *

$F \approx 8,28^{*} \quad F=19,00^{\circ}$ $p=0,0082 \quad p=0,0001$

\section{el GS} $\begin{array}{llll}F=15,69 * & F=17,88^{*} & F=29,22 * & F=3 \\ p=0,0001 & p=0,0001 & p=0,0001 & p\end{array}$ e' 66 $\begin{array}{ll}F=0,65 & F=0,86 \\ p=0,5344 & p=0,5593\end{array}$ $p=0,5344 \quad p=0,5593$

$p=0,0001 \quad p=0,0001$

\section{$F=28,65^{*}$} $p=0,0001$

$F=8,69$ *

$\mathrm{p}=0,0018=0,61$

$F=11,64^{*}$ $p=0,0001$ $F=6,54^{*}$ $p=0,0001$ $F(0,05$; $2,24)=3,40$
COMENTARIO

Não existe analogla entre GI G2 e 1sto ocorre em todos os trechos, exceto em $M 7$ a $M 8$.

Nāo oxiato analogia ontro $G 3$. G4 e 1sto ocorre de M1 a MS.De M6 a M8, as curvas podem ser. celtas como paralelas.

Não exlste analogla entre $G 5$ e G6 e 1sto ocorre nos trechos: M2 a M3, M4 a M5, M5 a M6, MG a $M 7$ e $M 7$ a $M 8$.

Não existe analogla entre os grupos G1, G3 e G5

Nāo existe analog la entre $G 2$, G4 e G6 e 1sto ocorre nos trechos $M 4$ a $M 5$ e MS a M6 1b) Hipóteses testadas para efeito de momento dentro de cada um dos grupos. Estatistica F multivariada e comentārio sobre
os rcaultados obtidos.

\begin{tabular}{|c|c|c|}
\hline GRUPO & ESTATISTICA & COMENTRRIO : F crlt. $=F(0,05 ; 1,24)=4,26$ \\
\hline Gl & $F=881,06^{\circ}$ & $M 1<M 2<M 3<M 4<M 5<M 6<(M 7-M 8)$ \\
\hline G2 & $F=10,11 *$ & $\begin{array}{l}\text { A partir de M3 houve dimınulção de peso com relação ao valor 1nicial, após o que, houve es- } \\
\text { tab1lizą̧a. }\end{array}$ \\
\hline G3 & $F=140,50^{*}$ & Ex1ate diferença entre momentos dentro de $G 3: M 1<M 2<M 3<M 4<M 5<(M 6-M 7-M 8)$ \\
\hline G4 & $F=41,48^{*}$ & $\begin{array}{l}\text { Existe diferenga entre momentos dentro de G4: M1 < M2< M3. Portanto, houve decréscimo do } \\
\text { peso de M1 a MJ. A seguir, houve estabilizaçăo de peso, de forma que os momentos consecuti- } \\
\text { vos nāo diferiram. }\end{array}$ \\
\hline G5 & $F=106,69^{\circ}$ & $\begin{array}{l}\text { Existe diferença entre momentos dentro de } G 5:(M 1=M 2)<(M 3-M 4=M 5) ; M 5<M 6 \text { e } M 6<M 7 \\
<M 8 \text {. Todos os momentos, exceto } M 2 \text { e } M 6 \text { säo malores que M1. M8 è ma1or que os dema1s nonentos. }\end{array}$ \\
\hline G6 & $F=260,25 *$ & \\
\hline
\end{tabular}

1c) II póteses testadas para diferença entre grupos e para a interaçāo entre falxa etāría e dieta em cada um dos momentos

Estatisticas $F$ e seus respectivos niveis de signiflcância $(p)$. Comentário sobre os resultados obtidos.

\begin{tabular}{|c|c|c|c|c|c|c|c|c|c|}
\hline $\begin{array}{l}\text { ONTRASTE } \\
\text { ENTRE }\end{array}$ & $M I$ & $M 2$ & $\frac{M}{M 3}=$ & $\begin{array}{lll}M & E \\
4 & N \\
\end{array}$ & $\begin{array}{ll}T & 0 \\
& M 5 \\
\end{array}$ & M6 & MT & $M 8$ & COMENTARIO \\
\hline$G 1$ e $G 2$ & $\begin{array}{l}F=0,00 \\
p=0,9666\end{array}$ & $\begin{array}{l}F=6,43 \\
p=0,0172\end{array}$ & $\begin{array}{l}F=23,80 \\
p=0,0002\end{array}$ & $\begin{array}{l}F=41,89 \\
p=0,0001\end{array}$ & $\begin{array}{l}F=70,95 * \\
p=0,0001\end{array}$ & $\begin{array}{l}F=75,67 * \\
p=0,0001\end{array}$ & $\begin{array}{l}F=91,98 . \\
p=0,0001\end{array}$ & $\begin{array}{l}F=219,70^{*} \\
p=0,0001\end{array}$ & $\begin{array}{l}\text { Em } M 1: G 1=G 2: \text { em } M 2, M 3, H 4 \text {, } \\
M 5, M 6, M 7 \text { e } M 8: G 1>G 2\end{array}$ \\
\hline 63 e 64 & $\begin{array}{l}F=0,00 \\
p=0,9558\end{array}$ & $\begin{array}{l}F=4,27 \\
p=0,0471\end{array}$ & $\begin{array}{l}F=10,00 \\
p=0,0044\end{array}$ & $\begin{array}{l}F=13,34^{*} \\
p=0,0016\end{array}$ & $\begin{array}{l}F=18,15^{*} \\
P=0,0005\end{array}$ & $\begin{array}{l}F=16,62 * \\
P=0,0007\end{array}$ & $\begin{array}{l}F=18,38 * \\
p=0,0005\end{array}$ & $\begin{array}{l}F=44,86 * \\
p=0,0001\end{array}$ & $\begin{array}{l}\text { A partix de M2 os grupos pas- } \\
\text { sam a difer1x estatisticamente } \\
\text { com G3 }>\text { G4 }\end{array}$ \\
\hline 65 e 66 & $\begin{array}{l}F=0,19 \\
p=0,6699\end{array}$ & $\begin{array}{l}F=0,75 \\
p=0,6020\end{array}$ & $\begin{array}{l}F=5,30 * \\
P=0,0286\end{array}$ & $\begin{array}{l}F=6,22 \star \\
P=0,0189\end{array}$ & $\begin{array}{l}F=11,93 * \\
p=0,0024\end{array}$ & $\begin{array}{l}F=13,34 * \\
p=0,0016\end{array}$ & $\begin{array}{l}F=16,42 \\
p=0,0007\end{array}$ & $\begin{array}{l}F=69,97 \star \\
p=0,0001\end{array}$ & $\begin{array}{l}\text { Começa a existir diferença sig } \\
\text { niflcativa entre } 65 \text { e } 66 \text { a paE } \\
\text { tir de } M 3 \text {, com } G 5>66\end{array}$ \\
\hline$={ }_{65}^{1, G 3}$ & $\begin{array}{l}F=325,71 \\
P=0,0001\end{array}$ & $\begin{array}{l}F=285,92 * \\
p=0,0001\end{array}$ & $\begin{array}{l}F=234,99 * \\
p=0,0001\end{array}$ & $\begin{array}{l}F=169,68 \\
P=0,0001\end{array}$ & $\begin{array}{l}F=140,01 * \\
p=0,0001\end{array}$ & $\begin{array}{l}F=90,73^{\circ} \\
P=0,0001\end{array}$ & $\begin{array}{l}F=82,21 * \\
P=0,0001\end{array}$ & $\begin{array}{l}F=176,82 \\
p=0,0001\end{array}$ & $\begin{array}{l}\text { Näo tem sentido para peso, ja } \\
\text { que as Idades săo diferentes. }\end{array}$ \\
\hline 62,64 & $\begin{array}{l}F=314,86^{\circ} \\
p=0,0001\end{array}$ & $\begin{array}{l}F=328,10^{\circ} \\
p=0,0001\end{array}$ & $\begin{array}{l}F=291,78 \\
p=0,0001\end{array}$ & $\begin{array}{l}F=246,67 * \\
P=0,0001\end{array}$ & $\begin{array}{l}F=227,35 " \\
p=0,0001\end{array}$ & $\begin{array}{l}F=163,83^{*} \\
p=0,0001\end{array}$ & $\begin{array}{l}F=158,63^{\circ} \\
P=0,0001\end{array}$ & $\begin{array}{l}F=293,52 \\
p=0,0001\end{array}$ & $\begin{array}{l}\text { Nāo tem sentido para peso, pe- } \\
\text { las ldodes diferentes. }\end{array}$ \\
\hline $\begin{array}{l}\text { interação } \\
\text { ileta e } \\
\text { dade }\end{array}$ & $\begin{array}{l}F=0,07 \\
P=0,9343\end{array}$ & $\begin{array}{l}F=0,74 \\
p=0,5082\end{array}$ & $\begin{array}{l}F=1,72 \\
p=0,1990\end{array}$ & $\begin{array}{l}F=4,19 * \\
p=0,0269\end{array}$ & $\begin{array}{l}F=7,11^{\star} \\
p=0,0040\end{array}$ & $\begin{array}{l}F=7,84^{*} \\
p=0,0027\end{array}$ & $\begin{array}{l}F=9,81 \\
p=0,0010\end{array}$ & $\begin{array}{l}F=18,41^{*} \\
p=0,0001\end{array}$ & $\begin{array}{l}\text { Existe interação dleța e falxa } \\
\text { etärla. Esta interação começaa } \\
\text { ocorrer em M4, indo até m8. }\end{array}$ \\
\hline
\end{tabular}


foi de 938 do peso inicial, tendo este grupo apresentado taxa de crescimento de $-0,4 \mathrm{~g} / \mathrm{dia}$. A diferença de peso em relação ao peso inicial ocorreu significativamente nos animais dos grupos jovem e velho, a partir do $128 \mathrm{dia}$. No grupo jovem a queda de peso ocorreu gradativamente até o final do experimento enquanto no gru po velho isto se verificou apenas até o 308 dia (momento 6) estą bilizando-se a seguir. Em oposição ao comportamento do grupo jovem, o grupo adulto apresentou perda significativa de peso somen te no início do experimento, isto é, até o 12 \% dia (Fig. 3 e Tabela 1).

\section{Ingestão Alimentar}

\subsection{Efeito da Idade}

A ingestão diāria de dieta controle aumentou com a idade (Fig. 4 e Tabela 2) sendo a ingestão média nos dias de experimento de: grupo jovem $12,9 \mathrm{~g} / \mathrm{dia}$, grupo adulto 12,5 g/dia e grupo velho 18,7 g/dia. A correção dos valores para determinado peso corporal inverteu esta taxa de ingestão, com os jovens ingerindo em média $7,8 \mathrm{~g} / 100 \mathrm{~g}$ peso/dia, contra 5,2 do gru po adulto e 4,0 do grupo velho (Fig. 5 e Tabela 3 ).

\subsection{Efeito da Dieta}

o tipo de dieta oferecida influenciou a ingestão alimentar diāria marcadamente no grupo jovem, com os animais desnutridos ingerindo quantidades significativamente menores a partir do sexto dia (momento 2) do experimento (Fig. 4). Entretanto, esta diferença foi eliminada com a correção da ingestão alimentar para o peso corporal. Nesta base de referência, os ani 


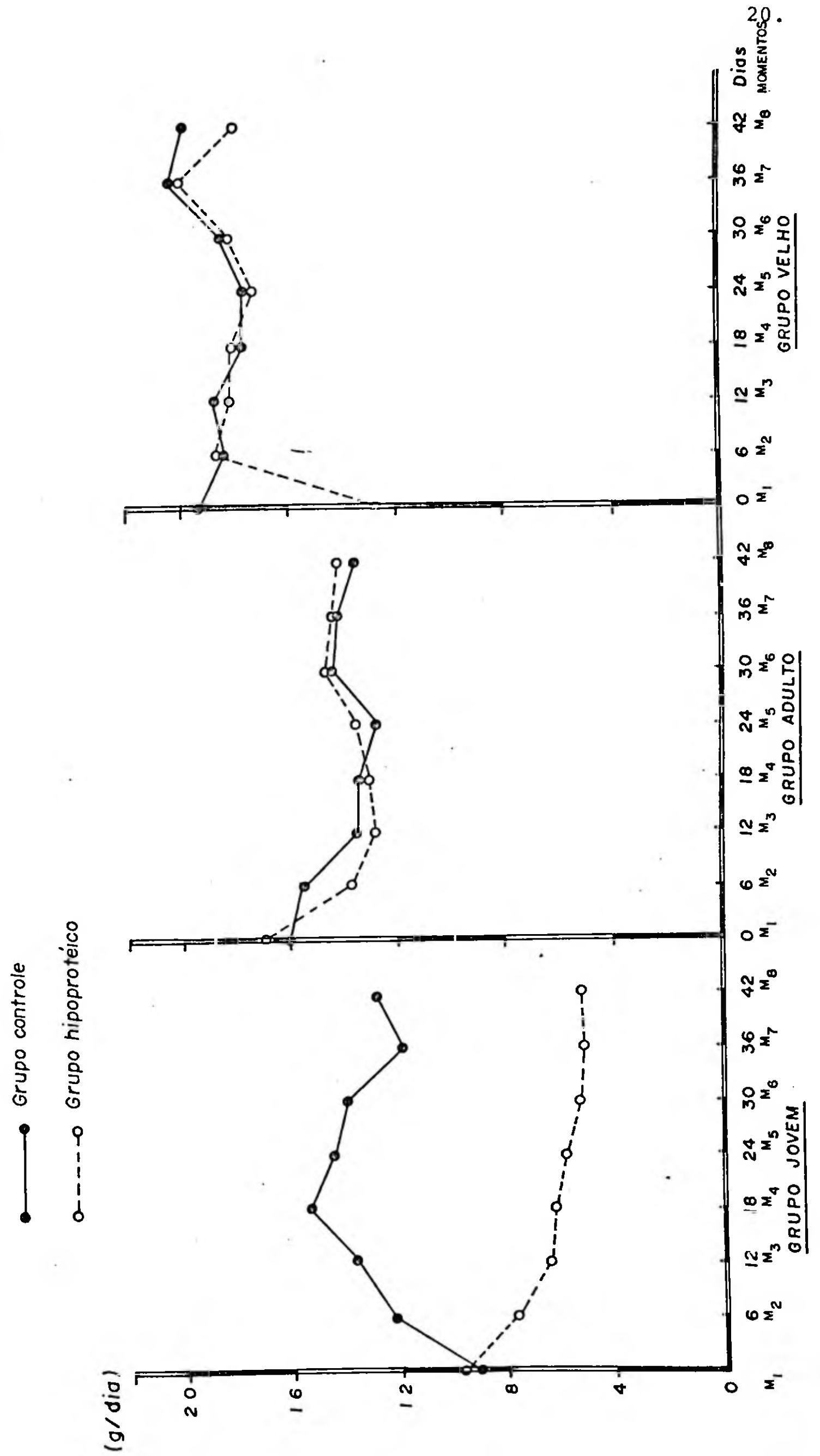



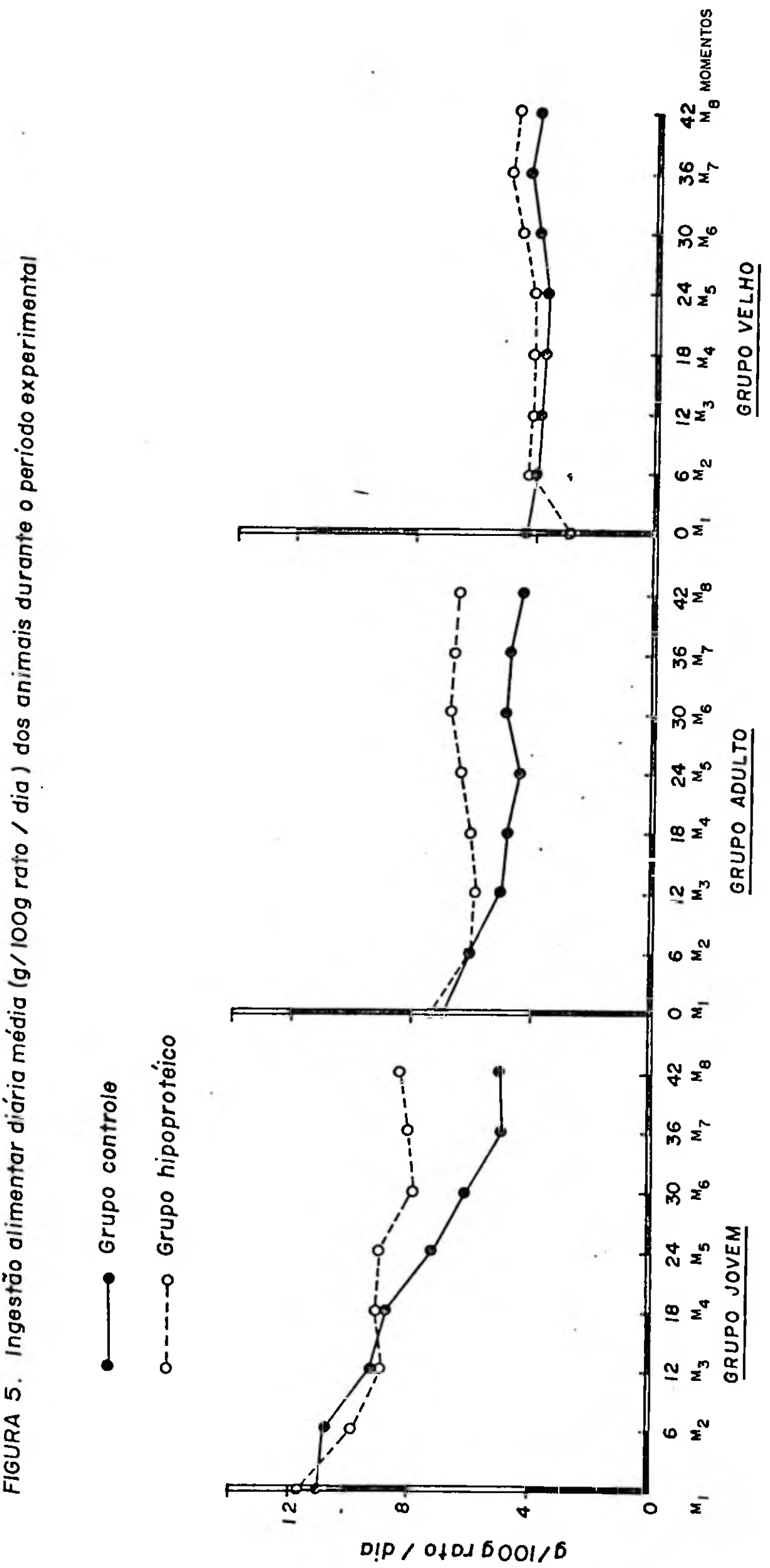

22. 
mais jovens e adultos hipoprotéicos apresentaram taxas significa tivamente maiores do que as dos grupos controles a partir do 188 dia. No grupo velho houve diferença apenas no primeiro período do experimento (Fig. 5 e Tabela 3).

\section{Excreção Urināria de Nitrogênio Uréico}

\subsection{Efeito da Idade}

A excreção diāria de nitrogênio uréico foi cres cente até a fase adulta dos animais, estabilizando-se a seguir (Fig. 6 e Tabela 4). Os valores médios observados nos 42 dias de experimento foram: jovem, $102 \mathrm{mg} / \mathrm{dia}$; adulto, $196 \mathrm{mg} / \mathrm{dia}$ e velho, $178 \mathrm{mg} /$ dia. A correção dos valores para o peso corporal praticamente eliminou estas diferenças e nesta base de referência a excreção apresentada pelo grupo velho foi cerca de 408 e 478 menor do que as verificadas para os grupos jovem e adulto, respectivamente (Fig. 7 e Tabela 5). A análise sequlencial da excreção de nitrogênio uréico mostrou alternância significativa das médias entre os momentos nos três grupos etários, nas duas bases de referência utilizadas (Figs. 6 e 7 e Tabelas 4 e 5).

\subsection{Efeito da Dieta}

A ingestão de dieta hipoprotéica resultou em redução significativa da excreção de nitrogênio uréico em todos os grupos etários, independentemente da base de referência utili zada (Figs. 6 e 7). A redução dos valores em todas as idades ocorreu logo após a implantação do regime dietético, estabilizando-se a seguir (Figs. 6 e 7 e Tabelas 4 e 5). 

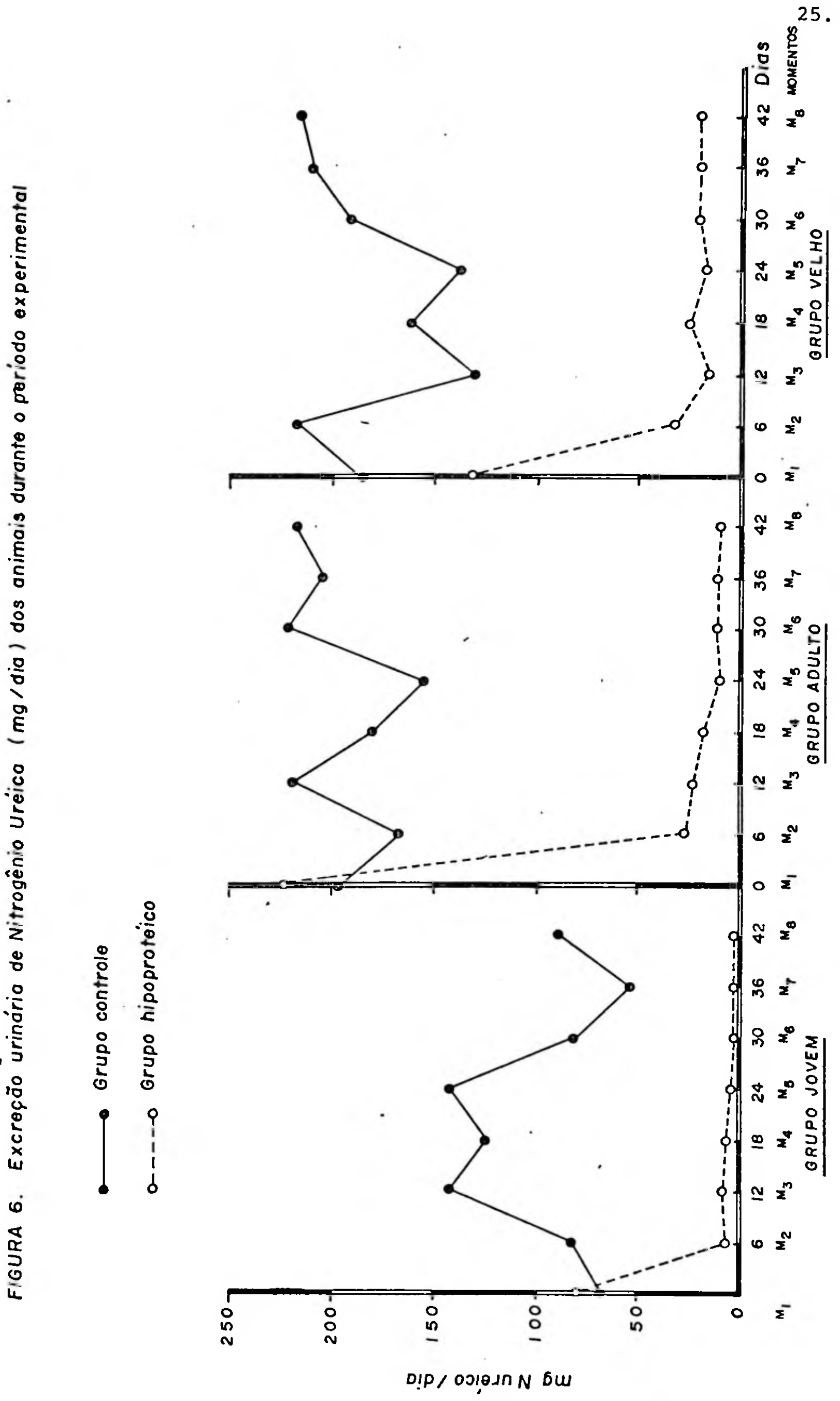
TABELA 4 - Excrę̧ão urinärla de nitrogênlo urëico (mg/dia) dos anımala dos grupos controles e hlpoprotēicos durante o perlodo experimental.

4a) Illpöteses testadas para analogia entre grupos, valores multivarlados de $F$ calculado, valores critlcos de f e valores unlvarlados de $F$ acompanhados dos respectivos nlveis de significâncla. Comentärio sobre os resultados obtidos.

\begin{tabular}{|c|c|c|c|c|c|c|c|c|c|}
\hline \multirow{2}{*}{$\begin{array}{l}\text { ANALOGIA } \\
\text { ENTRE }\end{array}$} & \multirow[b]{2}{*}{$M 1$ a M2 } & \multirow[b]{2}{*}{$\mathrm{M} 2$ a $\mathrm{M3}$} & \multirow{2}{*}{$\begin{array}{ll}M & O \\
M 3 a M 4 & \end{array}$} & \multirow{2}{*}{$\begin{array}{l}M \text { E N } \\
\text { M4 a M5 }\end{array}$} & \multirow{2}{*}{$\begin{array}{l}\mathrm{T} O \\
\text { M5 a M6 }\end{array}$} & \multirow[b]{2}{*}{$M 6$ a $M 7$} & \multirow[b]{2}{*}{$M 7$ a $M B$} & \multirow{2}{*}{$\begin{array}{l}\text { ESTATIS- } \\
\text { TICA MUL } \\
\text { TIVARIADA }\end{array}$} & \multirow[b]{2}{*}{ COMENTARIO } \\
\hline & & & & & & & & & \\
\hline$G 1$ e $G 2$ & $\begin{array}{l}F=4,03 \\
p=0,0532\end{array}$ & $\begin{array}{l}F=1,92 \\
p=0,1758\end{array}$ & $\begin{array}{l}F=0,77 \\
p=0,6080\end{array}$ & $\begin{array}{l}F=0,92 \\
p=6520\end{array}$ & $\begin{array}{l}F=8,77^{\circ} \\
p=0,0068\end{array}$ & $\begin{array}{l}F=2,82 \\
p=0,1029\end{array}$ & $\begin{array}{l}F=8,07 \\
p=0,0089\end{array}$ & $\begin{array}{l}F=5,84 \\
p=0,0015\end{array}$ & $\begin{array}{l}\text { Nāo existe analogia entre G1 } \\
G 2 \text { e } 1 \text { sto ocorre nos trechos de } \\
M 5 \text { a M6 e M7 a M8 }\end{array}$ \\
\hline G3 C G4 & $\begin{array}{l}F=14,32 \\
p=0,0012\end{array}$ & $\begin{array}{l}F=1,82 \\
p=0,1871\end{array}$ & $\begin{array}{l}F=4,45 \\
p=0,0430\end{array}$ & $\begin{array}{l}F=0,93 \\
p=0,6525\end{array}$ & $\begin{array}{l}E=10,58 \\
p=0,0036\end{array}$ & $\begin{array}{l}F=1,14 \\
p=0,2967\end{array}$ & $\begin{array}{l}F=1,57 \\
p=0,2199\end{array}$ & $\begin{array}{l}F=15,32 \\
p=0,0001\end{array}$ & $\begin{array}{l}\text { Não existe analogia entre G3 e } \\
\text { G4 e 1sto ocorre nos trechos de } \\
\text { M1 a M2, M3 a M4 e M5 a M6 }\end{array}$ \\
\hline$G 5$ e 66 & $\begin{array}{l}F=8,95 \\
p=0,0064\end{array}$ & $\begin{array}{l}F=2,74 \\
p=0,1073\end{array}$ & $\begin{array}{l}F=1,63 \\
p=0,2115\end{array}$ & $\begin{array}{l}F=0,71 \\
p=0,5863\end{array}$ & $\begin{array}{l}F=6,05 * \\
p=0,0204\end{array}$ & $\begin{array}{l}F=1,66 \\
p=0,2082\end{array}$ & $\begin{array}{l}F=0,17 \\
p=0,6857\end{array}$ & $\begin{array}{l}F=5,42 \\
p=0,0021\end{array}$ & $\begin{array}{l}\text { Nāo existe analogla entreos gru } \\
\text { pos o } 1 \text { sto ocorre nos trechos de } \\
M 1 \text { a M2 e M5 a M6 }\end{array}$ \\
\hline${ }_{e}^{G 1, G S}$ & $\begin{array}{l}F=1,07 \\
p=0,3610\end{array}$ & $\begin{array}{l}F=7,72 \\
P=0,0029\end{array}$ & $\begin{array}{l}F=9,56 \\
P=0,0012\end{array}$ & $\begin{array}{l}F=2,92 \\
p=0,0721\end{array}$ & $\begin{array}{l}F=23,87^{*} \\
p=0,0001\end{array}$ & $\begin{array}{l}F=4,73 * \\
p=0,0182\end{array}$ & $\begin{array}{l}F=3,14 \\
p=0,0604\end{array}$ & $\begin{array}{l}F=8,03^{*} \\
p=0,0001\end{array}$ & $\begin{array}{l}\text { Nāo ocorre analogia nos trechos } \\
\text { de M2 a M3, M3 a M4, M5 a M6 e } \\
M 6 \text { a M7. }\end{array}$ \\
\hline$e^{G 2, G 6}$ & $\begin{array}{l}F=4,32 * \\
p=0,0244\end{array}$ & $\begin{array}{l}F=0,10 \\
P=0,9007\end{array}$ & $\begin{array}{l}F=0,45 \\
P=0,6495\end{array}$ & $\begin{array}{l}F=0,04 \\
p=0,9632\end{array}$ & $\begin{array}{l}F=0,03 \\
p=0,9720\end{array}$ & $\begin{array}{l}F=0,00 \\
p=0,9980\end{array}$ & $\begin{array}{l}F=0,00 \\
p=0,9972\end{array}$ & $\begin{array}{l}F=19,55 \\
P=0,0005\end{array}$ & $\begin{array}{l}\text { Nāo existe analogla entreos gru } \\
\text { pos e } 1 \text { sto ocorre nos trechos de } \\
\text { MI a M2 }\end{array}$ \\
\hline
\end{tabular}

(b) Hipóteses testadas para efelto de momento dentro de cada um dos grupos. Estatistica F multivariada e comentärio sobre os resultados obtidos.

\begin{tabular}{|c|c|c|}
\hline GRUPOS & ESTATISTICA & COMENTARIO: $F$ crit. $=F(0,05 ; 1,24)=4,26$ \\
\hline Gl & $F=83,02$ & $\begin{array}{l}\text { Existe diferença entre momentos dentro de Gl. Ocorre um acréscímo da variável de M3 a M5, a- } \\
\text { pós o que há um decréscimo,com a volta aos nivels Inicials. }\end{array}$ \\
\hline G2 & $F=24,75^{\circ}$ & Existe diferença entre momentos dentro de $\mathrm{G} 2: \mathrm{Ml}>\mathrm{M2}=\mathrm{M3}=\mathrm{M4}=\mathrm{M5}=\mathrm{M6}=\mathrm{M7}-\mathrm{M8}$. \\
\hline G3 & $F=57,30^{\circ}$ & $\begin{array}{l}\text { Existe diferença entre momentos dentro de } G 3 \text {. Hä um decréscimo da varlävel em M4 e MS, apx } \\
\text { o que a variăvel volta aos valores iniclals. }\end{array}$ \\
\hline G4 & $F=182,67 *$ & Existe diferenca entre momentos dentro de $\mathrm{G4}: M 1>M 2=M 3=M 4=M 5=M 6=M 7=M B$ \\
\hline GS & $F=59,88^{*}$ & $\begin{array}{l}\text { Existe diferenga entre momentos dentro do G5. Há um decréscimo a partir de H3 e este decrés- } \\
\text { cimo se prolonga ató } M 6 \text {. Em M8 existe uma volta aos nIvels Iniclais. }\end{array}$ \\
\hline G6 & $F=54,84^{\circ}$ & Existe diferença entre momentos dentro de $G 6: M 1>M 2=M 3 \cdot M 4=M 5=M 6=M 7=M 8$. \\
\hline
\end{tabular}

4c) Hipöteses testadas para diferença entre grupos e para a interação entre falxa etāria e dieta en cada um dos mosentos Estatisticas $F$ e seus respectivos nIvels de significäncia (p). Comentärio sobre os resultados obtidos.

\begin{tabular}{|c|c|c|c|c|c|c|c|c|}
\hline $\begin{array}{l}\text { CONTRASTE } \\
\text { ENTRE }\end{array}$ & मा & M2 & $M 3$ & $\begin{array}{lll}M O & O M \\
M 4 & \end{array}$ & $\begin{array}{ll}\mathrm{E} & \mathrm{N} \\
\mathrm{MS} & \mathrm{T} \\
& \end{array}$ & M6 & M7 & MB \\
\hline G1 e $G 2$ & $\begin{array}{l}F=0,29 \\
P=0,6007\end{array}$ & $\begin{array}{l}F=4,224 \\
P=0,0485\end{array}$ & $\begin{array}{l}F=106,69 \\
p=0,0001\end{array}$ & $\begin{array}{l}F=92,58 \\
p=0,0001\end{array}$ & $\begin{array}{l}F=68,75 \\
p=0,0001\end{array}$ & $\begin{array}{l}F=25,18 \\
p=0,0001\end{array}$ & $\begin{array}{l}F=10,64 \\
p=0,0036\end{array}$ & $\begin{array}{l}F=34,36^{*} \\
p=0,0001\end{array}$ \\
\hline G3e G4 & $\begin{array}{l}F=1,14 \\
p=0,2975\end{array}$ & $\begin{array}{l}F=14,73 * \\
p=0,0011\end{array}$ & $\begin{array}{l}F=232,44 \\
p=0,0001\end{array}$ & $\begin{array}{l}F=171,39 \\
p=0,0001\end{array}$ & $\begin{array}{l}F=75,00 \\
p=0,0001\end{array}$ & $\begin{array}{l}F=180,05 \\
p=0,0001\end{array}$ & $\begin{array}{l}F=149,67 \\
p=0,0001\end{array}$ & $\begin{array}{l}F=198,63^{*} \\
p=0,0001\end{array}$ \\
\hline$G 5$ e $G 6$ & $\begin{array}{l}F=5,20 \\
p=0,0300\end{array}$ & $\begin{array}{l}F=25,48 \\
p=0,0001\end{array}$ & $\begin{array}{l}F=77,91 \\
P=0,0001\end{array}$ & $\begin{array}{l}F=120,84 \\
p=0,0001\end{array}$ & $\begin{array}{l}F=52,33^{*} \\
p=0,0001\end{array}$ & $\begin{array}{l}F=118,32 * \\
p=0,0001\end{array}$ & $\begin{array}{l}F=147,06 \\
p=0,0001\end{array}$ & $\begin{array}{l}F=176,18 \\
P=0,0001\end{array}$ \\
\hline $\mathrm{Gl}_{\mathrm{G}} \mathrm{GS}^{\mathrm{G}}$ & $\begin{array}{l}F=18,50 * \\
P=0,0001\end{array}$ & $\begin{array}{l}F=7,05 \\
p=0,0042\end{array}$ & $\begin{array}{l}F=28,92 * \\
p=0,0001\end{array}$ & $\begin{array}{l}F=9,78 \\
P=0,0011\end{array}$ & $\begin{array}{l}F=0,60 \\
p=0,5619\end{array}$ & $\begin{array}{l}F=44,28 \\
P=0,0001\end{array}$ & $\begin{array}{l}F=63,52 * \\
p=0,0001\end{array}$ & $\begin{array}{l}F=50,10 \\
p=0,0001\end{array}$ \\
\hline${ }_{c}^{G 2, G 6}$ & $\begin{array}{l}F=18,71: \\
P=0,0001\end{array}$ & $\begin{array}{l}F=0,29 \\
P=0,7568\end{array}$ & $\begin{array}{l}F=0,66 \\
p=0,5293\end{array}$ & $\begin{array}{l}F=1,15 \\
p=0,3343\end{array}$ & $\begin{array}{l}E=0,33 \\
p=0,7236\end{array}$ & $\begin{array}{l}F=0,68 \\
P=0,5188\end{array}$ & $\begin{array}{l}F=0,62 \\
p=0,5492\end{array}$ & $\begin{array}{l}F=0,68 \\
p=0,5179\end{array}$ \\
\hline $\begin{array}{l}\text { Interação } \\
\text { dlcta a } \\
\text { ldade }\end{array}$ & $\begin{array}{l}F=3,24 \\
p=0,0556\end{array}$ & $\begin{array}{l}F=2,27 \\
p=0,1236\end{array}$ & $\begin{array}{l}F=21,27 * \\
p=0,0006\end{array}$ & $\begin{array}{l}F=3,05 \\
P=0,0644\end{array}$ & $\begin{array}{l}F=0,55 \\
P=0,5903\end{array}$ & $\begin{array}{l}F=18,56 * \\
p=0,0001\end{array}$ & $\begin{array}{l}F=26,52 * \\
p=0,0001\end{array}$ & $\begin{array}{l}F=20,56 * \\
P=0,0001\end{array}$ \\
\hline
\end{tabular}



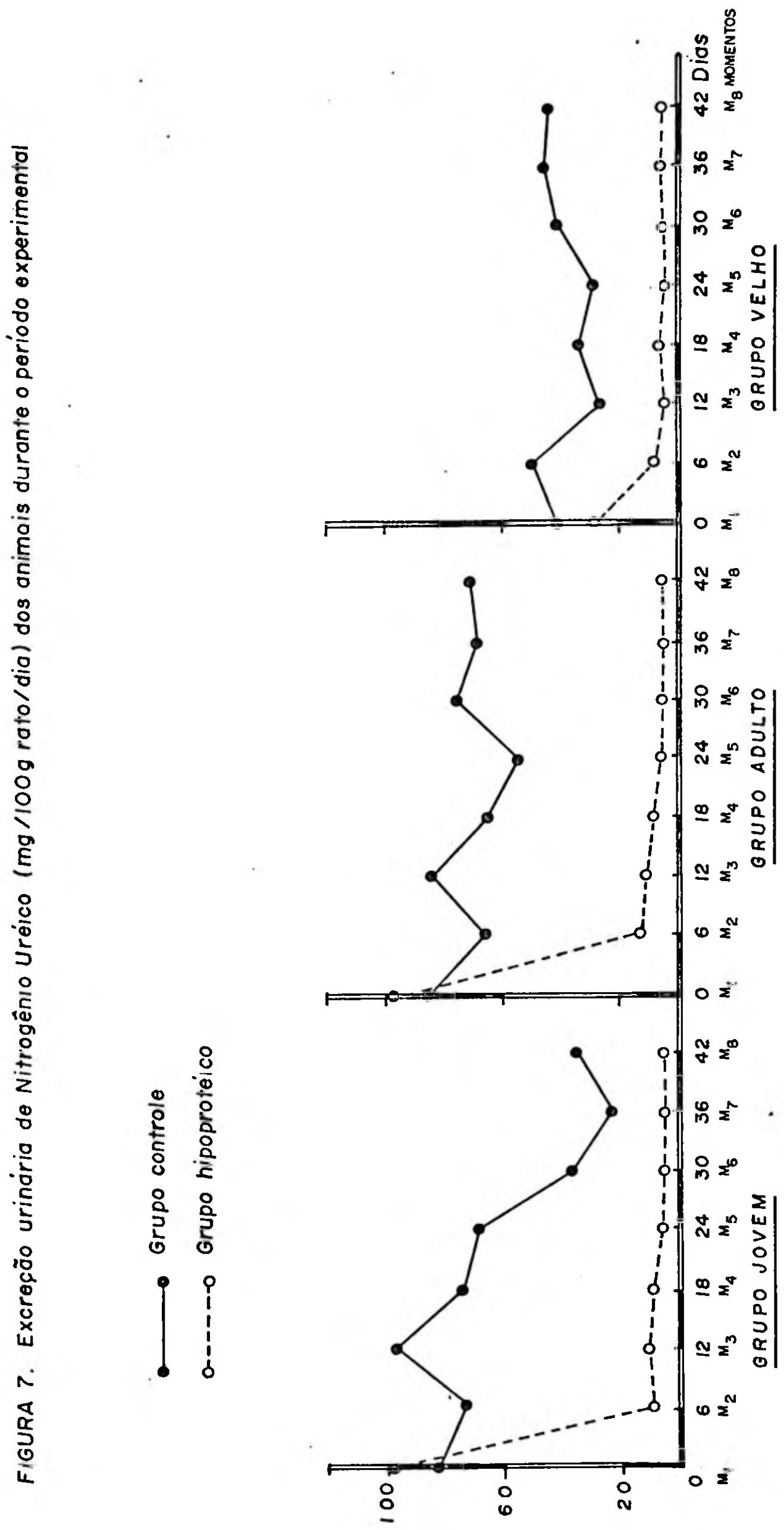

27. 
TABELA 5 - Excreçāo urlnärla de nitrogênlo urëlco (mg/100g rato/dla) dos animals dos grupos controles e hlpoprotéicos durante 0 perlodo experimental.

5a) H1pöteses testadas para analogía entre grupos, valores multivarlados de $F$ calculado, valores criticos de $P$ unlvariados de $F$ acompanhados dos respectivos nivels de significâncla. Comentário sobre os resultados obtidos.

AMALOGIA
ENTRE

EHTRE MI A M2 M2 a M3 MJ a MA M4 a M5 M5 M6 M6 a M7 M7 a M8 TICA MUL

Gl e G2 $\quad F=38,39 * F=3,33 \quad F=6,18 * \quad F=0,07 \quad F=15,46 * F=6,18 * \quad F=8,55 * \quad F=23,43 *$

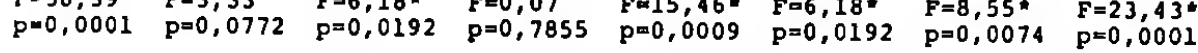

Não exiate analogia entreos gru pos e isto ocorre nos trechos de M1 a M2, M3 a M4, M5 a M6, M6 a $M 1$ a $M 2, M 3$ a

G3 e G4 $\quad F=24,48 * \quad F=2,65 \quad F=3,87 \quad F=0,73 \quad F=7,67 * \quad F=1,95 \quad F=0,77 \quad F=12,91 *$ Nāo existe analogia entreos gru pos e 1sto ocorre nos trechos de M1 a M2 e $M 5$ a $M 6$.

G5 e G6 $\quad F=5,61 . \quad F=2,47 \quad F=0,27 \quad F=0,11 \quad F=1,84 \quad F=0,59 \quad F=0,13 \quad F=3,77$
$\begin{array}{llllllll}p=0,0248 & p=0,1258 & p=0,6138 & p=0,7405 & p=0,1852 & p=0,5444 & F=0,13 & F=3,77 \\ & & p=0,7224 & p=0,0045\end{array}$

Näo existe analogia entreos gru pos e isto ocorre no trecho de pos a 18

\begin{tabular}{lllllllll} 
& $P=0,0248$ & $p=0,1258$ & $p=0,6138$ & $p=0,7405$ & $p=0,1852$ & $p=0,5444$ & $p=0,7224$ & $p=0,0045$ \\
\hline$G 1, G 3$ & $F=2,40$ & $F=9,09 *$ & $F=7,44^{*}$ & $F=0,24$ & $F=27,03 *$ & $F=5,32 *$ & $F=5,36 *$ & $F=10,76 *$
\end{tabular}

$\begin{array}{lllllllll}\text { e GS } & F=2,40 & F=9,09 * & F=7,44^{\star} & F=0,24 & F=27,03 * & F=5,32 \star & F=5,36 * & F=10,76 * \\ 0 & p=0,1104 & p=0,0015 & p=0,0034 & p=0,7873 & p=0,0001 & p=0,0121 & p=0,0118 & p=0,0001\end{array}$ Nāo existe analogia entre os gru pos e isto ocorre nos trechos de M2 a M3, M3 a M4 e de MS até M8

\begin{tabular}{|c|c|c|c|c|c|c|c|c|c|}
\hline $\begin{array}{l}G 2,64 \\
\text { e } 66\end{array}$ & $\begin{array}{l}F=16,77 \% \\
p=0,0001\end{array}$ & $\begin{array}{l}F=0,14 \\
p=0,8694\end{array}$ & $\begin{array}{l}F=0,22 \\
p=0,8065\end{array}$ & $\begin{array}{l}F=0,01 \\
p=0,9908\end{array}$ & $\begin{array}{l}F=0,06 \\
P=0,9394\end{array}$ & $\begin{array}{l}F=0,00 \\
P=0,9984\end{array}$ & $\begin{array}{l}F=0,01 \\
P=0,9894\end{array}$ & $\begin{array}{l}F=3,08 \\
p=0,0035\end{array}$ & $\begin{array}{l}\text { Não existe analogia entreos gru } \\
\text { pos isto ocorre de M1 a M2. }\end{array}$ \\
\hline
\end{tabular}
Sb) Hipóteses testadas para efelto de momento dentro de cada um dos grupos. Estatistica F multivariada e comentārlo eobr
os resultados obtidos.

\begin{tabular}{|c|c|c|}
\hline GRUPO & ESTATISTICA & COMENTARIO: $F$ crit. $-F(0,05 ; 1,24)=4,26$ \\
\hline $\mathrm{Cl}$ & $F=297,55$ & $\begin{array}{l}\text { Existe diferença entre momentos. A varlävel sofre uma elevaçäo em Mu para decrescer a segu: } \\
\text { até } M 7 \text {, voltando a crescer em M8, embora sem atinglr os nivelo iniciais. }\end{array}$ \\
\hline G2 & $F=270,29$ & $\begin{array}{l}\text { Existe diferença entro momentos. Há um decréscimo acentuado da varíável de Ml a M2 e este } \\
\text { acentua a seguir. }\end{array}$ \\
\hline G3 & $F=53,49^{\circ}$ & 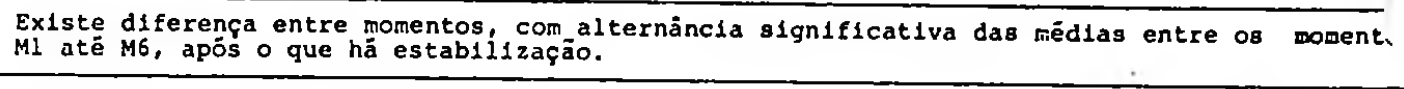 \\
\hline G4 & $F=248,19^{\circ}$ & $\begin{array}{l}\text { Existe diferença entre momentos. Há um decréscimo acentuado da variável de M1 a M2, após } \\
\text { que esta se estabiliza. }\end{array}$ \\
\hline G5 & $F=27,52$ & $\begin{array}{l}\text { Existe diferença entre momentos. As menores médias ocorrem em M3 e MS (M2> M3 e M5 < M6). } \\
\text { pós M5, a média volta a sublr alcançando os nivels inlcials no final do experimento. }\end{array}$ \\
\hline G6 & $F=20,72$ * & $\begin{array}{l}\text { Existe diferença entre os momentos. Hä um decréscimo acentuado da médía em M2, apōs o que,e } \\
\text { ta se estabiliza. }\end{array}$ \\
\hline
\end{tabular}

5c) Hipöteses testadas para diferença entre grupos e para a interaçāo entre fa1xa etāria e dieta em cada ura dos momentos.

Estatisticas $F$ e seus respectivos niveis de significância (p). Comentário sobre os resultados obtidos.

\begin{tabular}{|c|c|c|c|c|c|c|c|c|c|}
\hline $\begin{array}{l}\text { ONTRASTE } \\
\text { ENTRE } \\
\end{array}$ & $M 1$ & M2 & $M 3$ & $\frac{M O}{M 4}$ & $\begin{array}{lll}E & N & T \\
M 5 & 0\end{array}$ & M6 & MI & $M B$ & COMENTARIO \\
\hline$G 1$ e $G 2$ & $\begin{array}{l}F=3,09 \\
p=0,0882\end{array}$ & $\begin{array}{l}F=35,78 . \\
p=0,0001 .\end{array}$ & $\begin{array}{l}F=147,66 \\
p=0,0001\end{array}$ & $\begin{array}{l}F=93,89 \\
p=0,0001\end{array}$ & $\begin{array}{l}F=103,49 \\
p=0,0001\end{array}$ & $\begin{array}{l}F=49,22 \\
p=0,0001\end{array}$ & $\begin{array}{l}F=17,19 * \\
p=0,0006\end{array}$ & $\begin{array}{l}F=45,234 \\
p=0,0001\end{array}$ & $\begin{array}{l}\text { Existe d1ferença entre grupos, } \\
\text { com G1 > G2 em todos os momen- } \\
\text { tos, exceto } \mathrm{M} 1 \text {, onde } \mathrm{Gl}=\mathrm{G} 2 \text {. }\end{array}$ \\
\hline G3 e G4 & $\begin{array}{l}F=1,19 \\
p=0,2860\end{array}$ & $\begin{array}{l}F=25,51 \\
p=0,0001\end{array}$ & $\begin{array}{l}F=108,31 \\
p=0,0001\end{array}$ & $\begin{array}{l}F=72,27 \\
p=0,0001\end{array}$ & $\begin{array}{l}F=64,17 * \\
p=0,0001\end{array}$ & $\begin{array}{l}F=235,86 * \\
p=0,0001\end{array}$ & $\begin{array}{l}F=204,09 * \\
p=0,0001\end{array}$ & $\begin{array}{l}F=214,23 \\
p=0,0001\end{array}$ & $\begin{array}{l}\text { Existe diferença entre grupos } \\
\text { com G3 }>\text { G4 em todos os Domen- } \\
\text { tos, exceto em } M I: G 3=G 4 \text {. }\end{array}$ \\
\hline G5 e 66 & $\begin{array}{l}F=1,59 \\
p=0,2174\end{array}$ & $\begin{array}{l}F=15,90 * \\
P=0,0008\end{array}$ & $\begin{array}{l}F=11,29 \\
p=0,0029\end{array}$ & $\begin{array}{l}F=17,45 . \\
p=0,0006\end{array}$ & $\begin{array}{l}F=16,53^{*} \\
p=0,0007\end{array}$ & $\begin{array}{l}F=59,43 * \\
P=0,0001\end{array}$ & $\begin{array}{l}F=82,15 \\
p=0,0001\end{array}$ & $\begin{array}{l}F=71,13^{*} \\
P=0,0001\end{array}$ & $\begin{array}{l}\text { Existe diferenca entre gruposen en } \\
\text { todos os momentos, com } G 5>G 5 \text {, } \\
\text { exceto em } M I: G 5=G 6 .\end{array}$ \\
\hline $\begin{array}{l}\text { G1, GS } \\
\text { e }{ }^{2}\end{array}$ & $\begin{array}{l}F=13,61 \\
p=0,0002\end{array}$ & $\begin{array}{l}F=2,32 \\
p=0,1179\end{array}$ & $\begin{array}{l}F=54,94 * \\
P=0,0001\end{array}$ & $\begin{array}{l}F=19,50 * \\
P=0,0001\end{array}$ & $\begin{array}{l}F=20,96 * \\
p=0,0001\end{array}$ & $\begin{array}{l}F=44,01 \\
p=0,0001\end{array}$ & $\begin{array}{l}F=53,60 \\
p=0,0001\end{array}$ & $\begin{array}{l}F=35,21 * \\
p=0,0001\end{array}$ & $\begin{array}{l}\text { Diferem em todos os momentos, ex } \\
\text { ceto em } M 2 \text {. } E m M 1 \text { e } M 4: G 1=G 3 \\
>G 5 \text {. Em } M 3 \text { e } M 5: G 1>G 3, G 5 \\
\text { Em } M 6, M 7 \text { e } M 8: G 1<G 3 ; G 3>G 5\end{array}$ \\
\hline$e^{G 2, G 6}$ & $\begin{array}{l}F=34,58 * \\
p=0,0001\end{array}$ & $\begin{array}{l}F=0,10 \\
P=0,9027\end{array}$ & $\begin{array}{l}F=0,70 \\
p=0,5084\end{array}$ & $\begin{array}{l}F=0,10 \\
p=0,9056\end{array}$ & $\begin{array}{l}F=0,04 \\
p=0,9616\end{array}$ & $\begin{array}{l}F=0,03 \\
p=0,9721\end{array}$ & $\begin{array}{l}F=0,03 \\
P=0,9758\end{array}$ & $\begin{array}{l}F=0,03 \\
p=0,9758\end{array}$ & $\begin{array}{l}\text { G2 = G4, ambos malores que G6 em } \\
\text { M1. Nos dema1s momentos não e- } \\
\text { xiste d1ferença }\end{array}$ \\
\hline $\begin{array}{l}\text { Interação } \\
\text { dieta e } \\
\text { Idade }\end{array}$ & $\begin{array}{l}F=2,51 \\
P=0,1004\end{array}$ & $\begin{array}{l}F=1,00 \\
p=0,6100\end{array}$ & $\begin{array}{l}E=21,66 \ldots \\
P=0,0001\end{array}$ & $\begin{array}{l}F=8,41 * \\
p=0,0020\end{array}$ & $\begin{array}{l}F=9,59 \\
p=0,0012\end{array}$ & $\begin{array}{l}F=21,43 \\
p=0,0001\end{array}$ & $\begin{array}{l}F=25,71 * \\
p=0,0001\end{array}$ & $\begin{array}{l}F=17,33 \\
p=0,0001\end{array}$ & $\begin{array}{l}\text { Existe interaçāo em todos os too } \\
\text { mentos, exceto em } M 1 \text { e M2. }\end{array}$ \\
\hline
\end{tabular}




\section{Proteinas Plasmāticas}

Não foram observadas diferenças estatisticas en tre as concentrações plasmāticas de proteinas totais e alburnina entre os diferentes grupos etários alimentados com dieta controle (Tabela 6).

Todos os grupos hipoprotēicos apresentaram niveis médios de concentração de albumina menores que seus respectivos controles etários. A concentração de proteinas totais foi também significativamente menor nos grupos hipoprotéicos jovem e adulto, quando comparados com seus respectivos controles, enquan to não foi possível detectar diferença entre os valores desta vạ riável nos animais velhos hipoprotéicos e seus respectivos controles. A ingestão de dieta deficiente em proteínas não alterou significativamente os valores das globulinas plasmäticas (Tabela 6).

TABELA 6 - Valores estatísticos das proteínas plasmáticas ( $\mathrm{g} \%)$.

\begin{tabular}{|c|c|c|c|c|c|c|}
\hline & \multicolumn{2}{|c|}{ JOVEM } & \multicolumn{2}{|c|}{ ADULTO } & \multicolumn{2}{|c|}{ VELHO } \\
\hline & CONTROLE & $\begin{array}{l}\text { HIPOPRO- } \\
\text { TEICO }\end{array}$ & CONTROLE & $\begin{array}{l}\text { HIPOPRO- } \\
\text { TEICO }\end{array}$ & CONTROLE & $\begin{array}{l}\text { HIPOPRO- } \\
\text { TEICO }\end{array}$ \\
\hline$\frac{P T}{\bar{x} \pm S D}$ & $6,8 \pm 0,12^{a}$ & $4,7 \pm 0,23^{b}$ & $7,0 \pm 0,48^{a}$ & $5,9 \pm 0,42^{b}$ & $7,1 \pm 0,79^{a}$ & $6,3 \pm 0,43^{a}$ \\
\hline $\begin{array}{l}\mathrm{ALB} \\
\overline{\mathrm{x}} \pm \mathrm{SD}\end{array}$ & $4,0 \pm 0,20^{\mathrm{a}}$ & $2,2 \pm 0,40^{b}$ & $3,9 \pm 0,22^{a}$ & $3,0 \pm 0,05^{b}$ & $3,7 \pm 0,44^{a}$ & $2,9 \pm 0,23^{b}$ \\
\hline $\begin{array}{l}\text { GLOB } \\
\overline{\mathrm{x}} \pm \mathrm{SD}\end{array}$ & $2,8 \pm 0,19^{a}$ & $2,5 \pm 0,39^{a}$ & $3,1 \pm 0,45^{a}$ & $2,9 \pm 0,46^{a}$ & $3,4 \pm 0,54^{b}$ & $3,4 \pm 0,38^{b}$ \\
\hline
\end{tabular}

Diferenciação estatística entre grupos ( $p<0,05$ ) mostrada por letras diferen tes a e b. PT = proteínas totais; ALB = albumina; GLOB = globulinas 


\section{Análise Histológica do Fígado}

Não foram verificadas anormalidades histológicas nos fígados dos animais controles de todas as faixas etárias estudadas.

Nos animais submetidos à dieta hipoprotéica não foi constatada nenhuma alteração digna de nota, alēm da esteatose.

A Tabela 7 apresenta a distribuição de frequên cia dos animais carentes de proteinas com relação ao grau de com prometimento hepático pela degeneração gordurosa. Enquanto os animais jovens apresentaram mais frequentemente o grau mais inten so de esteatose, os animais adultos e velhos apresentaram-na com mais frequência, em graus menos intensos.

Tabela 7 - Freqlência de esteatose hepática segundo sua intensidade, nos animais tratados com dieta hipoprotéica após 42 dias de experi mento.

\begin{tabular}{lcccc}
\hline \multirow{2}{*}{ GRUPOS } & SEM & \multicolumn{2}{c}{ GRAUS } & DE ESTEATOSE \\
\cline { 3 - 4 } & ESTEATOSE & I & II & III \\
\hline Jovem & 1 & - & - & 4 \\
Adulto & - & - & 2 & 3 \\
Velho & - & 2 & 2 & 1 \\
\hline
\end{tabular}




\section{Excreção Urināria de Creatinina}

\subsection{Efeito da Idade}

A excreção diária de creatinina acompanhou a idade dos animais sendo a magnitude da diferença observada entre os grupos jovens e adultos, de cerca de $224 \%$ e entre os grupos adultos e velhos, de 1298 (Fig. 8 e Tabela 8). A excreção de crea tinina por unidade de peso corporal apresentou acréscimo de 1498 até a fase adulta, sofrendo decréscimo a seguir (Fig. 9 e Tabela 9) A análise sequlencial dos momentos mostrou que há um aumento sistemático da excreção diāria de creatinina nos grupos jovem e adulto, embora não tenha sido constatada diferença em momentos consecutivos. Este padrão de comportamento não foi observado no grupo velho (Fig. 8 e Tabela 8 ). Os valores de creatinina corrigidos para o peso corporal dos grupos jovem e adulto foram relativamente semelhantes para os diferentes momentos estudados(Fig. 9 e Tabela 9).

\subsection{Efeito da Dieta}

o tipo de dieta influenciou o comportamentodos grupos e de modo geral o grupo controle apresentou valores de ex creção diāria maiores do que os dos grupos hipoprotéicos.Esta dị ferenciação ocorreu de modo significativo a partir do 188 dia, nos grupos jovem e adulto, e do 248 dia, no grupo velho (Fig. 8 e Tabela 8). A curva de excreção mostrou comportamento não análo go para os grupos jovens e velhos, havendo analogia mas não coin cidência para os grupos adultos (Fig. 8 e Tabela 8). Para os gru pos jovem e adulto não houve diferença significativa entre a maio ria dos momentos em relação ao momento inicial (Fig. 8 e Tabela 8). As diferenças observadas entre os grupos dietéticos foram 

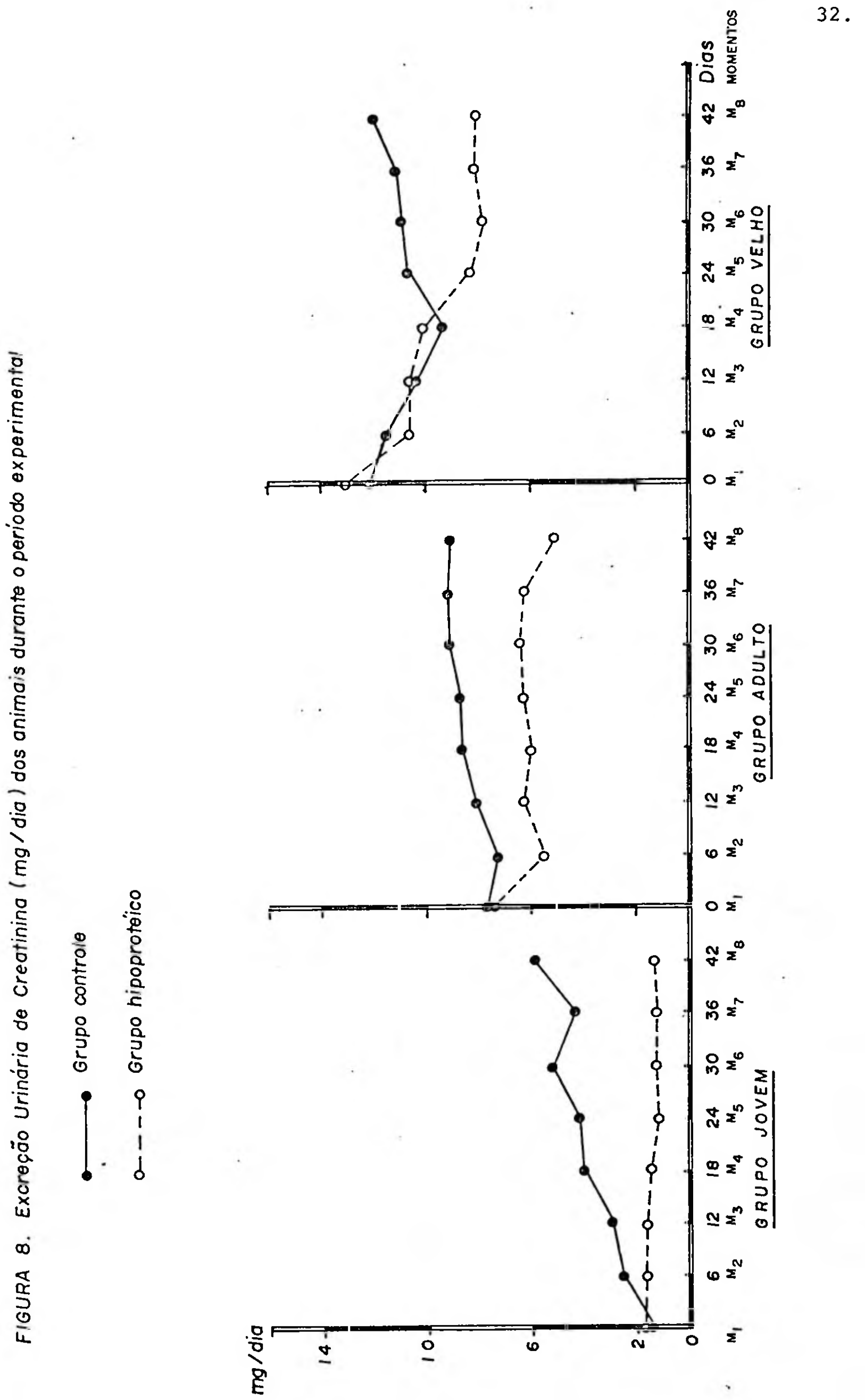

TABELA - Excreção urinärla de croatinina (mg/dia) dos animals dos grupos controles e hipoprotélcos durante o perlodo ex-
perimental.

9a) Hipóteses testadas para analogia entre grupos; valores multivarlados de $F$ calculado, valores criticos de $F$ e unlvariados de $F$ acompanhados dos respectivos nivels de significâncla. Comentárlo sobre os resultados obtidos.

\begin{tabular}{|c|c|c|c|c|c|c|c|c|c|}
\hline \multirow{2}{*}{$\begin{array}{l}\text { ANALOGIA } \\
\text { ENTRE }\end{array}$} & \multirow[b]{2}{*}{ M1 a M2 } & \multirow[b]{2}{*}{$M 2$ a $M 3$} & \multirow{2}{*}{$\frac{M O}{M 3 \text { a M4 }}$} & \multirow{2}{*}{$\begin{array}{l}M E N \\
M 4 \text { a } M 5\end{array}$} & \multicolumn{3}{|l|}{$\begin{array}{ll}\mathrm{T} & \mathrm{O} \\
\end{array}$} & \multirow{2}{*}{$\begin{array}{l}\text { ESTATIS- } \\
\text { TICA MUL } \\
\text { TIVARIADA } \\
\end{array}$} & \multirow[b]{2}{*}{ COMENTARIO } \\
\hline & & & & & M5 a M6 & $M 6$ a $M 7$ & M7 a M8 & & \\
\hline$G 1$ e G2 & $\begin{array}{l}F=0,65 \\
P=0,5651\end{array}$ & $\begin{array}{l}F=0,08 \\
P=0,7729\end{array}$ & $\begin{array}{l}F=0,63 \\
p=0,5583\end{array}$ & $\begin{array}{l}F=0,54 \\
p=0,5226\end{array}$ & $\begin{array}{l}F=0,87 \\
p=0,6383\end{array}$ & $\begin{array}{l}F=1,25 \\
p=0,2745\end{array}$ & $\begin{array}{l}F=1,84 \\
p=0,1851\end{array}$ & $\begin{array}{l}F=4,37 * \\
p=0,0057\end{array}$ & $\begin{array}{l}\text { Nāo existe analogla entre os gru } \\
\text { pos, embora Isto não fosse cong } \\
\text { tatada nos trechos anallsados. }\end{array}$ \\
\hline 63 e G4 & $\begin{array}{l}F=1,41 \\
p=0,2451\end{array}$ & $\begin{array}{l}F=0,00 \\
P=0,9955\end{array}$ & $\begin{array}{l}F=0,42 \\
P=0,5304\end{array}$ & $\begin{array}{l}F=0,08 \\
P=0,7727\end{array}$ & $\begin{array}{l}F=0,04 \\
P=0,8294\end{array}$ & $\begin{array}{l}F=0,31 \\
p=0,5879\end{array}$ & $\begin{array}{l}F=1,51 \\
p=0,2294\end{array}$ & $\begin{array}{l}F=1,84 \\
P=0,1398\end{array}$ & $\begin{array}{l}\text { Os grupos podem ser considera- } \\
\text { dos análogos, embora as curvas } \\
\text { d1f1ram, com } G 2>G 4 \text {. F=12,86, } \\
\text { pm0,0018. }\end{array}$ \\
\hline 65 e G6 & $\begin{array}{l}F=2,64 \\
p=0,1138\end{array}$ & $\begin{array}{l}F=0,06 \\
p=0,5481\end{array}$ & $\begin{array}{l}F=0,05 \\
p=0,8188\end{array}$ & $\begin{array}{l}F=14,00 k \\
p=0,0013\end{array}$ & $\begin{array}{l}E=0,87 \\
p=0,6383\end{array}$ & $\begin{array}{l}F=0,01 \\
p=0,9279\end{array}$ & $\begin{array}{l}F=0,95 \\
p=0,6587\end{array}$ & $\begin{array}{l}F=10,82 \\
P=0,0001\end{array}$ & $\begin{array}{l}\text { Os grupos não ado análogos e } 18 \\
\text { to ocorre no trecho: M1 a MS }\end{array}$ \\
\hline 1,63 & $\begin{array}{l}F=1,21 \\
p=0,3162\end{array}$ & $\begin{array}{l}F=0,83 \\
P=0,5492\end{array}$ & $\begin{array}{l}F=1,05 \\
p=0,3661\end{array}$ & $\begin{array}{l}F=1,34 \\
p=0,2796\end{array}$ & $\begin{array}{l}F=0,39 \\
p=0,6895\end{array}$ & $\begin{array}{l}F=1,40 \\
p=0,2655\end{array}$ & $\begin{array}{l}F=1,12 \\
p=0,3441\end{array}$ & $\begin{array}{l}F=2,75 \\
p=0,0075\end{array}$ & $\begin{array}{l}\text { Não existe analogia entre os gru } \\
\text { pos, embora 1sto năo possa ser } \\
\text { detectada nos trechos estudados. }\end{array}$ \\
\hline $6^{G 4}$ & $\begin{array}{l}F=2,66 \\
p=0,0891\end{array}$ & $\begin{array}{l}F=0,15 \\
p=0,8591\end{array}$ & $\begin{array}{l}F=0,07 \\
P=0,9284\end{array}$ & $\begin{array}{l}F=3,33^{*} \\
p=0,0500\end{array}$ & $\begin{array}{l}F=0,39 \\
p=0,6895\end{array}$ & $\begin{array}{l}F=0,34 \\
p=0,7169\end{array}$ & $\begin{array}{l}F=1,08 \\
p=0,3576\end{array}$ & & $\begin{array}{l}\text { Os grupos não são análogos e } 1 \mathrm{~s} \\
\text { to ocorre no trecho de } M 4 \text { a } M 5 \text {. }\end{array}$ \\
\hline
\end{tabular}

9b) Hipóteses testadas para efeito de momento dentro de cada un dos grupos. Estatistica f multivarlada e cosentár1o sobre os resultados obtidos.

\begin{tabular}{|c|c|c|}
\hline GRUPO & ESTATISTICA & COMENTARIO: $F$ cr1t. $=F(0,05 ; 1,24)=4,26$ \\
\hline G1 & $F=61,46^{*}$ & 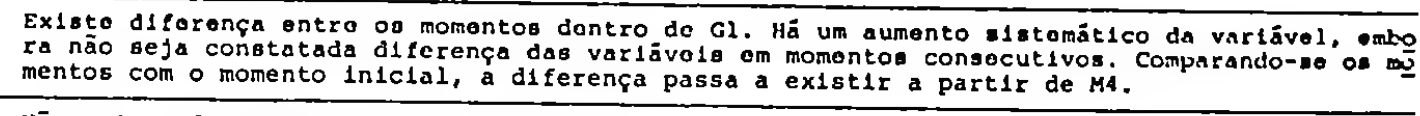 \\
\hline G2 & $F=3,10$ & Nāo existe diferença significativa entre os momentos. \\
\hline G3 & $F=51,51 *$ & $\begin{array}{l}\text { Existe diferença entre os momentos, embora momentos consecutivos näo diflram.A diferença siq } \\
\text { nLficativa ocorre para M8 }>M 2\end{array}$ \\
\hline G4 & $F=29,25$ & $\begin{array}{l}\text { Existe diferença entre os momentos, havendo um decrēscimo da variável ex M2, após o que esta } \\
\text { se mantém até M7, com posterior decrēscimo em M8. }\end{array}$ \\
\hline G5 & $F=58,31^{*}$ & $\begin{array}{l}\text { Existe diferença entre os momentos. Há um decréscimo da variável que atinge valor minimo em } \\
\text { M4, após o que ela volta aos valores inicla1s. }\end{array}$ \\
\hline G6 & $F=81,10^{\circ}$ & $\begin{array}{l}\text { Existe diferença entre momentos, havendo um decrésclmo da variável que atinge um valor minl- } \\
\text { mo em MS, após o que, esta se estabiliza. }\end{array}$ \\
\hline
\end{tabular}

9c) IIpótesos testadas para diferença ontre grupos e para a interação entro falxa etärla o dieta em cada un dos momentos. Estatiaticas $F$ e seus respectivos nlveis de significância (p). Comentário sobre os resultados obtidos. CONTRASTE
ENTRE

G1 e G2 $\quad F=0,00 \quad F=1,31 \quad F=0,74 \quad F=19,09 * \quad F=9,87 * \quad F=16,01 * \quad F=23,97 * \quad F=20,79 *$ $\begin{array}{llllllll}p=0,9648 & p=0,2638 & p=0,5983 & p=0,0004 & p=0,0046 & p=0,0008 & p=0,0002 & p=0,0003\end{array}$

G3 e G4 $\begin{array}{lllllll}F=0,05 & F=4,98 * & F=1,20 & F=21,27^{*} & F=6,19 * & F=7,30^{*} \quad F=22,16 * \quad F=18,58 *\end{array}$

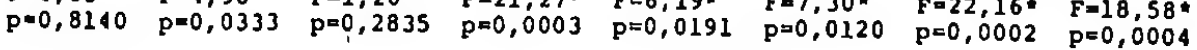

G5 e G6 $\begin{array}{llllllll}F=0,12 & F=1,63 & F=0,03 & F=1,16 & F=5,22 * & F=9,83 * & F=21,87 * & F=16,33 * \\ p=0,5289 & p=0,2122 & p=0,8506 & p=0,2932 & p=0,0297 & p=0,0047 & p=0,0002 & p=0,0007\end{array}$
$\begin{array}{llllll}p=0,5289 & p=0,2122 & p=0,8506 \quad p=0,2932 & p=0,0297 \quad p=0,0047 \quad p=0,0002 \quad p=0,0007\end{array}$

G1, G3 $\quad F=28,91 * \quad F=69,96 * \quad F=11,9 \theta^{*} \quad F=47,89 * \quad F=21,24 * \quad F=17,09 * \quad F=56,67 * \quad F=19,75 *$

Existe diferença entre os grupos em M4, M5, M6, M7 e M8, On-

Existe diferença entre os grupos em M2, M4, MS, M6, M7 e $\mathrm{MB}$, onde $G_{3}>G_{4}$.

Existe diferença entre os grupos em M5, M6, M7 e M8, com GS $>$ G6.

Os grupos diferem em todos os mo mentos com $\mathrm{Gl}<\mathrm{G} 3<\mathrm{G5}$.

Exiato diforença on tedoe os mo mentos com $\mathrm{G} 2<\mathrm{G} 4<\mathrm{G6}$

Existe Interação signiflcativa em M4. 


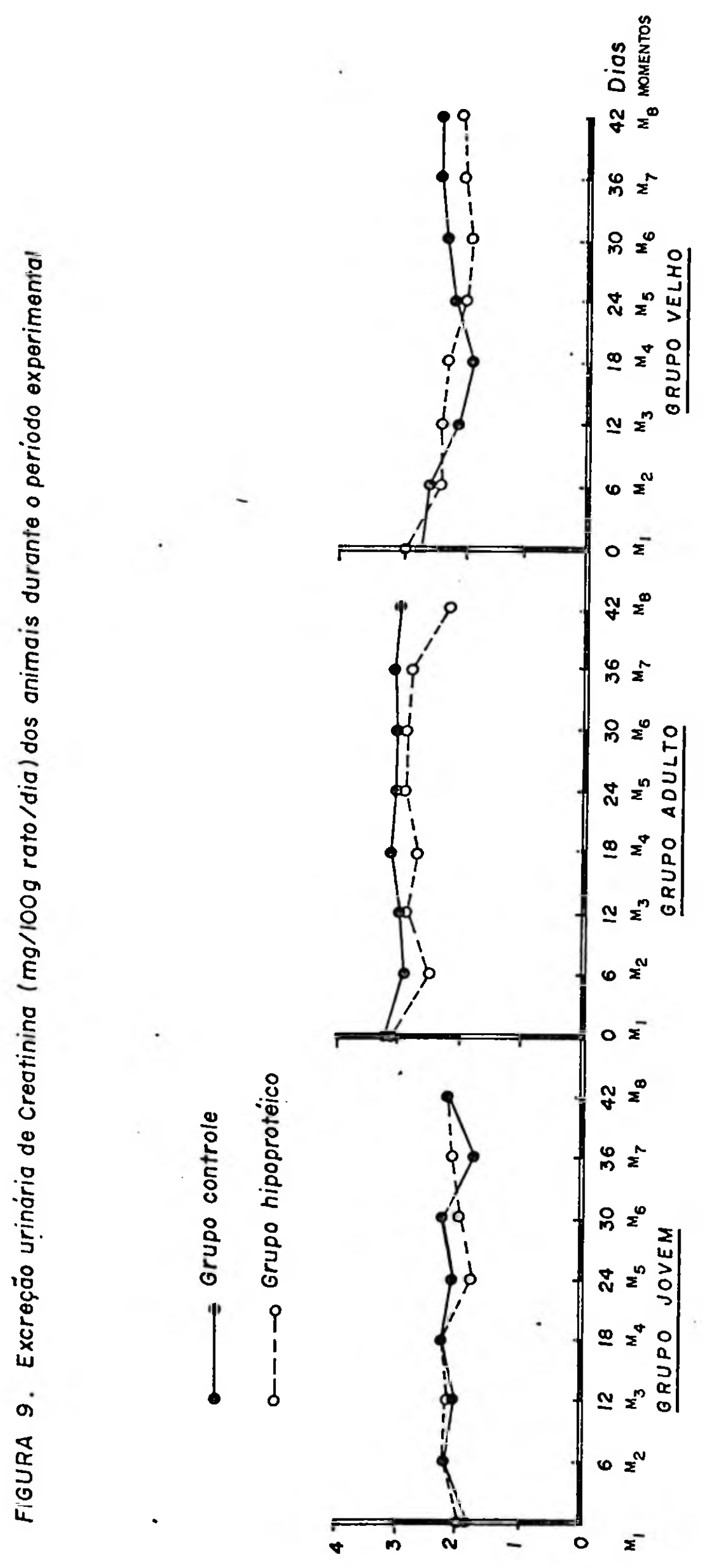

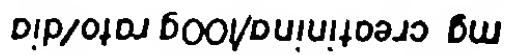



TABELA 9 - Excroço urinfirla do creatinina (mg/100g rato/dia) dos animals dos grupos controles o hipoprotelcos durante
perlodo experimental.

10a) Hipöteses testadas para analogia entre grupos, valoros multivariados de falculado, valores criticos de $\mathrm{F}$ e valores unlvarlados de $F$ acompanhados dos respectivos nivels de signiflcancla. Comentário sobre os resultados obtidos.

\begin{tabular}{|c|c|c|c|c|c|c|c|c|c|}
\hline \multirow{2}{*}{$\begin{array}{l}\text { ANALOGIA } \\
\text { ENTRE }\end{array}$} & & & $M$ & $\bar{E} N$ & 20 & & & \multirow{2}{*}{$\begin{array}{l}\text { ESTATIS- } \\
\text { TICA MUL } \\
\text { TIVARIADA }\end{array}$} & \multirow[b]{2}{*}{ COMENTARIO } \\
\hline & $M 1$ a $M 2$ & $M 2$ a $M 3$ & $M 3 \triangle M 4$ & M4 a MS & M5 a M6 & $M 6 \triangle M 7$ & $M 7$ a $M 8$ & & \\
\hline
\end{tabular}

G1 e G2 F=0,24 $F=0,30 \quad F=0,28 \quad F=1,00 \quad F=0,02 \quad F=6,57 * \quad F=0,52 \quad F=19,66$ Näo existe analog1a entreo gru $\begin{array}{llllllll} & & \end{array}$

is6 a $\mathrm{k7}$.

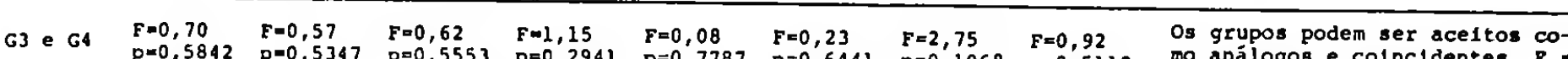

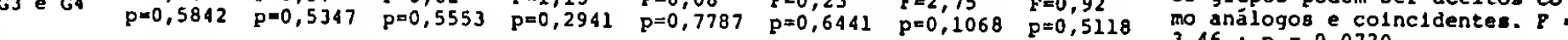

C5 e G6 F-2,14 $\quad F=0,91 \quad F=0,07 \quad F=4,61 * \quad F=0,31 \quad F=0,08 \quad F=0,00 \quad$ F=17,99* Näo existe analog1a entre os gru

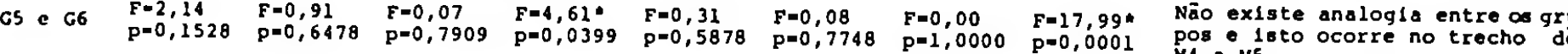

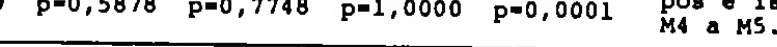

$G 1, G 3 \quad F=4,32^{*} \quad F=0,93 \quad F=1,01 \quad F=1,82 \quad F=0,32 \quad F=4,08 * \quad F=1,70 \quad F=2,88^{*} \quad$ Näo ex1ste analogla entreos gry

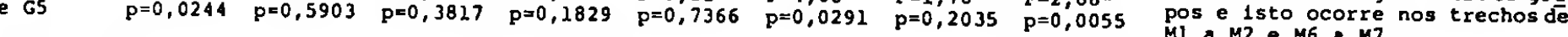

$\begin{array}{llllllllll}\text { CG6 } & F=6,05^{*} & F=0,89 & F=0,42 & F=3,75^{*} & F=0,60 & F=0,47 & F=4,25 * & F=2,41 * \quad \text { Näo existe analog1a entreos gru }\end{array}$ $p=0,6332 \quad p=0,0256 \quad p=0,0167$ pos e 1sto Ocorre nos trechos 10b) Hipóteses testadas para efelto de momento dentro de cada um dos grupos. Estatistica F multivarlada e comentário sobre
os resultados obtidos.

\begin{tabular}{|c|c|c|}
\hline GRUPO & ESTATISTICA & COMENTARIO: $F$ cr1t. $=F(0,05 ; 1,24)=4,26$ \\
\hline Gl & $F=39,66$ * & Exlste diferença entre os momentos e 1 sto se deve a M6 ser malor que M7. \\
\hline 62 & $F=14,12$ & Exlete diferença entro os momentos e 1 sto ocorre por M4 ser malor que MS. \\
\hline G3 & $F=8,96^{*}$ & Existe diferença entre os momentos e 1sto ocorre por MI ser malor que M2. \\
\hline G4 & $F=41,66 *$ & 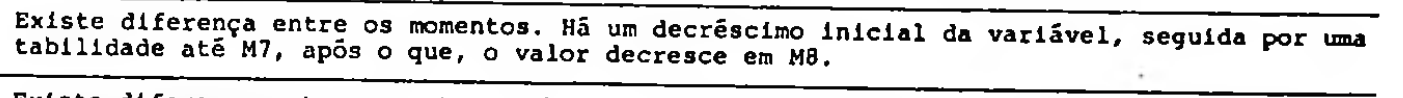 \\
\hline G5 & $F=18,81 *$ & $\begin{array}{l}\text { Existe diferença entre momentos, embora momentos consecutivos näo difiram. Isto ocorre dev } \\
\text { do ao pequeno valor da médla en } M 4 \text {. }\end{array}$ \\
\hline G6 & $F=20,59 \circ$ & $\begin{array}{l}\text { Existe diferença entre momentos. Hã um decréscimo acentuado da varlável em M4 e MS, após } \\
\text { gue a variável volta aos nivels iniclals, embora M8 sefa menor que Ml. }\end{array}$ \\
\hline
\end{tabular}

10c) Hipóteses testadas para diferença entre grupos e para a interação entre faixa etăria e dieta em cada um dos momentos.

Estatisticas $F$ e seus respectivos niveis de significâncla (p). Comentärio sobre os resultados obtidos.

\begin{tabular}{|c|c|c|c|c|c|c|c|c|c|}
\hline $\begin{array}{l}\text { CONTRASTE } \\
\text { ENTRE }\end{array}$ & $M I$ & $M 2$ & $M 3$ & $\begin{array}{lll}M & O & M \\
\end{array}$ & E ${ }^{N} \mathrm{~N}$ & M6 & MI & M8 & CCMENTARIO \\
\hline G1 \& G2 & $\begin{array}{l}F=0,13 \\
p=0,7184\end{array}$ & $\begin{array}{l}F=0,01 \\
P=0,9290\end{array}$ & $\begin{array}{l}F=0,29 \\
p=0,6010\end{array}$ & $\begin{array}{l}F=0,00 \\
p=0,9955\end{array}$ & $\begin{array}{l}F=1,13 \\
p=0,2993\end{array}$ & $\begin{array}{l}F=2,00 \\
P=0,1671\end{array}$ & $\begin{array}{l}F=2,05 \\
p=0,1625\end{array}$ & $\begin{array}{l}F=0,01 \\
p=0,9370\end{array}$ & $\begin{array}{l}\text { Näo existe dlferença entro os } \\
\text { grupos ea cada un dos momentos } \\
\text { experimentals. }\end{array}$ \\
\hline G3 e G4 & $\begin{array}{l}F=0,18 \\
p=0,6767\end{array}$ & $\begin{array}{l}F=2,73 \\
p=0,1081\end{array}$ & $\begin{array}{l}F=0,05 \\
p=0,8255\end{array}$ & $\begin{array}{l}F=3,96 \\
p=0,0553\end{array}$ & $\begin{array}{l}F=0,09 \\
p=0,7616\end{array}$ & $\begin{array}{l}F=0,50 \\
p=0,5071\end{array}$ & $\begin{array}{l}F=2,86 \\
p=0,1005\end{array}$ & $\begin{array}{l}F=7,75 \\
p=0,0100\end{array}$ & $\begin{array}{l}\text { G3 è malor que G4 em M8 e quase } \\
\text { en M4. }\end{array}$ \\
\hline G5 e G6 & $\begin{array}{l}F=0,83 \\
P=0,6269\end{array}$ & $\begin{array}{l}F=0,27 \\
P=0,6125\end{array}$ & $\begin{array}{l}F=0,49 \\
p=0,5030\end{array}$ & $\begin{array}{l}F=3,55 \\
p=0,0685\end{array}$ & $\begin{array}{l}F=0,83 \\
p=0,6250\end{array}$ & $\begin{array}{l}F=3,13 \\
p=0,0864\end{array}$ & $\begin{array}{l}F=4,88 \\
p=0,0349\end{array}$ & $\begin{array}{l}F=1,73 \\
p=0,1987\end{array}$ & Em M7, G5 > G6 \\
\hline$e_{\text {e } G 5}$ & $\begin{array}{l}F=10,16 \\
p=0,0009\end{array}$ & $\begin{array}{l}F=3,89 * \\
P=0,0335\end{array}$ & $\begin{array}{l}F=4,55 \\
p=0,0206\end{array}$ & $\begin{array}{l}F=19,90 \\
p=0,0001\end{array}$ & $\begin{array}{l}F=7,74 * \\
p=0,0029\end{array}$ & $\begin{array}{l}F=7,32 \\
p=0,0036\end{array}$ & $\begin{array}{l}F=32,77 \\
p=0,0001\end{array}$ & $\begin{array}{l}F=4,45^{\ldots} \\
p=0,0222\end{array}$ & $\begin{array}{l}\text { Existe diferença entze grupos } \\
\text { em todos os momentos. De modo } \\
\text { geral: Gl<G3 e G3>GS. }\end{array}$ \\
\hline $\begin{array}{l}\mathrm{G} 2, \mathrm{G} 4 \\
\text { e } \mathrm{G} 6\end{array}$ & $\begin{array}{l}F=7,58 \\
p=0,0031\end{array}$ & $\begin{array}{l}F=0,76 \\
p=0,5178\end{array}$ & $\begin{array}{l}F=2,22 \\
p=0,1289\end{array}$ & $\begin{array}{l}F=3,39 \\
p=0,0495\end{array}$ & $\begin{array}{l}F=11,21 \\
p=0,0006\end{array}$ & $\begin{array}{l}F=11,85 \\
p=0,0005\end{array}$ & $\begin{array}{l}F=17,17 * \\
p=0,0001\end{array}$ & $\begin{array}{l}F=0,32 \\
p=0,7315\end{array}$ & $\begin{array}{l}\text { Ex1ste diferença entre grupos en } \\
M 1, M 4, M 5, M 6, M 7 \text {, sendo } G 2<G 4 \\
\text { e } G 4>G 6 . E m M I G 4=G 6 .\end{array}$ \\
\hline $\begin{array}{l}\text { Interaçao } \\
\text { dieta c } \\
\text { I dinde } \\
\end{array}$ & $\begin{array}{l}F=0,45 \\
p=0,6457\end{array}$ & $\begin{array}{l}F=0,65 \\
P=0,5341\end{array}$ & $\begin{array}{l}F=0,24 \\
P=0,7918\end{array}$ & $\begin{array}{l}F=3,76 \\
p=0,0371\end{array}$ & $\begin{array}{l}F=0,16 \\
P=0,8526\end{array}$ & $\begin{array}{l}F=0,29 \\
P=0,7533\end{array}$ & $\begin{array}{l}F=3,87 \\
p=0,0339\end{array}$ & $\begin{array}{l}F=2,05 \\
P=0,1497\end{array}$ & $\begin{array}{l}\text { Exlste Interaçäo signiflcativa } \\
\text { em M4 e M7. }\end{array}$ \\
\hline
\end{tabular}


praticamente eliminadas quando a excreção de creatinina foi refe rida por $100 \mathrm{~g}$ de peso corporal. Nesta base de referência não fo ram observadas diferenças substanciais entre os momentos em rela ção ao momento inicial, para as duas dietas dentro de cada grupo etārio estudado (Fig. 9 e Tabela 9).

\section{Excreção Urināria de Hidroxiprolina Total}

\subsection{Efeito da Idade}

A excreção diāria de hidroxiprolina foi decres cente à medida que se analisava animais mais velhos, sendo a diferença entre os grupos jovem e adulto de apenas $2 \%$ enquanto a existente entre o grupo adulto e velho foi de $57 \%$ (Fig. 10 e Tabela 10). A correção dos valores de hidroxiprolina, tanto para - peso corporal, quanto para os níveis de creatinina, não alterou o padrão de redução dos valores do metabolito em relação ao envelhecimento (Figs. 11 e 12 e Tabelas 11 e 12). Nestas bases de referência observaram-se para os grupos jovem e adulto, decréscimo sistemático dos valores correspondentes a momentos consecutivos. Entretanto, no grupo velho não foi possível a constatação estatistica de diferenças entre os momentos entre si e em relação ao inicial (Figs. 11 e 12 e Tabelas 11 e 12).

\subsection{Efeito da Dieta}

A ingestão de dieta hipoprotēica resultou em redução da excreção de hidroxiprolina em todos os grupos etários, marcadamente nos animais jovens e adultos (Fig. 10 e Tabela 10). Nestas duas faixas etárias a diferença entre os grupos dietēticos se manteve mesmo quando a excreção foi relacionada ao peso 
corporal ou aos valores de creatinina (Figs. 11 e 12 e Tabelas 11 e 12). Nestas bases de referência não foram observadas diferenças entre os grupos dietéticos de animais velhos (Figs. 11 e 12 e Tabelas 11 e 12). A redução dos valores ocorreu, para os grupos jovem e adulto, logo após a instalação do regime dietético, havendo diminuição gradativa entre os momentos consecutivos, atingindo valores semelhantes no final do experimento (Figs. 11 e 12 e Tabelas 11 e 12).

A excreção de hidroxiprolina dos animais veIhos hipoprotéicos foi semelhante em todos os momentos estudados, quando os valores referiram-se à unidade de peso ou de creatinina (Figs. 11 e 12 e Tabelas 11 e 12 ). 

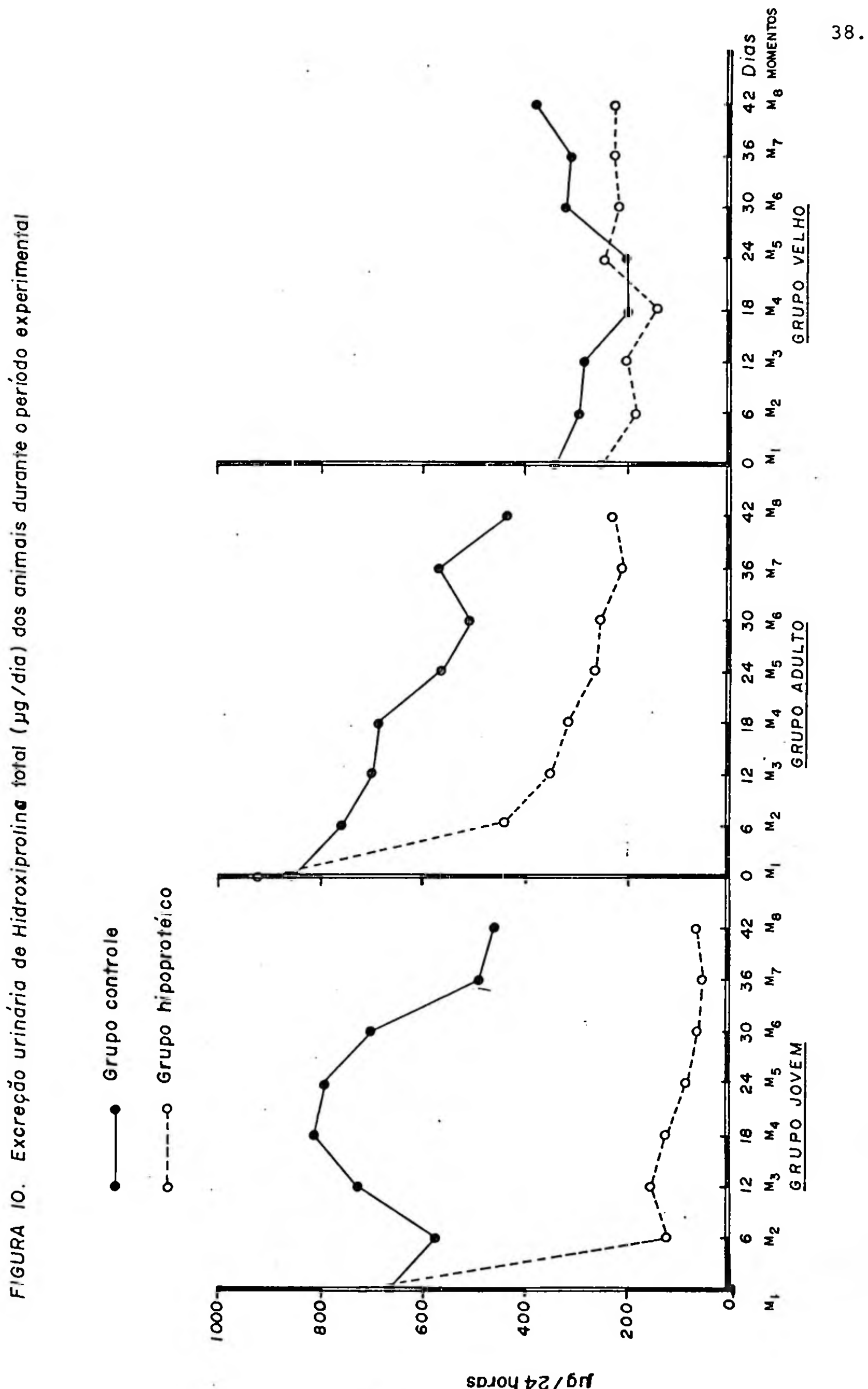

TABELA 10 - Excreçäo urinäria de hidroxiprolina total (ug/dia) dos anlmaí dos grupos controles e hipoprotëlcos durante o
perlodo experimental.

11a) Hipóteses testadas para analogia entre grupos; valores multivariados de $F$ calculado, valores criticos de $F$ e valores univarlados de $F$ acompanhados dos respectivos nivels de significáncla. Comentârlo sobre os resultados obtidos.

\begin{tabular}{|c|c|c|c|c|c|c|c|c|c|}
\hline \multirow{2}{*}{$\begin{array}{l}\text { ANALOGIA } \\
\text { ENTRE }\end{array}$} & \multirow{2}{*}{\multicolumn{3}{|c|}{$\begin{array}{ll} & M O \\
M 1 \text { a M2 M2 a M3 M3 a M4 }\end{array}$}} & \multicolumn{4}{|c|}{$\begin{array}{lllll}M & E & N & T & 0\end{array}$} & \multirow{2}{*}{$\begin{array}{l}\text { ESTATIS- } \\
\text { TICA MUL } \\
\text { TIVARIADA }\end{array}$} & \multirow[b]{2}{*}{ COMENTARIO } \\
\hline & & & M3 a M4 & M4 a MS & M5 a M6 & M6 a M7 & $M 7$ a $M 8$ & & \\
\hline$G 1 \cdot G 2$ & $\begin{array}{l}F=59,32 * \\
p=0,0001\end{array}$ & $\begin{array}{l}F=4,340 \\
p=0,0457\end{array}$ & $\begin{array}{l}F=16,15 \\
p=0,0008\end{array}$ & $\begin{array}{l}F=0,08 \\
P=0,7761\end{array}$ & $\begin{array}{l}F=0,66 \\
p=0,5685\end{array}$ & $\begin{array}{l}F=12,35 \\
p=0,0021\end{array}$ & $\begin{array}{l}F=0,63 \\
p=0,5604\end{array}$ & $\begin{array}{l}F=16,16 \\
p=0,0001\end{array}$ & $\begin{array}{l}\text { Näo exlste analogla entro Gl } \\
G 2 \text { para a curva toda.Isto ocr } \\
\text { re nos trechos do M1 a M2, M: } \\
M 3, M 3 \text { a M4, M6 a M7 }\end{array}$ \\
\hline G3 e G4 & $\begin{array}{l}F=34,23^{*} \\
p=0,0001\end{array}$ & $\begin{array}{l}F=0,27 \\
p=0,6149\end{array}$ & $\begin{array}{l}F=0,61 \\
p=0,5522\end{array}$ & $\begin{array}{l}F=0,87 \\
p=0,6377\end{array}$ & $\begin{array}{l}F=0,21 \\
P=0,6528\end{array}$ & $\begin{array}{l}F=3,04 \\
p=0,0904\end{array}$ & $\begin{array}{l}F=11,32 \\
p=0,0029\end{array}$ & $\begin{array}{l}F=5,06 \\
p=0,0029\end{array}$ & $\begin{array}{l}\text { Não existe analogia de comporta } \\
\text { mento entre os grupos e } 1 \text { sto o } \\
\text { corre no trecho } 1 \text { iclal (MI a } 12 \\
\text { e no trecho flnal (M7 a M8). }\end{array}$ \\
\hline$G 5$ e $G 6$ & $\begin{array}{l}F=0,21 \\
p=0,6547\end{array}$ & $\begin{array}{l}F=0,32 \\
P=0,5816\end{array}$ & $\begin{array}{l}F=0,66 \\
p=0,5683\end{array}$ & $\begin{array}{l}F=1,98 \\
p=0,1694\end{array}$ & $\begin{array}{l}F=2,27 \\
p=0,1414\end{array}$ & $\begin{array}{l}F=0,06 \\
P=0,7968\end{array}$ & $\begin{array}{l}F=1,62 \\
p=0,2127\end{array}$ & $\begin{array}{l}F=0,68 \\
p=0,6906\end{array}$ & $\begin{array}{l}\text { o comportamento de } \mathrm{G5} \text { e } \mathrm{G} 6 \text { pode } \\
\text { ger considerado análogo ao lon- } \\
\text { go do experlmento. }\end{array}$ \\
\hline$e^{61, G 5}$ & $\begin{array}{l}F=0,33 \\
P=0,7240\end{array}$ & $\begin{array}{l}F=6,99 \\
p=0,0043\end{array}$ & $\begin{array}{l}F=17,78 \\
P=0,0001\end{array}$ & $\begin{array}{l}F=1,77 \\
p=0,1899\end{array}$ & $\begin{array}{l}F=2,85 \\
P=0,0763\end{array}$ & $\begin{array}{l}F=11,91 \\
p=0,0004\end{array}$ & $\begin{array}{l}F=8,70 \\
P=0,0018\end{array}$ & $\begin{array}{l}F=15,26 * \\
p=0,0001\end{array}$ & 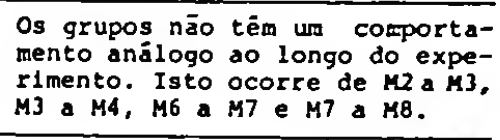 \\
\hline $\begin{array}{l}62,64 \\
e .66\end{array}$ & $\begin{array}{l}F=34,340 \\
P=0,0001\end{array}$ & $\begin{array}{l}F=2,38 \\
P=0,1129\end{array}$ & $\begin{array}{l}F=0,75 \\
p=0,5135\end{array}$ & $\begin{array}{l}F=3,06 \\
P=0,0643\end{array}$ & $\begin{array}{l}F=0,01 \\
P=0,9916\end{array}$ & $\begin{array}{l}F=0,30 \\
p=0,7472\end{array}$ & $\begin{array}{l}F=0,12 \\
P=0,8860\end{array}$ & $\begin{array}{l}F=8,57 \\
p=0,0001\end{array}$ & $\begin{array}{l}\text { o comportamento dos grupos não } \\
\text { é análogo. Isto se deve do tre- } \\
\text { cho Ml a M2. após o que poderla } \\
\text { Ber aceito como anălogo. }\end{array}$ \\
\hline
\end{tabular}
(1) Hipóteses testadas para efelto de momento dentro de cada um dos grupos. Estatistica F multivariada e comentärio sobre
os resultados obtidos.

\begin{tabular}{|c|c|c|}
\hline GRUPO & ESTATISTICA & COMENTARIO: $F$ crit. $=F(0,05 ; 1,24)=4,26$ \\
\hline G1 & $F=256,01 *$ & $\begin{array}{l}\text { Existe um decréscimo da variável (em média) nos trechos } M 7 \text { e M8. M4 parece indicar un ponto } \\
\text { médio māximo da variável. }\end{array}$ \\
\hline G2 & $F=238,00$ & $\begin{array}{l}\text { Existe efeito de momento dentro de G2. Hā um decréscimo pronunciado da variável de Ml a M2. } \\
\text { sendo em média, este nivel, mantido. atè o final do experimento. }\end{array}$ \\
\hline G3 & $F=134,64^{\circ}$ & 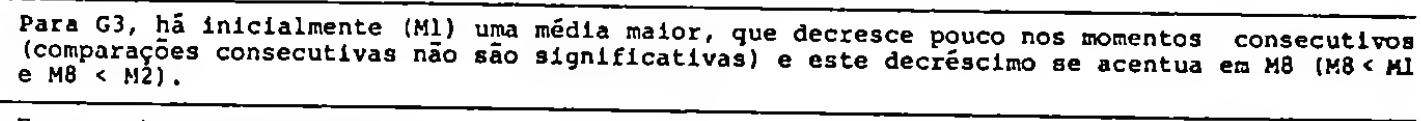 \\
\hline G4 & $F=276,59$ & 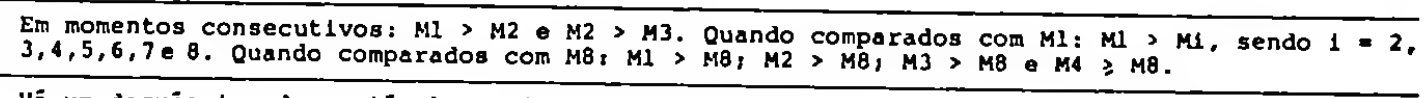 \\
\hline 65 & $F=51,25 *$ & Hã un decrēscimo da variăvel em M4 e M5, após o que hä recuperaçäo dos nivets inicials. \\
\hline G6 & $F=34,73^{\circ}$ & Hā un decréscimo da vartável em M4, após o que o valor se recupera. \\
\hline
\end{tabular}

11c) Hipöteses testadas pafa diferença entre grupos e para a interação entre falxa etárla e dleta em cada un dos momento Estatisticas $F$ e seus respectivos nivels de significäncia (p). Comentärlo sobre os resultados obtidos. ONTRASTE

\begin{tabular}{|c|c|c|c|c|c|c|c|c|}
\hline ENTRE & MI & $\overline{M 2}$ & M3 & $\begin{array}{lll}M & O & M \\
M 4 & \end{array}$ & E ${ }_{M}$ N $T$ & Mढ & M7 & M8 \\
\hline$G 1$ e $G 2$ & $\begin{array}{l}F=0,66 \\
p=0,5695\end{array}$ & $\begin{array}{l}F=59,67 * \\
p=0,0001\end{array}$ & $\begin{array}{l}F=120,444 \\
p=0,0001\end{array}$ & $\begin{array}{l}F=191,16^{*} \\
p=0,0001\end{array}$ & $\begin{array}{l}F=59,40 \\
p=0,0001\end{array}$ & $\begin{array}{l}F=338,68 \\
p=0,0001\end{array}$ & $\begin{array}{l}F=80,68 \\
p=0,0001\end{array}$ & $\begin{array}{l}F=58,57 \\
p=0,0001\end{array}$ \\
\hline
\end{tabular}

G3 CG $\begin{array}{lllllll}F=0,81 & F=30,24 * & F=45,09 * & F=55,97 * & F=10,98 * & F=57,65 * & F=55,42 * \quad F=14,50 *\end{array}$ $\begin{array}{llllllll}p=0,6192 & p=0,0001 & p=0,0001 & p=0,0001 & p=0,0032 & p=0,0001 & p=0,0001 & p=0,0012\end{array}$

\begin{tabular}{llllllllll}
\hline G5 e G6 & $\begin{array}{l}F=1,30 \\
p=0,2638\end{array}$ & $F=3,97$ & $p=0,0551$ & $F=2,46$ & $F=1,36$ & $F=0,23$ & $F=8,71 *$ & $F=3,25$ & $F=8,29 *$ \\
$p=0,1266$ & $p=0,2531$ & $p=0,6428$ & $p=0,0070$ & $p=0,0808$ & $p=0,0081$ \\
\hline \multirow{21,G5}{*}{$G 5$} & $F=23,70 *$ & $F=31,70 *$ & $F=45,39 *$ & $F=85,32 *$ & $F=20,97 *$ & $F=59,83 *$ & $F=15,01 *$ & $F=1,41$ \\
$p=0,0001$ & $p=0,0001$ & $p=0,0001$ & $p=0,0001$ & $p=0,0001$ & $p=0,0001$ & $p=0,0020$ & $p=0,2636$
\end{tabular}

$\begin{array}{llllllll}F=41,31 * & F=16,59 * & F=7,76 * & F=9,29 * & F=2,28 & F=16,45^{*} & F=7,29 * & F=6,85 * \\ p=0,0001 & p=0,0001 & p=0,0028 & p=0,0013 & p=0,1222 & p=0,0001 & p=0,0037 & p=0,0047\end{array}$

COMENTARIO

Inicialmente os dols grupos säo homogêneos (G1 - G2). Para OB de mals momentos $\mathrm{Gl}>\mathrm{G} 2$

G3 > G4 em todos os momentos, ex ceto en Ml. As diferenças decor rentes refletero efelto do trata mento. $\underset{\text { rem }}{\text { grupos como un todo não dile }}$

En M1: G1<G3; G3< G5: en M2:Cl $<\mathrm{G3} ; \mathrm{C3}<\mathrm{G5}$; en $\mathrm{M3}, \mathrm{M4}, \mathrm{MS}, \mathrm{MG}, \mathrm{M7}$ $(G 1=G 3)>G 5$ e em $M 8: G 1=G 3=G 5$

Existe diferença entre grupos. exceto em $M 5$. En M1,M2,M3,M4:G2 $<G 4 ; G 4<G 6$; en $M 5: C 2=G 4=G 6$, em $M 6, M 7, M 8: G 2<(G 4=G 6)$.

Existe Interaçāo dieta e Idade em todos os momentos, exceto em
Ml. 

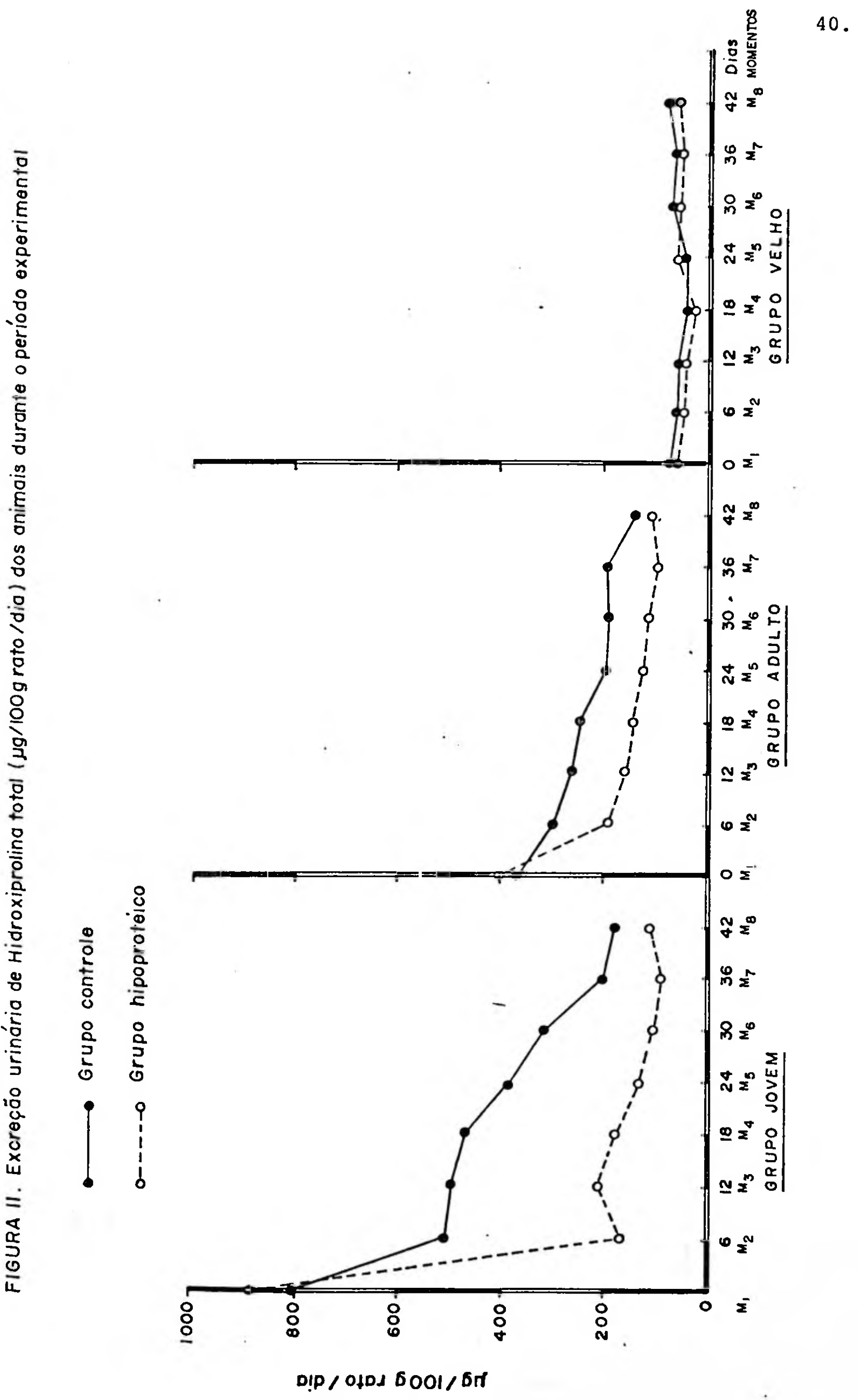

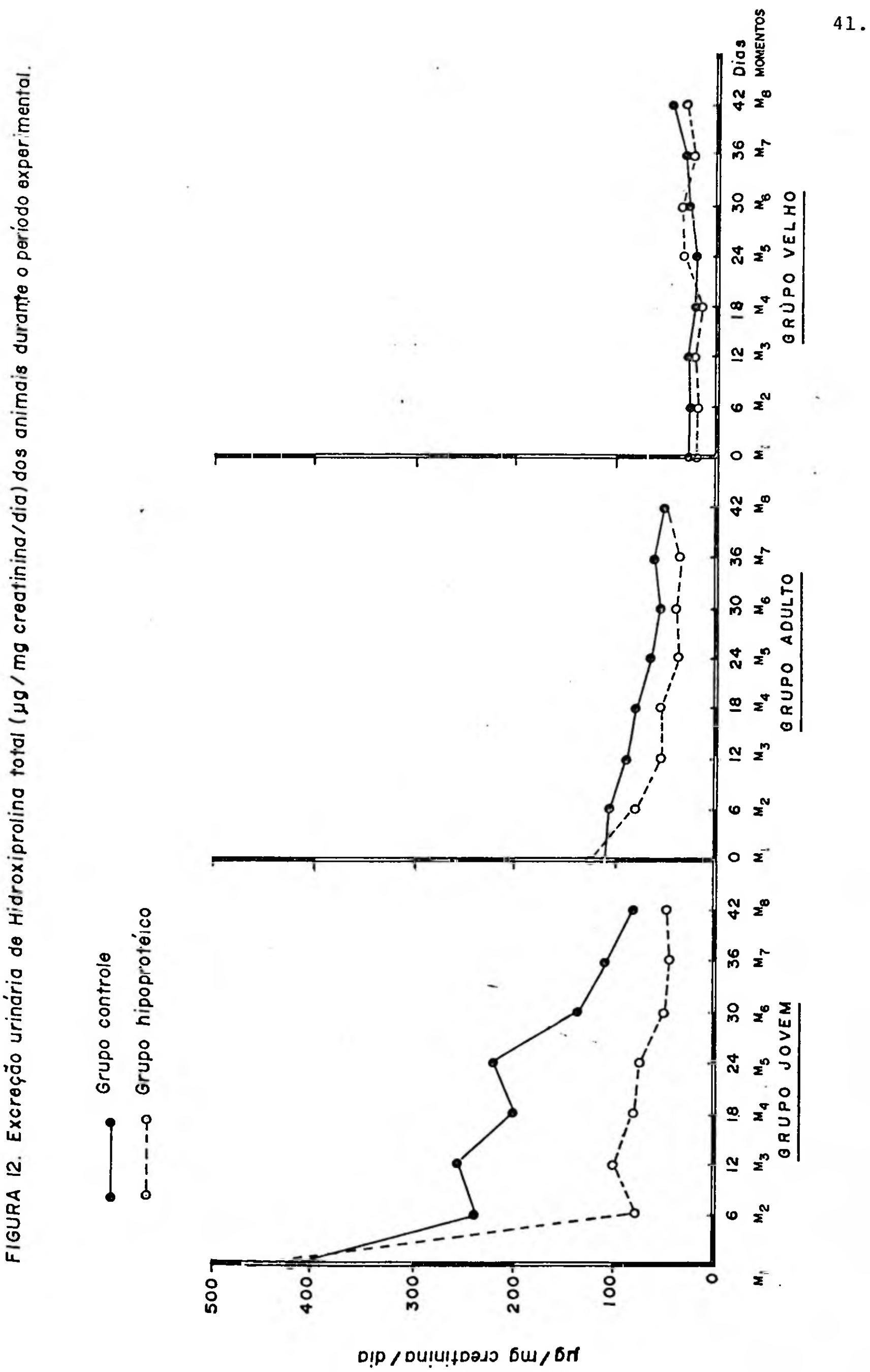


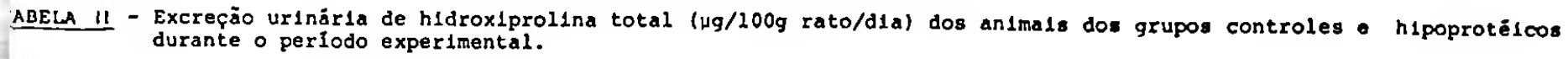

2a) II póteses testadas para analogia entre grupos, valores multivariados de F calculado, valores critlcos de Fe valores univariados de $F$ acompanhados dos respectivos nivels de significância. Comentärlo sobre os resultados obtidos.

\begin{tabular}{|c|c|c|c|c|c|c|c|c|c|}
\hline \multirow{2}{*}{$\begin{array}{l}\text { NALOGIA } \\
\text { ENTRE }\end{array}$} & \multirow[b]{2}{*}{ M1 a M2 } & \multirow[b]{2}{*}{ M2 a M3 } & \multirow{2}{*}{$\frac{M O}{13 \text { a M4 }}$} & \multirow{2}{*}{ MA A MS } & \multicolumn{3}{|l|}{$T 0$} & \multirow{2}{*}{$\begin{array}{l}\text { ESTATIS- } \\
\text { TICA MUL } \\
\text { TIVARIAD̄A }\end{array}$} & \multirow[b]{2}{*}{ COMENTARIO } \\
\hline & & & & & M5 a M6 & $M 6$ a $M 7$ & M7 a M8 & & \\
\hline i1 $\odot$ G2 & $\begin{array}{l}F=58,07 * \\
p=0,0001\end{array}$ & $\begin{array}{l}F=2,12 \\
p=0,1547\end{array}$ & $\begin{array}{l}F=0,03 \\
p=0,8514\end{array}$ & $\begin{array}{l}F=0,68 \\
P=0,5767\end{array}$ & $\begin{array}{l}F=0,99 \\
p=0,6687\end{array}$ & $\begin{array}{l}F=19,16 * \\
p=0,0004\end{array}$ & $\begin{array}{l}F=5,39 * \\
p=0,0275\end{array}$ & $\begin{array}{l}F=31,19 * \\
p=0,0001\end{array}$ & $\begin{array}{l}\text { Näo existe analogia entreos gru } \\
\text { pos \& 1sto ocorre nos trechos } \\
\text { de MI a M2 e M6 a M8. }\end{array}$ \\
\hline i3 e G4 & $\begin{array}{l}F=5,80^{\circ} \\
p=0,0227\end{array}$ & $\begin{array}{l}F=0,00 \\
p=0,9863\end{array}$ & $\begin{array}{l}F=0,00 \\
p=0,9509\end{array}$ & $\begin{array}{l}F=0,65 \\
p=0,5662\end{array}$ & $\begin{array}{l}F=0,01 \\
p=0,9096\end{array}$ & $\begin{array}{l}F=0,62 \\
P=0,5558\end{array}$ & $\begin{array}{l}F=14,27^{\circ} \\
p=0,0012\end{array}$ & $\begin{array}{l}F=2,87^{*} \\
p=0,0334\end{array}$ & $\begin{array}{l}\text { Não existe analogla e lsto ocor } \\
\text { re nos trechos de ML a } \mathrm{H2} \text { M7 } \\
\text { Mg. }\end{array}$ \\
\hline$: 5$ e 66 & $\begin{array}{l}F=0,01 \\
P=0,9116\end{array}$ & $\begin{array}{l}F=0,05 \\
p=0,8257\end{array}$ & $\begin{array}{l}F=0,05 \\
p=0,8130\end{array}$ & $\begin{array}{l}F=0,61 \\
p=0,5519\end{array}$ & $\begin{array}{l}F=0,46 \\
P=0,5109\end{array}$ & $\begin{array}{l}F=0,02 \\
p=0,8847\end{array}$ & $\begin{array}{l}F=0,21 \\
p=0,6526\end{array}$ & $\begin{array}{l}F=0,20 \\
p=0,9815\end{array}$ & $\begin{array}{l}\text { Existe analogia entre os grupos } \\
\text { e o comportamento das duas cur- } \\
\text { vas são colncidentes. } F=0,51 \text {; } \\
p=0,5106 \text {. }\end{array}$ \\
\hline $\begin{array}{l}\text { il, }{ }^{63} \\
=65\end{array}$ & $\begin{array}{l}F=14,46^{*} \\
p=0,0002\end{array}$ & $\begin{array}{l}F=0,19 \\
p=0,8290\end{array}$ & $\begin{array}{l}F=0,22 \\
p=0,8095\end{array}$ & $\begin{array}{l}F=3,18 \\
p=0,0582\end{array}$ & $\begin{array}{l}F=2,73 \\
p=0,0840\end{array}$ & $\begin{array}{l}F=15,10 \\
p=0,0002\end{array}$ & $\begin{array}{l}F=7,13^{*} \\
p=0,0040\end{array}$ & $\begin{array}{l}F=21,11 * \\
P=0,0001\end{array}$ & $\begin{array}{l}\text { Não existe analogia entre os gru } \\
\text { pos e lsto ocorre nos trechos de } \\
\text { M1 a M2 e M6 a M8. }\end{array}$ \\
\hline${ }_{66}^{2,}{ }^{64}$ & $\begin{array}{l}F=85,31 * \\
p=0,0001\end{array}$ & $\begin{array}{l}F=1,63 \\
P=0,2156\end{array}$ & $\begin{array}{l}F=0,43 \\
P=0,6594\end{array}$ & $\begin{array}{l}F=3,11 \\
p=0,0617\end{array}$ & $\begin{array}{l}F=0,20 \\
p=0,8200\end{array}$ & & & & $\begin{array}{l}\text { Näo existe analogia entreos gru } \\
\text { pos e } 1 \text { sto ocorre no trecho de } \\
\text { M1 a M2. }\end{array}$ \\
\hline
\end{tabular}
(2b) Hipöteses testadas para efeito de momento dentro de cada um dos grupos. Estatistica F multivariada e conentário sobre
os resultados obtldos.

\begin{tabular}{|c|c|c|}
\hline ;RUPO & ESTATISTICA & COMENTARIO: $F$ cr1t. $=F(0,05 ; 1,24)=4,26$ \\
\hline G1 & $F=1731,09 *$ & $\begin{array}{l}\text { Exlste efelto de momento dentro de G1. Hä um decrēscimo de M1 para M2, uma estabillzaçāo de } \\
\text { M2 a M4, após o que, volta a haver decréscimo da variável. }\end{array}$ \\
\hline G2 & $F=1156,78^{\circ}$ & $\begin{array}{l}\text { Existe diferença entro os momentos. Há um decréscíno da variável até M5, após o que há uma } \\
\text { estabilizoçăo. }\end{array}$ \\
\hline G3 & $F=154,40^{\circ}$ & $\begin{array}{l}\text { Existe um decréscimo da variāvel, embora este decréscimo não seja slgniflcativo quandose com } \\
\text { param momentos consecutivos, excetó } M 4>M 5 \text { e } M 7>M 8\end{array}$ \\
\hline G4 & $F=190,77^{*}$ & Existe un decréscimo da variävel até $M 4$, após o que há una estabillzação. \\
\hline G5 & $F=15,82^{\circ}$ & $\begin{array}{l}\text { Existe diferença entre os momentos e } 1 \text { sto ocorre, pols M4 < MB. De manelra geral, podemos di } \\
\text { zer que praticamente não houve alteraça do nivel da variável no grupo G5. }\end{array}$ \\
\hline G6 & $F=1,53$ & Dentro de G6, não fol possivel constatar diferença entre os momentos. \\
\hline
\end{tabular}

2c) Hipöteses testadas para diferença entre grupos e para a Interacāo entre falxa etária e dieta em cada um dos momentos. Estatisticas $F$ e seus respectivos nivels de significäncia (p). Comentáxio sobre os resultados obtidos. ONTRASTE $M$ O M E

\begin{tabular}{|c|c|c|c|c|c|c|c|c|c|}
\hline $\begin{array}{l}\text { DNTRASTE } \\
\text { ENTRE } \\
\end{array}$ & $M I$ & $M 2$ & $M 3$ & $\frac{O}{M 4}$ & $\begin{array}{llll} & N & T & 0 \\
& & M 5 & \\
\end{array}$ & $\mathrm{M} 6$ & $M 7$ & 18 & COMENTARIO \\
\hline e $G 2$ & $\begin{array}{l}F=2,43 \\
p=0,1286\end{array}$ & $\begin{array}{l}F=88,76^{*} \\
p=0,0001\end{array}$ & $\begin{array}{l}F=165,04 \\
p=0,0001\end{array}$ & $\begin{array}{l}F=305,72 \\
p=0,0001\end{array}$ & $\begin{array}{l}F=43,81^{*} \\
p=0,0001\end{array}$ & $\begin{array}{l}F=170,88 \\
p=0,0001\end{array}$ & $\begin{array}{l}F=51,90 \\
p=0,0001\end{array}$ & $\begin{array}{l}F=19,73^{*} \\
p=0,0003\end{array}$ & $\begin{array}{l}\text { En M1, os grupos nāo diferem. } \\
\text { Nos dema is momentos: G1 > G2. }\end{array}$ \\
\hline e $\mathrm{Gs}$ & $\begin{array}{l}F=0,41 \\
p=0,5362\end{array}$ & $\begin{array}{l}F=7,71 * \\
p=0,0102\end{array}$ & $\begin{array}{l}F=21,49 \\
p=0,0002\end{array}$ & $\begin{array}{l}F=39,73 \\
p=0,0001\end{array}$ & $\begin{array}{l}F=3,82 \\
p=0,0595\end{array}$ & $\begin{array}{l}F=24,36 * \\
P=0,0001\end{array}$ & $\begin{array}{l}F=38,99 * \\
P=0,0001\end{array}$ & $\begin{array}{l}F=4,32 \\
p=0,0461\end{array}$ & $\begin{array}{l}\text { Não difexem no momento inicial } \\
\text { e em MS. Nos demais momentos : } \\
\text { G3 > G4. }\end{array}$ \\
\hline e $G 6$ & $\begin{array}{l}F=0,13 \\
p=0,7260\end{array}$ & $\begin{array}{l}F=0,43 \\
p=0,5263\end{array}$ & $\begin{array}{l}F=0,43 \\
p=0,5232\end{array}$ & $\begin{array}{l}F=0,36 \\
p=0,5593\end{array}$ & $\begin{array}{l}F=0,18 \\
P=0,6798\end{array}$ & $\begin{array}{l}F=0,69 \\
P=0,5808\end{array}$ & $\begin{array}{l}F=0,43 \\
p=0,5239\end{array}$ & $\begin{array}{l}F=1,07 \\
p=0,3131\end{array}$ & $\begin{array}{l}\text { Nāo fol possivel constatar dife } \\
\text { rença entre os dols grupos. }\end{array}$ \\
\hline $1, G 3$ & $\begin{array}{l}F=104,68 \\
p=0,0001\end{array}$ & $\begin{array}{l}F=73,39 * \\
p=0,0001\end{array}$ & $\begin{array}{l}F=196,53 \\
p=0,0001\end{array}$ & $\begin{array}{l}F=340,92 \\
p=0,0001\end{array}$ & $\begin{array}{l}F=38,98 \\
p=0,0001\end{array}$ & $\begin{array}{l}F=110,58 \\
p=0,0001\end{array}$ & $\begin{array}{l}F=46,57 \\
p=0,0001\end{array}$ & $\begin{array}{l}F=19,16 \\
p=0,0001\end{array}$ & $\begin{array}{l}\text { Exlste diferença entre os trēs } \\
\text { grupos. Em todos os momentos: } \\
\text { Gl }>\text { G3>G5. }\end{array}$ \\
\hline 2,64 & $\begin{array}{l}F=133,96 * \\
p=0,0001\end{array}$ & $\begin{array}{l}F=9,77^{*} \\
p=0,0011\end{array}$ & $\begin{array}{l}F=30,65 \\
p=0,0001\end{array}$ & $\begin{array}{l}F=46,70 \\
p=0,0001\end{array}$ & $\begin{array}{l}F=1,95 \\
p=0,1628\end{array}$ & $\begin{array}{l}F=6,95 \\
p=0,0044\end{array}$ & $\begin{array}{l}F=3,59 \\
p=0,0421\end{array}$ & $\begin{array}{l}F=5,06 \\
P=0,0145\end{array}$ & $\begin{array}{l}\text { Existe diferença em todos os mo } \\
\text { mentos, exceto em M5. Em ML, M3 } \\
M 4: G 2>G 4>G 6 . \mathrm{Em} M 2, M 6, M 7 \\
\text { e MB:G2=G4> G6. }\end{array}$ \\
\hline $\begin{array}{l}\text { teração } F \\
\text { ta e } \\
\text { de }\end{array}$ & $\begin{array}{l}F=0,92 \\
p=0,5837\end{array}$ & $\begin{array}{l}F=20,92 \\
p=0,0001\end{array}$ & $\begin{array}{l}F=38,63 * \\
p=0,0001\end{array}$ & $\begin{array}{l}F=73,76 * \\
p=0,0001\end{array}$ & $\begin{array}{l}F=12,84 \\
p=0,0003\end{array}$ & $\begin{array}{l}F=38,82 * \\
p=0,0001\end{array}$ & $\begin{array}{l}F=12,50 * \\
p=0,0004\end{array}$ & $\begin{array}{l}F=3,13 \\
p=0,0604\end{array}$ & $\begin{array}{l}\text { Exlste Interação signiflcativa } \\
\text { em todos os momentos, exceto ed } \\
\text { MI. }\end{array}$ \\
\hline
\end{tabular}




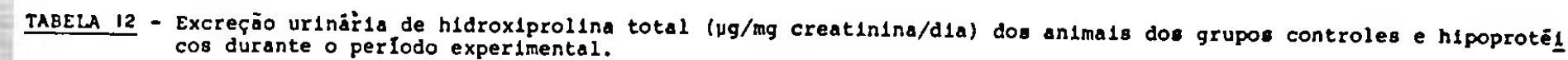

13a) Hipöteses testadas para anslogla entre grupos, valores multivarlados de $F$ calculado, valores criticos de $P$ e valores unıvariados de $F$ acompanhados dos respectivos nivels de slgnificâncla. Comentárlo sobre os resultados obtidos.

\begin{tabular}{|c|c|c|c|c|c|c|c|c|c|}
\hline \multirow{2}{*}{$\begin{array}{l}\text { ANALOGIA } \\
\text { ENTRE }\end{array}$} & \multirow[b]{2}{*}{$M 1$ a M2 } & \multirow[b]{2}{*}{ M2 a M3 } & \multirow{2}{*}{$\frac{M}{M 3}=$} & \multicolumn{2}{|c|}{$M E N T O$} & \multirow[b]{2}{*}{ M6 a M7 } & \multirow[b]{2}{*}{$M 7$ a $M B$} & \multirow{2}{*}{$\begin{array}{l}\text { ESTATIS- } \\
\text { TICA MUL } \\
\text { TIVARIADA } \\
\end{array}$} & \multirow[b]{2}{*}{ COMENTARIO } \\
\hline & & & & M4 \& MS & M5 a M6 & & & & \\
\hline$G 1 \subset G 2$ & $\begin{array}{l}F=35,32^{\circ} \\
p=0,0001\end{array}$ & $\begin{array}{l}F=0,22 \\
p=0,6494\end{array}$ & $\begin{array}{l}F=10,40 \\
P=0,0038\end{array}$ & $\begin{array}{l}F=0,60 \\
p=0,5496\end{array}$ & $\begin{array}{l}F=2,15 \\
P=0,1519\end{array}$ & $\begin{array}{l}F=3,37 \\
p=0,0756\end{array}$ & $\begin{array}{l}F=15,55 \\
p=0,0009\end{array}$ & $\begin{array}{l}F=20,75 * \\
P=0,0001\end{array}$ & $\begin{array}{l}\text { Näo existe analogio entre os gru } \\
\text { pos e } 1 \text { to ocorre nos trechos do } \\
M 1 \text { a M2; M3 a M4 e M7 a MB } \\
\end{array}$ \\
\hline$G 3$ e $G 4$ & $\begin{array}{l}F=1,81 \\
p=0,1883\end{array}$ & $\begin{array}{l}F=0,20 \\
p=0,6648\end{array}$ & $\begin{array}{l}F=0,25 \\
p=0,6259\end{array}$ & $\begin{array}{l}F=0,01 \\
P=0,9375\end{array}$ & $\begin{array}{l}F=0,02 \\
P=0,8856\end{array}$ & $\begin{array}{l}F=1,19 \\
P=0,2851\end{array}$ & $\begin{array}{l}F=8,75 \\
p=0,0069\end{array}$ & $\begin{array}{l}F=3,26 \\
p=0,0066\end{array}$ & $\begin{array}{l}\text { Näo existe analogla entre os gru } \\
\text { pos e lsto ocorre somente no úI } \\
\text { timo trecho. }\end{array}$ \\
\hline G5 e $G 6$ & $\begin{array}{l}F=0,01 \\
P=0,9410\end{array}$ & $\begin{array}{l}F=0,00 \\
P=0,9800\end{array}$ & $\begin{array}{l}F=0,00 \\
p=0,9955\end{array}$ & $\begin{array}{l}F=0,25 \\
p=0,6295\end{array}$ & $\begin{array}{l}F=0,05 \\
p=0,8170\end{array}$ & $\begin{array}{l}F=0,11 \\
p=0,7430\end{array}$ & $\begin{array}{l}F=1,50 \\
p=0,2301\end{array}$ & $\begin{array}{l}F=0,38 \\
p=0,9036\end{array}$ & $\begin{array}{l}\text { Existe analogia entre os grupos } \\
\text { que, alêm disso, são colnciden- } \\
\text { tes. F } 0,10 ; p=0,7514 \text {. }\end{array}$ \\
\hline$e^{G 1, G S}$ & $\begin{array}{l}F=27,04 k \\
p=0,0001\end{array}$ & $\begin{array}{l}F=1,50 \\
p=0,2422\end{array}$ & $\begin{array}{l}F=10,64^{\circ} \\
p=0,0007\end{array}$ & $\begin{array}{l}F=0,43 \\
p=0,6614\end{array}$ & $\begin{array}{l}F=2,81 \\
p=0,0785\end{array}$ & $\begin{array}{l}F=5,25 \\
p=0,0127\end{array}$ & $\begin{array}{l}F=13,16^{*} \\
p=0,0003\end{array}$ & $\begin{array}{l}F=12,70 \\
p=0,0001\end{array}$ & $\begin{array}{l}\text { Näo existe analogia entre os gru } \\
\text { pos e } 1 \text { sto ocorre nos trechos dé } \\
\text { M1 a M2; M3 a M4 e M6 a M8. }\end{array}$ \\
\hline $\begin{array}{l}G 2, G 6 \\
e G^{6}\end{array}$ & $\begin{array}{l}F=91,91 \\
p=0,0001\end{array}$ & $\begin{array}{l}F=3,48 \\
p=0,0458\end{array}$ & $\begin{array}{l}F=0,80 \\
p=0,5370\end{array}$ & $\begin{array}{l}F=0,35 \\
P=0,7104\end{array}$ & $\begin{array}{l}F=0,17 \\
P=0,8427\end{array}$ & $\begin{array}{l}F=0,02 \\
p=0,9804\end{array}$ & $\begin{array}{l}F=0,65 \\
p=0,5345\end{array}$ & $\begin{array}{l}F=10,51 * \\
P=0,0001\end{array}$ & $\begin{array}{l}\text { Não existe analogia entre os gru } \\
\text { pos e } 1 \text { sto ocorre nos trechos de } \\
\text { M1 a M2 e M2 a M3. }\end{array}$ \\
\hline
\end{tabular}
23b) 11 pöteses testadas para efeito de momento dentro de cada um dos grupos. Estatistica f multivariada e comentário sobre
os resultados obtidos.

\begin{tabular}{|c|c|c|}
\hline GRUPO & ESTATISTICA & COMENTARIO: $F$ crit. $=F(0,05 ; 1,24)=4,26$ \\
\hline GI & $F=831,33^{*}$ & Existe diferença entre os momentos com um decrésclmo slstemát1co da variävel. \\
\hline G2 & $F=480,08^{\circ}$ & Existe um decréscimo da variável até M4, spōs o que esta se establliza. \\
\hline G3 & $F=54,76^{\circ}$ & $\begin{array}{l}\text { Existe diferença entre os momentos. Há um decréscimo nāo slgniflcativo da variável até m5. a } \\
\text { pós o que, o nfvel passa a ser menor que o lnicial. }\end{array}$ \\
\hline G4 & $F=46,95^{\circ}$ & Exlste um decréscimo da variävel até $M 3$, apös o que, esta se establliza. \\
\hline G5 & $F=13,99 *$ & $\begin{array}{l}\text { Existe efeito de momento e } 1 \text { sto é decorrência da elevação de M8, quando comparado a M7, eabo } \\
\text { ra MB nāo difira de Ml. }\end{array}$ \\
\hline G6 & $F=15,27^{*}$ & $\begin{array}{l}\text { Existe diferença entre os momentos e 1sto ocorre devido à elevação de } M 8 \text {, quando con } \\
\text { a M4, embora M8 não difira de M1. }\end{array}$ \\
\hline
\end{tabular}

13c) Hipōteges testadas para diferença entre grupos e para a interaçāo entre falxa etāria e dieta em cada um dos momentos. Estatisticas F e seus respectivos nivels de significância (p). Comentārio sobre os resultados obtidos.

\begin{tabular}{|c|c|c|c|c|c|c|c|c|c|}
\hline $\begin{array}{l}\text { CONTRASTE } \\
\text { ENTRE }\end{array}$ & $\mathrm{MI}$ & $M 2$ & $\mathrm{M3}$ & $\begin{array}{ll}O \quad M \\
4\end{array}$ & 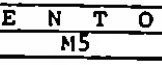 & M6 & M7 & $M 8$ & COMENTARIO \\
\hline$G 1$ e $G 2$ & $\begin{array}{l}F=0,31 \\
P=0,5920\end{array}$ & $\begin{array}{l}F=67,69 \\
p=0,0001\end{array}$ & $\begin{array}{l}F=139,51 \\
p=0,0001\end{array}$ & $\begin{array}{l}F=290,12 \\
p=0,0001\end{array}$ & $\begin{array}{l}F=12,64 \\
p=0,0019\end{array}$ & $\begin{array}{l}F=139,20 \\
p=0,0001\end{array}$ & $\begin{array}{l}F=99,14 \\
p=0,0001\end{array}$ & $\begin{array}{l}F=16,99 \\
p=0,0006\end{array}$ & $\begin{array}{l}\text { Existe diferença entre os gru- } \\
\text { pos em todos os momentos. com } \\
G 1>G 2 \text {, exceto ed } M 1 \text {, onde } G 1=G 2\end{array}$ \\
\hline 63 e $G_{4}$ & $\begin{array}{l}F=0,28 \\
p=0,6091\end{array}$ & $\begin{array}{l}F=1,52 \\
p=0,2282\end{array}$ & $\begin{array}{l}F=6,04 \\
p=0,0205\end{array}$ & $\begin{array}{l}F=14,54 \\
p=0,0011\end{array}$ & $\begin{array}{l}F=0,32 \\
p=0,5853\end{array}$ & $\begin{array}{l}F=5,86 \\
p=0,0222\end{array}$ & $\begin{array}{l}F=17,05 \\
p=0,0006\end{array}$ & $\begin{array}{l}F=0,02 \\
P=0,8729\end{array}$ & $\begin{array}{l}\text { Ex1ste diferença entre os gru- } \\
\text { pos nos momentos M3, M4, M6 e } \\
M 7 \text {, onde G3> G4. }\end{array}$ \\
\hline$G 5$ e $G 6$ & $\begin{array}{l}F=0,10 \\
P=0,7536\end{array}$ & $\begin{array}{l}F=0,15 \\
P=0,7059\end{array}$ & $\begin{array}{l}F=0,30 \\
p=0,5940\end{array}$ & $\begin{array}{l}F=1,07 \\
p=0,3131\end{array}$ & $\begin{array}{l}F=0,08 \\
p=0,7706\end{array}$ & $\begin{array}{l}F=0,11 \\
p=0,7429\end{array}$ & $\begin{array}{l}F=0,01 \\
p=0,9036\end{array}$ & $\begin{array}{l}F=2,39 \\
p=0,1319\end{array}$ & $\begin{array}{l}\text { Não existe diferença significa- } \\
\text { tlva entre os grupos. }\end{array}$ \\
\hline$e_{G S}^{G l, G J}$ & $\begin{array}{l}F=95,83 \\
p=0,0001\end{array}$ & $\begin{array}{l}F=59,17 \\
p=0,0001\end{array}$ & $\begin{array}{l}F=157,92 \\
p=0,0001\end{array}$ & $\begin{array}{l}F=346,01 \\
p=0,0001\end{array}$ & $\begin{array}{l}F=12,81 \\
p=0,0003\end{array}$ & $\begin{array}{l}F=114,55 \\
p=0,0001\end{array}$ & $\begin{array}{l}F=74,99 \\
p=0,0001\end{array}$ & $\begin{array}{l}F=13,10 \\
p=0,0003\end{array}$ & $\begin{array}{l}\text { Os grupos diferem em todos os mo } \\
\text { mentos: De MI a M?:GI>G3>G5 } \\
\text { e em } M 8: G 1>G 3=G 5\end{array}$ \\
\hline$e^{62,} 6^{G 4}$ & $\begin{array}{l}P=105,46 \\
p=0,0001\end{array}$ & $\begin{array}{l}F=6,01 \\
p=0,0078\end{array}$ & $\begin{array}{l}F=17,41 \\
p=0,0001\end{array}$ & $\begin{array}{l}F=48,52 \circ \\
p=0,0001\end{array}$ & $\begin{array}{l}F=0,52 \\
p=0,6045\end{array}$ & $\begin{array}{l}F=2,99 \\
p=0,0679\end{array}$ & $\begin{array}{l}F=2,77 \\
p=0,0815\end{array}$ & $\begin{array}{l}F=3,01 \\
p=0,0666\end{array}$ & $\begin{array}{l}\text { Existe diferença em M1, M2, M3 } \\
\text { e M4. Ea M1: M3, M4: G2 }>G 4>G 6 \\
\text { em M2: }(G 2=G 4)>G 6\end{array}$ \\
\hline $\begin{array}{ll}\operatorname{letaçaor} \\
\text { eta e } \\
\text { ade }\end{array}$ & $\begin{array}{l}F=0,24 \\
P=0,7885\end{array}$ & $\begin{array}{l}F=18,53 \\
P=0,0001\end{array}$ & $\begin{array}{l}F=36,330 \\
p=0,0001\end{array}$ & $\begin{array}{l}F=73,08 \\
p=0,0001\end{array}$ & $\begin{array}{l}F=4,08 \\
p=0,0291\end{array}$ & $\begin{array}{l}E=40,43 * \\
p=0,0001\end{array}$ & $\begin{array}{l}F=24,48 \\
p=0,0001\end{array}$ & $\begin{array}{l}F=4,05 \\
p=0,0297\end{array}$ & $\begin{array}{l}\text { Existe interaçāo em todos os mo } \\
\text { mentos, exceto em Ml. }\end{array}$ \\
\hline
\end{tabular}




\section{COMENTARIOS}

1. Peso Corpóreo, Ingestão Alimentar e Excreção de Nitrogênio Uréico

Ratos em fase de crescimento submetidos a dietas contendo composição adequada de nutrientes apresentam acentuado ganho de peso. O ganho de peso, em valores absolutos, depende do peso inicial dos ratos e, portanto, de sua idade na fase experimental analisada.

No presente trabalho, a velocidade de crescimento, definida como sendo o ganho diário médio de peso observado nos 42 dias de experimento, foi decrescente com a idade dos a nimais. NOLEN (1972), observou que o crescimento de ratos ocorre mais rapidamente durante os quatro meses após o desmame, e a seguir se processa mais lentamente. O peso máximo dos animais é atingido entre 21 e 24 meses, podendo ocorrer decréscimo posterior. Em trabalhos realizados anteriormente neste laboratório (Botucatu), utilizando-se animais de mesma linhagem, alimentados com dieta controle preparada em laboratório foram observados os indices de crescimento e ingestão alimentar, que constam na Tabe la 13 .

\begin{tabular}{|c|c|c|c|c|c|c|c|}
\hline $\begin{array}{l}\text { IDALE } \\
\text { INICIAL } \\
\text { (d।aB) }\end{array}$ & $\begin{array}{l}\text { PPROTEINA } \\
\text { (CASEINA) } \\
\text { UA DIETA } \\
\end{array}$ & $\begin{array}{l}\text { NQ DE } \\
\text { ANIMAIS }\end{array}$ & $\begin{array}{l}\text { DU:WÇIIO DA } \\
\text { EXPERIENCIA } \\
\text { (dIas) }\end{array}$ & $\begin{array}{c}\text { GANIIO DE } \\
\text { PESO } \\
\text { (g/dLa) }\end{array}$ & $\begin{array}{l}\text { INGESTAO } \\
\text { (g/dia) }\end{array}$ & $\begin{array}{l}\text { ALINENTAR } \\
\text { (g/100 } \\
\text { rato/d1a) } \\
\end{array}$ & REFERENC:A \\
\hline 35 & 20 & 5 & 72 & 4,1 & 13,0 & 8,1 & CAMARGO, 1981 \\
\hline 65 & 20 & 5 & 72 & 2,6 & 16,8 & 5,7 & CANARCO, 1981 \\
\hline $60-72$ & 10 & 36 & 35 & 2,4 & 19,1 & 7,5 & REZENDE, 1973 \\
\hline $.70-75$ & 17 & 10 & 32 & 1,4 & 14,7 & 6,1 & BURINI et al11, $1981 \mathrm{a}$ \\
\hline 124 & 17 & 40 & $7-84$ & $0,7-1,4$ & $17,6-18,1$ & $5,0-5,6$ & ANGELELI et al11, 1978 \\
\hline 310 & 20 & 5 & 72 & 2,6 & 19,6 & 4,1 & CAMARGO, 1981 \\
\hline
\end{tabular}


Sabe-se que os nutrientes são captados pelas cế lulas e utilizados nas reações metabölicas, as quais asseguram o crescimento, a maturação e a duplicação celular, assumindo signi ficado diferente nas fases jovem e adulta do organismo. Durante o período de crescimento rápido há necessidade de grande quantidade de nutrientes para a formação de grande número de novas células relacionadas com as estruturas do organismo. Na fase adulta as reações metabólicas ocorrem mais no sentido da manutenção das atividades básicas das células existentes exigindo, portanto, menor aporte celular de nutrientes (CAMPANA \& BURINI, 1982). Tambëm no presente trabalho, enquanto a veloci dade de crescimento foi decrescente com o aumento da idade, verí ficou-se o inverso com relação à ingestão alimentar. De fato, re lacionando-se o ganho de peso com a correspondente taxa de inges tão alimentar, foram obtidos os seguintes valores: 33,13 e $5 \mathrm{~g} /$ $100 \mathrm{~g}$ de dieta ingerida, respectivamente para os grupos jovem, adulto e velho, sugerindo que a diminuição da intensidade de ganho de peso não ocorreu em função da redução da oferta de alimen to e sim, em consequência do menor aproveitamento dos nutrientes dietēticos na formação da massa corporal.

Dentre os componentes dietēticos figuram as proteínas, oferecidas à corrente circulatória na forma de seus aminoácidos constituintes. Sabe-se que alēm de função plástica os aminoácidos também podem ser utilizados como substrato energé tico. Assim, quando não são solicitados para a biossíntese de pro teínas, os aminoácidos são desaminados, sendo o cetoácido resultante metabolizado no ciclo de Krebs ou então convertido em glicose ou glicogênio (neoglicogênese) ou em corpos cetônicos (cetó gênese) ou ácidos graxos. O nitrogênio amínico, resultante do processo de desaminação, é utilizado na metabolização da amônia 
em uréia a qual é recuperada quase que totalmente na urina(SCHIM KE, 1962a; KREBS, 1969; GUYTON, 1977; SHAMBAUGH III, 1977; SNODGRASS \& LIN, 1981). O nitrogênio uréico representa cerca de $90 \%$ do nitrogênio total excretado na urina (WALLIN, 1977); portanto, a quantidade excretada reflete o aproveitamento orgânico da proteina da dieta, nas condições de função renal normal (TAYLOR et alii, 1974). No presente trabalho, a queda da capacidade em promover crescimento pela dieta controle observada nos animais velhos foi paralela ao baixo aproveitamento do nitrogênio alimentar, avaliado pela excreção de nitrogênio uréico (Fig. 6 e Tabela 4).

Animais submetidos à restrição protéica perdem peso (ANTHONY \& EDOZIEN, 1975; CAMPANA et alii, 1975;ANGELELI et alii, 1978). No presente experimento todos os animais deficientes em proteina perderam peso, embora tenham mantido ingestão alimentar por unidade de peso semelhante ou mesmo superior à dos grupos recebendo dieta controle (Tabela 3). Os organismos jovens são mais sensiveis à restrição protéica do que os adultos, devido à grande utilização de nutrientes com finalidade plástica (WINICK \& NOBLE, 1966). Assim, a queda de peso foi mais constante e consistente no grupo jovem, resultando em perda de $25 \%$ do peso inicial, perda apreciável considerando-se o valor absoluto do peso inicial e o fato de se tratar de estrutura orgânica ain da em formação.

Os animais velhos, pelo fato de apresentarem pouca solicitação de nutrientes para a formação de massa estrutū ral, foram menos afetadas pela restrição protéica, apresentando no final do experimento redução de apenas 148 do peso inicial, embora com uma taxa diária média de $-1,5 \mathrm{~g} / \mathrm{dia}$, valor três vezes superior ao observado para o grupo jovem (Tabela 1). 
WATERLOW \& STEPHEN (1966) e PICOU \& TAYLOR-ROBERTS (1969) foram os pioneiros em mostrar os mecanismos gerais de adaptação do corpo à dieta hipoprotéica, em ratos e em seres humanos. Ambos os grupos de pesquisadores notaram que o corpo se adapta ao regime deficiente em proteínas, não pela diminuição do fluxo de aminoácidos (turnover protéico total) mas pela redução da excreção de aminoácidos.

Nestas condições dietēticas ocorre diminuição da sintese de uréia (SCHIMKE, 1962b;ANTHONY \& EDOZIEN, 1975;GRANT \& HOFFENBERG, 1977; SHAMBAUGH III, 1978) e maior reutilização de aminoācidos (WATERLOW \& STEPHEN, 1966; PICOU \& TAYLOR-ROBERTS, 1969), nitrogênio uréico (PICOU \& PHILLIPS, 1972) e outras formas de nitrogênio não essencial. Estes nitrogênios são reciclados na formação de compostos envolvidos em funções orgânicas indispensāveis. A adaptação da atividade das enzimas do ciclo da uréia no fígado constitui exemplo da marcada redução do catabolismo protéico (HORIE \& ASHIDA, 1973). A atividade destas enzimas é regulada pelo teor protéico da dieta, sendo que na deficiência protéica ocorre redução da excreção de urēia associada à diminuição da atividade enzimática das cinco enzimas participantes do ciclo da uréia; entretanto não há diferença no teor destas enzimas (SCHIMKE, $1962 \mathrm{a}$ e b). Os dados do presente trabalho documentam este processo adaptativo pelos valores da excreção de nitrogênio uréico dos animais desnutridos que se apresentaram sig nificativamente reduzidos logo no início do regime dietético (Figs. 6 e 7 ). 
48.

\section{Excreção Urināria de Creatinina}

A creatinina é derivada da fosfocreatina por reação irreversível, não enzimātica, de modo que a sua produção por unidade de peso do músculo é praticamente constante (WATERLOW \& ALLEYNE, 1971). A creatina é o ünico precursor da creatinina e 98\% da creatina do corpo está localizada no músculo, existindo, portanto, boa correlação entre a excreção de creatinina e a massa magra do corpo (FORBES \& BRUINING, 1976). Considerando-se que, com função normal, toda a creatinina formada é totalmente excretada e que a quantidade excretada reflete a massa magra do corpo, apenas os processos que resultem em grandes alterações da massa magra do corpo, isto é, da musculatura provocarão variações da creatinina urinária.

Sabe-se que a musculatura esquelética è pouco comprometida na deficiência protēica-normocalórica, contrariamen te ao que ocorre com a restrição energética (HAVERBERG et alii, 1975; BURINI et alii, 1981b). Portanto, a manutenção da taxa de excreção de creatinina em níveis normais, observada no presente experimento para os dois grupos dietéticos (Fig. 9) sugere que o aporte calórico foi suficiente para a preservação da massa muscu lar (BURINI et alii, 1981b).

Isto indica que a carência instalada foi de ca rater protéico isolado e não calórico ou protéico-calórico. 
49.

\section{Avaliação do Estado Nutricional}

\subsection{Desnutrição Protéica e Desnutrição Calōrica}

A desnutrição humana constitui complexo de alterações traduzidas por sinais clínicos característicos dependen do se o processo foi instalado na infância ou na fase adulta. Re tardo de crescimento e perda de peso são os sinais mais comuns. Ambos aparecem nas situações de deficiências protéica, calórica ou mista, protēico-calórica. A identificação e denominação destes estágios da desnutrição ainda é confusa e heterogênea, embora a maioria dos estudiosos do assunto reconheça a existência em humanos de duas sindromes de carência nutricional: marasmo e kwashiorkor.

A teoria clássica atribui ao kwashiorkor a deficiência predominantemente protéica e ao marasmo a deficiência global de alimentos (WATERLOW,1974). A diferenciação entre @s dois estados depende da interpretação pessoal dos autores;para alguns a diferenciação não está na dieta mas sim na capacidade de adaptação da criança. Assim, uma determinada dieta marginal tanto em proteínas quanto em calorias, quando oferecida para uma criança com elevada necessidade energética, será limitante em calorias, enquanto para outra criança com maior necessidade proteíca, a proteína será o fator limitante. Segundo esta teoria a primeira criança tornar-se-a marasmática enquanto a segunda desenvolverá kwashiorkor (WATERLOW, 1974). 
Conforme postulado defendido em revisão mais recente (Nutr. Rev., 1979) o marasmo constitui resultado final da adaptação do organismo à deficiência protéico-calórica enquan to o kwashiorkor representa a quebra deste processo de adaptação sendo, portanto, o primeiro mais relacionado com as condições do meio ambiente (adequação do suprimento alimentar) enquanto o segundo está intimamente relacionado com o hospedeiro.

Fatores outros como diarrēia, infecções e in festações, acompanhantes usuais das deficiências nutricionais, tambēm podem induzir alterações metabólicas adicionais desequili brando os processos de adaptação (DEO et alii, 1965). Estes mūltiplos fatores dificultam a investigação do papel da carência pro têica na patogênese das alterações bioquímicas e estruturais induzidas pela desnutrição. Isto tem levado os pesquisadores à cria ção de modelos experimentais para estudo de deficiência protéica. Entre os modelos mais compativeis com o.humano estão aqueles que empregam cães, macacos e porcos(KIRSCH et alii, 1968). Entretanto, os modelos mais utilizados envolvem o rato, uma vez que apresentam vantagens como a manipulação simultānea de grande número de animais e indução rápida de deficiência nutricional (MCCANCE \& WIDDOWSON, 1966), necessitando de pouco espaço físico em biotêrio, com experimentos de baixo custo operacional.

Como kwashiorkor e marasmo são mais caracterís ticos da espēcie humana, aconselha-se o uso das terminologias de ficiência protéica ou deficiência protéico-calórica em substitui ção às sindromes (MCCANCE \& WIDDOWSON, 1966).

$\mathrm{Na}$ deficiência protéico-calörica ocorre redu- 
Ção da ingestão dos nutrientes em intensidade variável, podendo atingir estágio próximo do jejum crônico. Para suprir suas neces sidades essenciais, principalmente as energéticas, o organismo consome seus próprios tecidos de reserva (músculo e tecido adipo so), havendo grande mobilização de nutrientes, mascarando sinais sangulineos de deficiências especificas, embora o dispêndio energético toțal esteja adaptativamente diminuído (LEHNINGER, 1975; CAHILL JR., 1976). As proteỉnas plasmáticas são mantidas em níveis normais devido ao influxo hepático dos aminoácidos provenientes do catabolismo muscular (JAYA RAO, 1974).

O edema é ausente à medida que o débito cardía co consegue manter adequadamente a perfusão renal e os níveis normais de albuminemia mantêm a pressão oncótica regularizada sem consequlente acúmulo de água no espaço extracelular. A quebra des ta homeostase, seja por hipoalbuminemia ou por redução do débito cardỉaco secundária a deficiência de nutrientes resultará em retenção de sódio e aparecimento de edema, interrompendo o equilíbrio adaptativo e resultando o quadro associado de deficiência protéica (kwashiorkor-marasmático).

Quando ocorre consumo de dieta adequada em calorias mas limitante em proteínas há ajuste endocrinológico difẹ rente com pouco estímulo do eixo hipotálamo-hipófise-supra-renal, resultando em pouca elevação de cortisol (JAYA RAO, 1974;EDOZIEN et alii, 1978).

Na presença de aporte calórico adequado, a mobilização de ācidos graxos do depósito gorduroso e de aminoācidos musculares não ocorre na mesma extensão que o marasmo, resul tando em melhor preservação destes tecidos no kwashiorkor. Nesta situação, hā acúmulo de gorduras no fígado, principalmente na forma de triglicerídeos resultante da diminuição da síntese de 
proteinas transportadoras (MAÝES, 1977; MILNER, 1979). Ainda como resultado da deficiência de aminoácidos há negativação do balanço nitrogenado, queda da sintese de proteinas plasmáticas,par ticularmente albumina, com consequlente redução da pressão oncóti ca. A água se acumula no espaço extracelular, há redução do débí to cardíaco e diminuição da perfusão renal e consequente filtração glomerular com maior produção de renina-angiotensina aldoste rona, resultando em retenção de sódio e água que agravará a hemo diluição das proteínas, fechando o ciclo que se repete mais e mais.

\subsection{Edema}

Nenhum dos animais do presente experimento apresentou sinal clínico de edema ou diarréia. Edema tem sido referido em ratos jovens submetidos à dietas com até 1,0\% de proteínas (EDOZIEN, 1968; ANTHONY \& EDOZIEN, 1975), mas não em ratos adultos, mesmo que consumam dietas aprotéicas (CAMPANA et alii, 1975; ANGELELI et alii, 1978), apesar de nestas condições a concentração de água estar aumentada no músculo gastrocnêmio (BURINI et alii, 1972) e demais órgãos, exceto encéfalo (BURINI et alii, 1976a).

\subsection{Proteinas Plasmäticas}

Apesar da ausência de edema é interessante con siderar que, neste trabalho, todos os animais deficientes em pro teinas apresentaram hipoalbuminemia (Tabela 6).WHITEHEAD (1967), em trabalho sobre desnutrição infantil, refere que a albuminemia é parâmetro mais aconselhável para avaliar a desnutrição protéica do que a proteinemia total, uma vez que a primeira não é afetada pe las alterações das globulinas. No presente trabalho a dieta hi- 
poprotéica não afetou significativamente os nîveis de globulinas enquanto a proteinemia total apresentou-se reduzida apenas nos grupos jovem e adulto.

A sintese de albumina responde rapidamente à quantidade de aminoácidos oferecida ao fígado (GRANT \& HOFFENBERG, 1977). JEEJEEBHOY (1977) trabalhando com ratos alimentados com dieta isenta de proteínas mostrou que a síntese de albumina esta va drasticamente diminuída 24 horas após a instalação da dieta e praticamente cessou no 149 dia de dieta. Por outro lado, a sín tese de fibrinogênio inicialmente se elevou, decrescendo vagarosamente com o prolongamento do experimento. A sintese de transferrina apresentou comportamento intermediário entre o observado para a albumina e fibrinogènio. Concluiu o autor que a síntese de albumina é altamente sensível à privação de aminoácidos enquanto a transferrina o é parcialmente e a síntese de fibrinogênioé vir tualmente resistente, exceto na deficiência mais prolongada. Outro aspecto a ser considerado no trabalho mencionado é que o "pool" destas proteínas circulantes não variou tão rapidamente, principalmente porque a velocidade de catabolismo também decresceu. Assim, a medida da albumina plasmática não espelha a perda real da albumina total do corpo consequlente à deficiência protéi ca, uma vez que a albumina vascular è mantida às custas do "pool" extravascular (COWARD \& SAWYER, 1977). Através destes mecanismos o organismo tende a manter dentro de estreitos limites, a "massa circulante de albumina". A partir do momento em que esta constân cia não for mantida, pode-se inferir que a capacidade fisiológica de adaptação tenha sido superada, sendo a hipoalbuminemia sinal de deficiência protéica avançada. 
54.

\subsection{Esteatose hepática}

Alēm da hipoalbuminemia e do edema, tem sido observado aparecimento da esteatose hepática na deficiência protéica em seres humanos (RAMALINGASWAMI, 1964) e em animais, como macados (DEO et alii, 1965; KUMAR et alii, 1972) e ratos (KIRSCH et alii, 1968; MADI et alii, 1970; ENWONWU \& SREEBNY,1971, NDIKA, 1972; REZENDE, 1973; CAMPANA et alii, 1975; CAMARGO et alii,1978; EDOZIEN \& SWITZER, 1978). O fígado constitui indice bastante sensível do estado nutricional sendo que as alterações da sua integridade morfológica ou do seu funcionamento refletem com fidelidade as anormalidades nutricionais (PORTA \& HARTROFT, 1970).

A indução de esteatose hepática tem sido demonstrada nas condições de: a) maior oferta de ācido graxos livres do fígado, acompanhadas de maior captação e maior esterificação dos mesmos sem, contudo, um acompanhamento adequado do aumento da sintese de lipoproteinas e b) bloqueio metabólico da produção de lipoproteínas, normalmente associada à deficiência de substâncias conhecidas como fatores lipotrópicos ou então con sequência de tratamento com compostos tóxicos como tetracloreto de carbono, clorofórmio, etionina, fósforo, arsênio, chumbo,etc. (MAYES, 1977).

São vārios os nutrientes essenciais que, quando ausentes na dieta, provocam o aumento do teor hepático de lipídeos, entre os quais vitaminas B6 e ácido pantotênico, ácidos graxos essenciais e agentes lipotrópicos (metionina, lecitina,co lina e derivados) assim denominados por agirem na prevenção ou na supressão do fígado gorduroso (GANONG, 1971). A colina é sintetí zada pelo organismo em velocidade limitada pela disponibilidade de grupo metila doado pela s-adenosil metionina (metionina ativa da pelo ATP). A lecitina contēm colina em sua molēcula; portan- 
to, o agente lipotrópico mais essencial é a colina sendo a sua disponibilidade hepātica dependente da suplementação dietética de metionina e de lecitina ou de colina (RODWELL, 1977).

Vários mecanismos têm sido sugeridos para explicar o papel da colina como agente lipotrópico. As lipoproteinas de densidade muito baixa (VLDL) estão praticamente ausentes no sangue de ratos deficientes em colina, indicando que a altera ção induzida está localizada na retirada dos triglicerídeos hepá ticos. A perfusão dos fígados destes ratos com ácidos graxos 1ivres marcados mostrou a existência de captação e oxidação normais. Entretanto, a utilização de ácidos graxos estava alterada, com maior incorporação dos mesmos em triglicerỉdeos e em fosfoli pídeos não contendo colina. Assim, a menor sintese de fosfolipideos contendo colina em sua molécula poderia alterar a sintese de membranas intracelulares relacionadas com a sintese de lipoproteinas (MAYES, 1977).

Os animais deficientes em proteinas aqui estudados não foram privados de colina exógena, uma vez que ambas as dietas apresentaram a mesma composição desta substância (Material e Métodos - item 2.2), sendo que a ingestão alimentar, por unidade de peso foi semelhante para os dois grupos dietéticos (Tabela 3).

Alēm da metionina, a arginina também estā envolvida na etiologia do acúmulo hepático de gorduras. MILNER \& PERKINS (1978) observaram elevação de 6008 nos triglicerídeos he páticos em ratos alimentados durante 14 dias com dieta deficiente em arginina. Estes animais apresentaram excreção urināria aumentada de ācido orótico. Este dado, associado à analogia entre o padrão lipídico hepātico e sangulineo (hipotrigliceridemia e hi pocolesterolemia) destes ratos e o observado em animais receben 
do dieta rica em ácido orótico (STANDERFER \& HANDLER, 1955), per mitiu a inferência da participação do ácido orótico como agente indutor da infiltração gordurosa no fígado de ratos deficientes em arginina. Ratos recebendo dieta contendo $1 \%$ de ácido orótico apresentaram incorporação "in vivo" da radioatividade derivada de acetato-Cl4 em triglicerídeos hepático aumentada em cerca de 15 vezes (CREASEY et alii, 1961). Além disso o ácido orótico bloqueou a sintese da apoproteina B (MAYES, 1977) dificultando a mo bilização dos lipídeos formados no fígado.

A acidúria orótica da deficiência de arginina foi proposta como conseqtente à sobrecarga do ciclo da uréia com desvio de nitrogênio para a biossintese das pirimidinas. Assim,o fornecimento de dieta de composição desbalanceada de aminoácidos, resulta em mau aproveitamento do nitrogênio com elevação da produção de amônia. o mecanismo de metabolização (desintoxicação)da amônia envolve a participação de alguns aminoácidos, entre eles a arginina, que transformam a amônia em uréia (Fig. 13). Na deficiência de arginina há redução da atividade do ciclo da uréia, acumulando amônia, cujo nitrogênio (carbamil-fosfato) é desviado para a via pirimidina com aumento da produção de ácido orótico (MILNER \& VISEK, 1975) (Fig. 13).

O acúmulo hepático de gorduras resultante de dieta rica em ácido orótico ou deficiente em arginina é corrigido pela suplementação dietētica de adenina (CREASEYet alii,1961; MILNER, 1979) mas não de guanina (MILNER, 1979) ou por fatores lipotrópicos (STANDERFER \& HANDLER, 1955). O acúmulo de lipídeos no fígado seria consequente ao desequilíbrio da relação entre as bases púricas e pirimidínicas no fígado; assim o fornecimentodie tético de adenina corrigiria a desproporção, normalizando o meta bolismo lipídico (MILNER, 1979). 


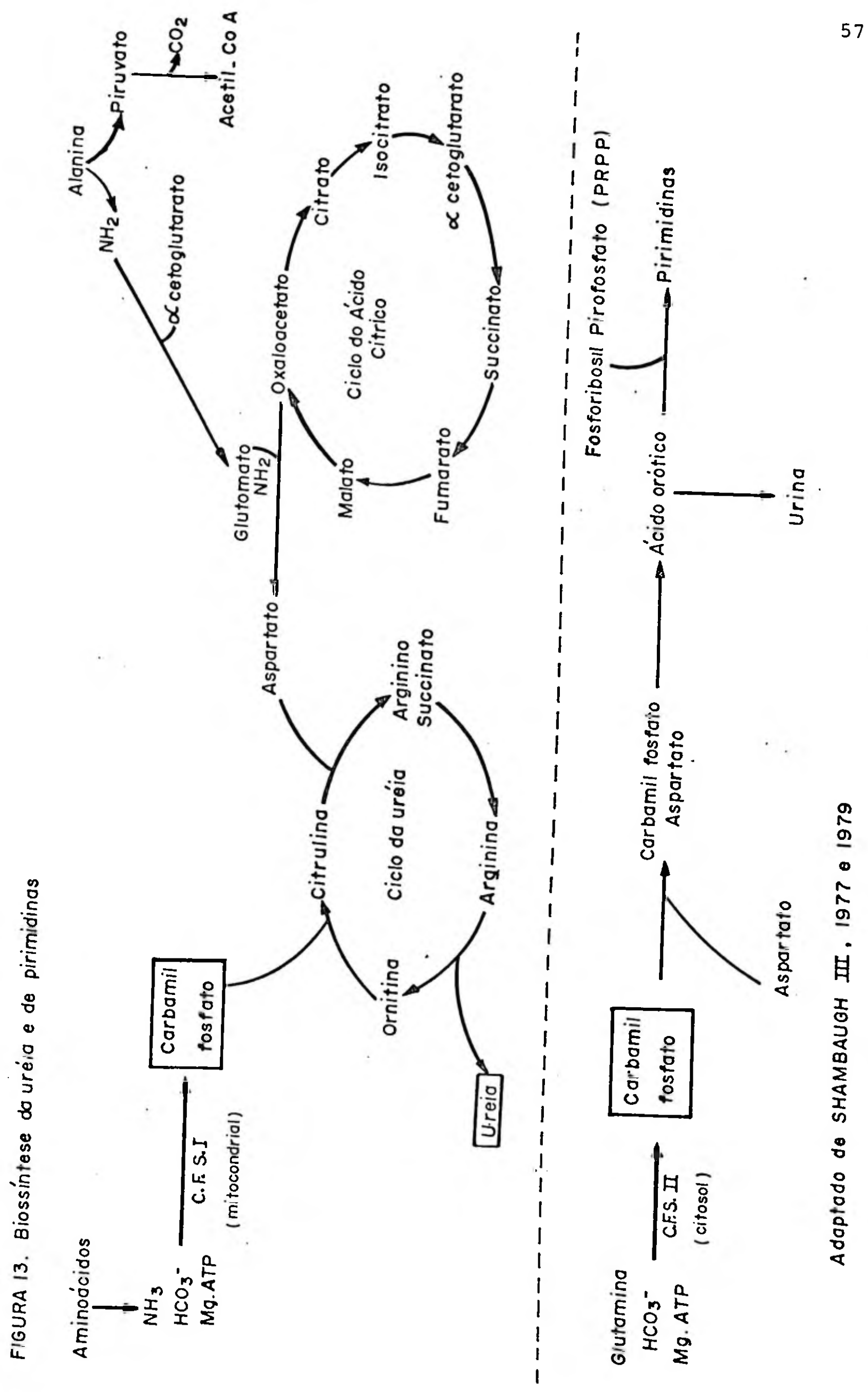


A deficiência protéica provocada neste trabaIho foi total, com restrição de todos os aminoácidos. Nestas cir cunstâncias, a esteatose observada também não pode ser justifica da em função do desequilíbrio do metabolismo nitrogenado de aminoácidos com aumento de formação de amônia e sobrecarga do ciclo da uréia, com produção de ácido orótico (Fig. 13). Portanto, a e tiologia do acúmulo de lipídeos hepático permanece em aberto, cạ recendo de estudos mais aprofundados sobre o assunto. Outro aspecto a ser esclarecido é o referente à influência da idade do animal desnutrido sobre o grau de esteatose hepática.

\subsection{Validação do Modelo de Deficiência Protéica}

Os animais alimentados com dieta deficiente em proteinas apresentaram perda de peso (Fig. 3 e Tabela 1), hipoal buminemia (Tabela 6) e quadro histológico de esteatose hepática (Tabela 7), sinais característicos de modelos de carência protéi ca (WATERLOW \& ALLEYNE, 1971; CAMPANA et alii, 1975; ANGELELI et alii, 1978; CAMARGO et alii, 1978). Além disso, deve-se acrescen tar que os animais hipoprotéicos apresentaram ingestão alimentar por unidade de peso corporal $(100 \mathrm{~g})$, igual ou mesmo maior que seus controles (Fig. 5 e Tabela 3 ).

$$
\text { Considerando-se que ambos os tipos de dieta }
$$

oferecidos foram isocalóricos, pode-se afastar a possibilidade dos animais hipoprotēicos estarem em deficiência calórica. A cor reção da ingestão alimentar por unidade de peso foi proposta como melhor método para corrigir as distorções motivadas pela variação de peso corpóreo (NDIKA, 1972; CAMPANA et alii, 1975; AN GELELI et alii, 1978). A diminuição na excreção de nitrogênio uréico tambëm ēcaracterística de deficiência predominantemente pro: téica, uma vez que nafalta de energia o organismo promove neoglico 
gênese a partir de aminoácidos, resultando em grande formação e excreção de urēia (SCHIMKE, 1962b; BURINI, 1980).

Os dados de perda de peso, ingestão adequada de calorias e menor excreção de nitrogênio uréico associados à hipoalbuminemia e esteatose hepática, observados nos animais deficientes comprovam expressivamente a validade do modelo de carência protéica adotado. A variação da intensidade destes dados encontrados, de comportamento inverso à idade dos animais mostra a maior resistência do organismo já formado ou a maior sensibilí dade daqueles ainda em formação frente às condições nutricionais adversas.

4. Hidroxiprolina Urinária e Metabolismo do Colágeno

A molécula de colágeno é constituída principal mente de glicina, prolina, hidroxiprolina e alanina, representan do a participação da hidroxiprolina cerca de 13-14\% do total (NEUMAN \& LOGAN, 1950; ANASUYA \& NARASINGA RAO, 1966; SMITH JR. et alii, 1974).

Sabe-se que a hidroxiprolina nãoē utilizada na sintese do colágeno (SMITH JR. et alii, 1974) e que a hidroxipro lina da molécula do colágeno é formada pela hidroxilação da prolina das cadeias peptídicas do colágeno. A hidroxilação, assim como a glicosilação, são processos que ocorrem após a fase de tradução do mRNA do colágeno e constituem caracteristica deste tipo de proteina (SJOERDSMA et alii, 1965; JUVA \& PROCKOP, 1966; SMITH Jr. etalii,1974). Essas evidências, associadas ao fato de ZIFF et alii (1956) terem observado que pacientes mantidos em dieta livre de hidroxiprolina continuavam a excretar quantidades significativas deste iminoácido na urina, mostram ser a hidroxi- 
prolina urinária originária da degradação do colāgeno.

A partir de dados isotópicos, WEISS \& KLEIN (1969) mostraram que as principais vias de excreção dos metabolí tos do colágeno são $\mathrm{CO}_{2}$ respiratōrio (75\%) e peptídeos contendo hidroxiprolina na urina (25\%). A maior parte (90-95\%) da hidroxi prolina liberada pelo catabolismo do colágeno é rapidamente meta bolizada, parcialmente a aminoácidos derivados como alanina e ácido glutâmico (WOLF et alii, 1956) e/ou, completamente oxidada a $\mathrm{CO}_{2}$, àgua e uréia (KIVIRIKKO, 1970).

Embora o catabolismo do colágeno resulte na li beração de hidroxiprolina predominantemente na forma livre, apenas 5-108 da quantidade total excretada na urina é recuperada na forma livre. Isto se deve à elevada eficiência dos mecanismos re nais de reabsorção, resultando na reabsorção quase total do iminoācido existente na luz tubular. Em vista disso, a fração da hị droxiprolina ligada a peptídeos, que representa apenas cerca de 108 da hidroxiprolina liberada pela degradação do colágeno, cons titui a quase totalidade (cerca de 90-95\%) do iminoácido excreta do pela urina (KIVIRIKKO, 1970). Entretanto, a hidroxiprolina urināria não reflete apenas a degradação do colágeno mas também a metabolização do iminoácido durante interconversão entre os dife rentes "pools" (Fig. 14). LINDSTEDT \& PROCKOP (1961), medindo a atividade específica da ${ }^{14}$ C-hidroxiprolina urinária após a administração de dose simples de ${ }^{14}$ C-prolina em ratos, mostraram a existência de pelo menos três "pools" de hidroxiprolina,cujas ve locidades de mobilização são: rápida, com meia vida de cerca de um dia, intermediária com meia vida de cerca de cinco dias e len ta, com meia vida de 50 a 100 dias. o "pool" de mobilização rápí da corresponde ao colágeno recēm sintetizado, de metabolismo mais ativo e que corresponde à fração colágena solúvel em $\mathrm{NaCl}$ 0,14M; 
- "pool" de mobilização lenta está relactonado ao colágeno maduro, de atividade metabólica baixa, quase inerte, correspondente à fração colágena insolúvel em $\mathrm{NaCl} 0,14 \mathrm{M}$ (KIVIRIKKO,1970). A anā lise da Figura 14 permite concluir que o aumento da excreção uri nária de hidroxiprolina não necessariamente indica maior degrada ção do colágeno, em termos de quantidade catabolizada por grama de colägeno existente. Se o tamanho de um "pool" especifico de colágeno aumentar, a quantidade de hidroxiprolina na urina se elevará, mesmo que a taxa de degradação do colágeno deste "pool" estiver normal. Assim, o aumento da excreção de hidroxiprolina pode ser ocasionado por: a) aumento da velocidade de sintese do colágeno (K1 e K2 - ver Fig. 14); b) diminuição da velocidade de conversão do colágeno solúvel a formas menos solúveis ( $K 3$ e K5); c) aumento da velocidade de degradação de colágeno insolúvel a formas mais solúveis $(K 6)$; d) aumento da velocidade de degradação das vārias formas de colágeno à hidroxiprolina livre ou liga da a peptídeos (K7, K8 e K9); ou e) diminuição da velocidade de degradação da hidroxiprolina ligada a peptídeos (K10). Quando es tas variáveis são consideradas apropriadamente, a análise da hidroxiprolina urinária pode fornecer informações que refletem variações do metabolismo do colágeno (PROCKOP \& KIVIRIKKO, 1967).

Assim, tendo em vista que:

a) a hidroxiprolina é iminoācido quase exclusivamente confina do ao colágeno, pois apenas pequena quantidade se encontra presente na elastina, em proporção dez vezes menor que no colágeno, sendo que o corpo contém muito mais colágeno do que elastina; também a contribuição hepática de hidroxipro lina livre a partir de glioxilato e piruvato é insignificante; 
62.

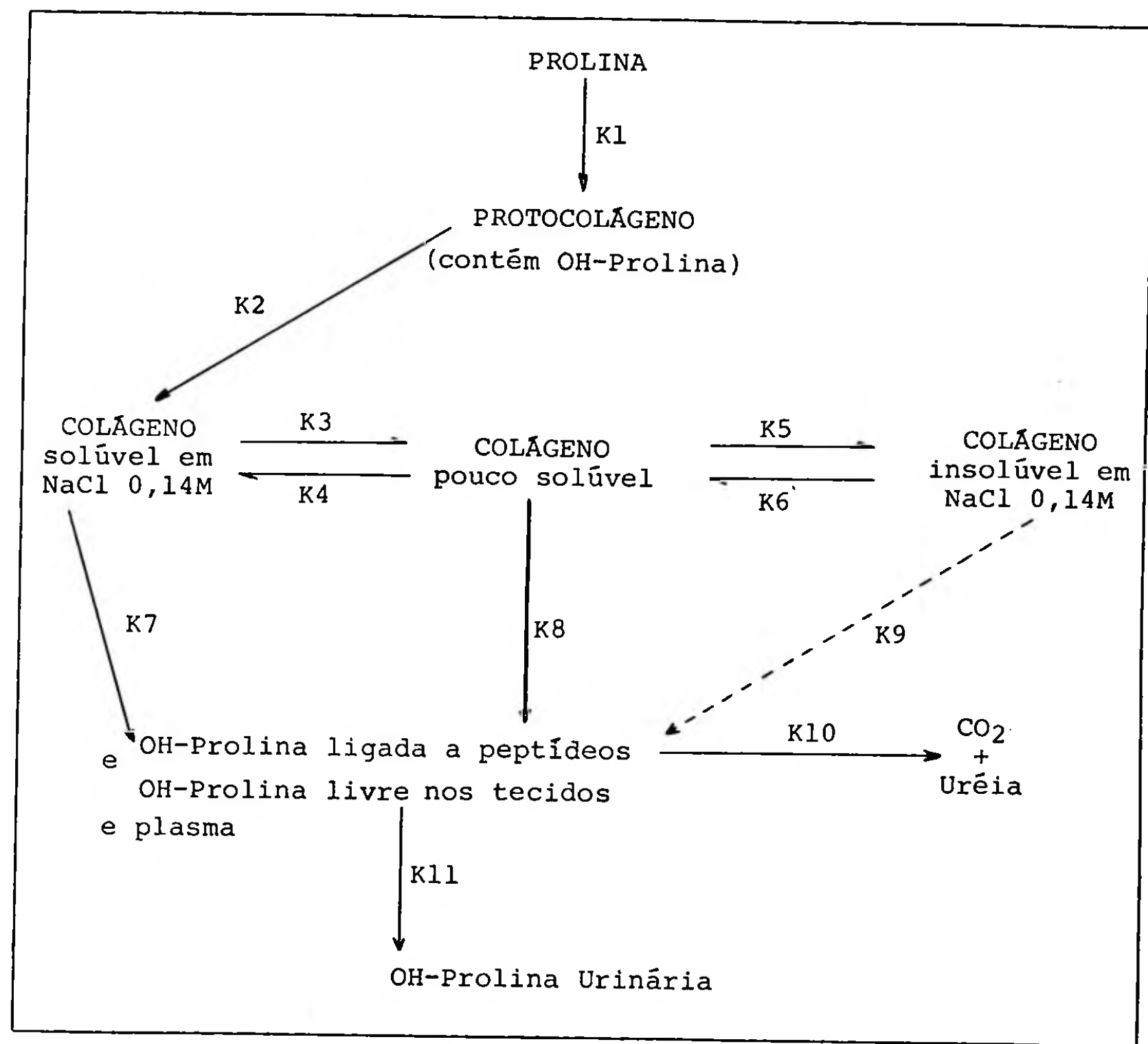

$K=$ velocidade de conversão.

$\rightarrow=$ mecanismo ainda não confirmado

Figura 14: Degradação do colägeno atē hidroxiprolina urināria. (PROCKOP \& KIVIRIKKO, 1967 e KIVIRIKKO, 1970). 
b) a hidroxiprolina livre e os peptídeos contendo hidroxiprolina presentes nos lỉquidos biológicos não se originam em quantidades significativas da hidroxilação direta da prọ lina livre, nem do prolil-tRNA ou de passagens metabólicas não relacionadas ao metabolismo do colágeno (elastina, piruvato e glioxilato);

a hidroxiprolina urināria tem sido utilizada como índice para es tudo do metabolismo do colágeno (LAITINEN et alii, 1966; NUSGENS \& LAPIERI, 1973).

\section{Influência da Idade Sobre o Metabolismo do Colágeno}

Os animais jovens apresentaram maior atividade metabólica, evidenciada por maior velocidade de crescimento(Fig. 3) e maior taxa de excreção de creatinina (Fig. 9 e Tabela 9) e de hidroxiprolina (Fig. 11 e Tabela 11).

o turnover do colágeno apresenta-se mais rápido em animais jovens, embora em menor intensidade que o turnover das proteinas intracelulares (NEUBERGER \& SLACK, 1953). O organismo jovem apresenta maior atividade da prolil-hidroxilase,"tu nover" de colágeno rápido e,por isso, excreta maior quantidade de hidroxiprolina por unidade de peso (ZIFF et alii, 1956;LINDSTEDT \& PROCKOP, 1961; ANASUYA \& NARASINGA RAO, 1970).

PROCKOP \& KIVIRIKKO (1967), comparando resulta dos de animais jovens e velhos, concluíramque tanto a maior excreção de hidroxiprolina quanto a maior relação colágeno solúvel/coláge no insolúvel refletem a idade e o crescimento do animal. JASIN et alii (1962), estudando crianças, observaram maior excreção de hidroxiprolina nas fases de 0-1 e 10-14 anos, periodos em que fó ram notadas as maiores taxas de crescimento em termos de super- 
fície corporal por idade. Por outro lado, os autores observaram baixa excreção do iminoácido em crianças com crescimento lento. Uma vez tratadas, estas crianças retornavam ao ritmo de crescimento, associado a um aumento da excreção urinária de hidroxipro lina. Os autores sugerem que a excreção aumentada de hidroxiprolina em crianças é resultado da presença, durante o crescimento, de grande quantidade de colágeno metabolicamente ativo, em dispo nibilidade para degradação.

Utilizando-se glicina radiativa para o estudo do metabolismo de colágeno em tecidos de ratos normais de diferentes idades, NEUBERGER \& SLACK (1953) observaram atividade metabólica elevada em todos os tecidos dos animais jovens enquanto os velhos apresentaram atividade baixa. Os animais adultos apre sentaram atividades variáveis nos diferentes tecidos analisados. Apesar de ser metabolicamente pouco ativo, o teor total de colágeno do corpo é maior no organismo velho (KIVIRIKKO \& PROCKOP, 1967), pois o conteúdo colágeno do tecido aumenta durante o enve lhecimento (ANGELELI et alii, 1978), enquanto a concentração de ácido hialurōnico permanece constante (MEYER \& SILBERBERG, 1976), demonstrando o processo de maturação do colágeno (VASANTHA et alii, 1970).

6. Influência da Deficiência Protéica Sobre a Excreção de Hidroxiprolina

O fornecimento de dieta hipoprotéica aos animais resultou em alteração do padrão de excreção de hidroxiproli na observado para os diferentes grupos etários, nas condições de dieta controle. A ingestão de dieta hipoprotêica induziu redução quase imediata da quantidade de hidroxiprolina excretada pelos 
animais (Fig. 10). Nestas condições dietéticas ocorre redução do turnover do colágeno do corpo (ANASUYA \& NARASINGA RAO, 1970), re fletido pela diminuição da excreção de hidroxiprolina (WIDDOWSON \& WHITEHEAD, 1966; ANASUYA \& NARASINGA RAO, 1970; DAWSON \& MILNE, 1978; BURINI, 1980) consequlente à diminuição da velocidade de sintese (WILEY et alii, 1973) e de catabolismo (PICOU et alii, $1966)$.

Quando a excreção de hidroxiprolina foi referi da por $100 \mathrm{~g}$ de peso corpóreo ou mg de creatinina observou-se atenuação da diferença existente entre os grupos dietéticos. Este fato foi marcante nos grupos adulto e velho (Figs. 11 e 12) a pon to de o grupo velho apresentar supressão da diferenciação estatistica entre os dois regimes dietéticos (Tabelas 11 e 12). Uma tentativa para explicar esta maior resistência do metabolismo co lāgeno de animais velhos frente à situação de deficiência protéi ca pode ser feita baseando-se nas variações das diferentes formas de colágeno do corpo, conforme mencionado no item anterior. Considerando-se que a atividade metabólica do colágeno diminui com o envelhecimento (PROCKOP \& KIVIRIKKO, 1967; ANASUYA \& NARASINGA RAO, 1970), é esperado que o colágeno do organismo envelhe cido seja mais resistente à deficiência protéica, com manutenção da velocidade de degradação a níveis normais. Isto em consequência dos organismos velhos serem pobres em colágeno solúvel lou imaturo) sendo esta fração colágena a que dá a maior contribuição para a hidroxiprolina eliminada pela urina (PROCKOP \& KIVIRIKKO, 1967; KIVIRIKKO, 1970). 
Do presente estudo conclui-se que:

1. a dieta controle promoveu crescimento dos animais, apresentando curva de evolução ponderal característica para cada idade;

2. a curva de evolução ponderal dos animais controle, distinta para cada grupo, foi consequência da idade e não da ingestão alimentar;

3. animais tratados com dieta hipoprotéica perderam peso, com efeito mais pronunciado no grupo jovem;

4. a perda de peso dos animais tratados com dieta hipoprotēica foi causada pela composição da dieta oferecida e não pela ingestão alimentar;

5. a excreção urinária de nitrogênio uréico foi comprovada ser parâmetro sensível para avaliação do estado nutricio nal protéico;

6. a creatinina urinária não foi influenciada pela restrição protéica;

7. 0 modelo experimental proposto mostrou caracteristicas fi siolōgicas, bioquímicas e histológicas de carência predo minantemente protéica;

8. dieta e idade interagem no metabolismo protéico e o fornecimento de dieta hipoprotéica normocalórica por um mes mo período, a animais de idades diferentes resultou em alterações metabólicas de intensidadades variadas, afetando preferencialmente o grupo mais jovem; 
67.

9. a excreção urinäria de hidroxiprolina total constitui in dice sensível para avaliação do metabolismo do colágeno, marcadamente no grupo jovem;

10. animais velhos não podem ser avaliados quanto ao metabolismo de colágeno apenas pela excreção urinária de hidro xiprolina total. 
Foi estudado o efeito da dieta hipoprotéica (2,08 de proteína) isocalórica sobre o padrão de excreção urināria de hidroxiprolina em ratos jovens, adultos e velhos, mantidos em gaiolas metabólicas durante 42 dias. As excreções urinárias de nitrogênio uréico e de hidroxiprolina foram utilizadas como indice do aproveitamento do nitrogênio alimentar e do metabolismo do colāgeno, respectivamente.

Todos os animais recebendo dieta controle (20,08 de proteina) apresentaram ganho de peso. A velocidade de crescimento foi decrescente com a idade dos animais, enquanto a ingestão diāria de dieta aumentou com a idade dos animais, confirmando a menor necessidade de nutrientes com finalidade plástí ca nos organismos adultos. A queda da capacidade da dieta de pro mover crescimento, observada com o envelhecimento, foi paralela ao baixo aproveitamento do nitrogênio alimentar, avaliado pela maior excreção de nitrogênio uréico observado.

Os animais hipoprotéicos apresentaram perda de peso, hipoproteinemia, hipoalbuminemia, quadro histológico de es teatose hepática, queda brusca da excreção de produtos nitrogena dos como nitrogênio uréico e hidroxiprolina. A intensidade dos dados encontrados foi inversa à idade dos animais. A ingestão alimentar por unidade de peso dos ratos hipoprotēicos foi igual ou mesmo superior à dos animais controles, confirmando o estado de deficiência protéica-normocalörica nestes animais.

A taxa de metabolização do colágeno, avaliada pela excreção urinária de hidroxiprolina por unidade de peso ou de creatinina, apresentou-se mais elevada nos organismos jovens, mostrando a grande participação do colāgeno imaturo na excreção 
do iminoácido. O fornecimento de dieta hipoprotéica alterou este padrão de excreção de hidroxiprolina. A queda de excreção foi in versamente proporcional à idade dos animais.

Os dados do presente experimento mostram que idade e dieta interagem no metabolismo protéico. o fornecimento de dieta hipoprotéica, num mesmo período, para ratos de diferentes idades resulta em alterações metabólicas de intensidades variáveis.

A excreção diāria de hidroxiprolina constitui indice sensivel para avaliação do metabolismo do colágeno em aní mais de diferentes idades submetidos a dieta controle ou deficiente em proteínas. 
The effect of hypoproteic isocaloric diet $(2,08$ protein) on collagen metabolism was studied in young, adult and old rats. The animals were kept in metabolic cages during 42 days. Urinary excretions of urea-nitrogen and hydroxyproline were used as indexes of dietetic nitrogen utilization and total body collagen metabolism, respectively.

All the animals receiving control diet $(20,0$ \% protein) gained body weight. The rate of growth decresed with age; conversely, the daily diet intake increased with aging. The decreasing capacity of the diet in promoting growth, observed with aging, paralelled the poor dietary nitrogen retention observed in those groups.

Hypoproteic animals showed body weight loss, plasma low levels of protein and albumin, hepatic steatosis and dramatic fall in the nitrogen output measured as urea-nitrogen and hydroxyproline. The degree of the findings was reverse to the animal aging. Food intake per unit of body weight of the hypoproteic rats was the same or even greater than the normoproteic ones, confirmming a proteic-normocaloric deficiency state in these animals.

The rate of collagen metabolism assessed by the urinary excretion of hydroxyproline/body weight was increased in the young animals; this was attributed to the greater participation of the immature collagen fraction in the iminoacid excretion. When the animals were fed on hypoproteic diet there was a change in this urinary hydroxyproline excretion pattern. Results of the present work show great interaction between age and diet upon protein metabolism, mainly 
71.

collagen. Therefore, animals from different ages fed on hypoproteic diet for similar periods of time have different degrees of metabolic changes in the whole body.

Hydroxyproline excretion is a

sensible index to assess collagen metabolism in animals of different ages receiving either a control or a protein deficient diets. 
REFERENCIAS BIBLIOGRAFICAS *

ACHILlES, P. Teor do hormônio de crescimento no plasma e na hipó fise e balanço de nitrogênio em ratos submetidos à dieta carente em proteinas. Botucatu, 1974. 123p. (Tese - Doutoramento Faculdade de Ciências Médicas e Biológicas de Botucatu)

ADAPTATION in protein calorie malnutrition (PCM). Nutr. Rev.' $37(8): 250-2,1979$.

ANASUYA, A. \& NARASINGA RAO, B.S. Relationship between body collagen and urinary hydroxyproline excretion in young rats fed on a low-protein or low-calorie diet. Brit. J. Nutr., 24:97$-107,1970$.

ANASUYA, A. \& NARASINGA RAO, B.S. Urinary excretion of hydroxyproline in kwashiorkor. Indian J. med. Res., 54:849-57, 1966.

ANGELELI, A.Y.O.; BURINI, R.C.; CAMPANA, A.O. Body collagen nitrogen in protein-deficient adult rats. J. Nutr., 108: $1147-54,1978$.

ANTHONY, L.E. \& EDOZIEN, J.C. Experimental protein and energy deficiencies in the rat. J. Nutr., 105:631-48, 1975.

BERGMAN, I. \& LOXLEY, R. The determination of hydroxyproline in urine hydrolysates. Clin. chim. Acta, 27:347-9, 1970.

BURINI, R.C. Efeito da tireioidectomia e da tiroxina sobre o metabolismo do colágeno em ratos. Estudo "in vitro" e "in vivo". Influência da idade e da ingestão protéico-calórica. Araraquara,

* ASSOCIAÇÃO BRASILEIRA DE NORMAS TÉCNICAS. Comissão de Estudos de Documentação. Rio de Janeiro. Referências bibliogräficas. In:- Normas ABNT sobre documentação. Rio de Janeiro, 1978. p.13-30. 
1980. 145p. (Tese - Livre docência - Faculdade de Ciências Farmacêuticas de Araraquara - Universidade Estadual Paulista "Júlio de Mesquita Filho)

BURINI, R.C. Influência da carência dietética de potássio, provocada em ratos adultos jovens, sobre o ganho de peso e o metabolismo de nitrogênio, sódio e potássio. Estudo de balanço metabólico, plasma e músculo esquelētico; teor muscular de ácidos nucléicos. Botucatu, 1974. 128p. (Tese - Doutoramento - Faculdade de Ciências Médicas e Biológicas de Botucatu)

BURINI, R.C.; OUTA, A.Y.; SILVA, C.A.; CAMPANA, A.O. Carência protéica experimental do rato. II. Teor de água e de sódio da carcaça e de órgãos. Ciên. Cult., São Paulo, 28 (supl.):538, $1976 \mathrm{a}$.

BURINI, R.C.; PERES, R.F.C.; ANGELELI, W.A.; CAMPANA, A.O. Carência protéica e carência calórica experimental do rato. Teor de ácidos nucléicos do músculo, fígado e encéfalo. Ciên. Cult., São Paulo, 28 (supl.):538, 1976b.

BURINI, R.C.; ANGELELI, A.Y.O.; ACHILLES, P.; GUIMARÃES Jr., C.; PERES, R.F.C.; CAMPANA, A.O. Adaptation du muscle du rat aux deficiences alimentaires en potassium et en proteines. Teneurs en azote total et on divers composes protidiques et nucleiques. Med et Nut., 17:447-51, 1981a.

BURINI, R.C.; OUTA, A.Y.; REZENDE, T.A.; SILVA, C.A.; ANGELELI, W.A.; CAMPANA, A.O. Desnutrição protéica em ratos: alterações da composição hidroeletrolítica no músculo esquelētico. In: JORNADA CIENTIFICA DA FACULDADE DE CIENCIAS MEDICAS E BIOLOGICAS DE BOTUCATU, 2, Botucatu, 1972. Anais... Botucatu, 1972. p.354.

BURINI, R.C.; SANTIDRIAN, S.; MOREYA, M.; BROWN, P.; MUNRO, H.N.; YOUNG, V.R. Interaction of thyroid status and diet on muscle protein breakdown in the rat, as measured by $\mathrm{N}^{\mathrm{T}}$-methylhistidine excretion. Metabolism, 30:679-87, 1981b.

CAHILL JR., G.F. Starvation in man. Clin. Endocrinol. Metab., $\underline{5}: 397-415,1976$. 
CAMARGO, J.L.V. A mucosa gástrica de ratos jovens, adultos e velhos submetidos à carência de proteínas e à recuperação nutricional; estudo quantitativo e qualitativo óptico e ultraestrutural. Botucatu, 1981. 11lp. (Tese - Doutoramento - Faculdade de Medicina de Botucatu - Universidade Estadual Paulista "Júlio de Mesquita Filho")

CAMARgO, J.L.V.; ANGELELI, A.Y.O.; BURINI, R.C.; CAMPANA, A.O. Hepatic lesions in protein-deficient adult rats. Brit. J. exp. Path., 59:158-66, 1978.

CAMPANA, A.O. \& BURINI, R.C. Potassium contents of organs and carcass in protein deficients rats. In: CONGRESSO INTERNACIONAL DE NUTRIÇÃo, 11, Rio de Janeiro, 1978. Resumos... Rio de Janeiro, 1978. p.212.

CAMPANA, A.O. \& BURINI, R.C. Digestão, Absorção e Utilização de Nutrientes. In: DUTRA DE OLIVEIRA, J.E. et alii. Nutrição Básica. São Paulo, Sarvier, 1982, cap. 5, p.67.

CAMPANA, A.O.; BURINI, R.C.; OUTA, A.Y.; CAMARGO, J.L.V. Experimental protein deficiency in adult rats. Rev. bras. Pesq. Med. Biol., 8: $221-6,1975$.

CHAPMAN, J.A. Fibroblasts and collagen. Br. med. Bull., $18: 223-37,1962$.

CHVAPIL, M. Mechanisms controlling the functions of connective tissue. In:- Physiology of connective tissue. London, Butterworths, 1967. cap. 5, p.297-354.

CLARK, L.C. \& THOMPSON, H.L. Determination of creatine and creatinine in urine. Analyt. chem., 21:1218-20, 1949.

COCHRAN, W.G. \& COX, G.M. Experimental designs. 2.ed. London, John Wiley \& Sons, 1957. 661p.

COWARD, W.A. \& SAWYER, M.B. Whole-body albumin mass and distribution in rats fed on low-protein diets. Brit. J. Nutr. , 37:127-33, 1977. 
CREASEY, W.A.; HANKINS, L.; HANDSCHUMACHER, R.E. Fatty liver induced by orotic acid. I. Accumulation and metabolism of lipids. J. biol. chem., 236:2064-9, 1961.

DAWSON, R. \& MILNE, G. The effects of dietary nitrogen level on the collagen of rat skin. Brit. J. Nutr., 39:181-92, 1978.

DEO, M.G.; SOOD, S.K.; RAMALINGASWAMI, V. Experimental protein deficiency. Arch. Path., 80:14-23, 1965.

EDOZIEN, J.C. Experimental kwashiorkor and marasmus. Nature, Lond. , 220:917-9, 1968.

EDOZIEN, J.C. \& SWITZER, B.R. Fatty liver in experimental protein-energy malnutrition in the rat. Exp. \& Mol. Path.' $29: 1-11,1978$.

EDOZIEN, J.C.; NIEHAUS, N.; MAR, M.; MAKOU, T.; SWITZER, B.R. Diet hormone interrelationship in the rat. J. Nutr., 108: $1767-76,1978$.

ENWONWU, C.O. \& SREEBNY, L.M. Studies of hepatic lesions of experimental protein-calorie malnutrition in rats and immediate effects of refeeding an adequate protein diet. J. Nutr., 101:501-14, 1971 .

FORBES, G.B. \& BRUINING, G.J. Urinary creatinine excretion and lean body mass. Am. J. clin. Nutr., 29:1359-66, 1976.

FOSTER, L.B. \& HOCHHOLZER, J.M. A single reagent manual method for directly determining urea nitrogen in serum. Clin. Chem., 17:921-5, 1971 .

GANONG, W.F. Energy balance, metabolism \& nutrition. In:Review of medical physiology. Los Altos, Lange Medical Publ., 1971. cap. 17, p.225.

GOLDEN, M.H.N.; WATERLOW, J.C.; PICOU, D. Protein turnover-synthesis and breakdown before and after recovery from protein-energy malnutrition. Clin. Sci. \& Mol. Med., 53:473-77, 1977a. 
GOLDEN, M.H.N.; WATERLOW, J.C.; PICOU, D. The relationship between dietary intake, weight change, nitrogen balance, and protein turnover in man. Am. J. clin. Nutr., 30:1345-8, $1977 \mathrm{~b}$.

GRANT, A.G. \& HOFFENBERG, R. The effect of dietary protein deprivation on protein synthesis in the isolated liver parenchymal cell. Brit. J. Nutr., 38:255-60, 1977.

GUYTON, A.C. Lipid and protein metabolism. In:- Basic human physiology; normal function and mechanisms of disease. 2.ed. Philadelphia, Saunders, 1977. cap. 46, part. 2, p. 730.

HAVERBERG, L.N.; DECKELBAUM, L.; BILMAZES, C.; MUNRO, H.N.; YOUNG, V.R. Myofibrillar protein turnover and urinary N-methil-histidine output. Response to dietary supply of protein and energy. Biochem. J., 152:503-10, 1975.

HORIE, Y. \& ASHIDA, K. Effect of an adequate-protein diet after a low-protein diet on protein catabolism in growing rats. Brit. J. Nutr. , 29:23-31, 1973.

JASIN, H.E.; FINK, C.W.; WISE, W.; ZIFF, M. Relationship between urinary hydroxyproline and growth. J. c'lin. Invest., 41: 1928-35, 1962 .

JAYA RAO, K.S. Evolution of kwashiorkor and marasmus. Lancet, $20: 709-11,1974$.

JEEJEEBHOY, K.N. Role of measuring albumin synthesis as a way of measuring protein body repletion. In: GREENE, H.L. et alii. Clinical nutrition update; aminoacids. Chicago, American Medical Association, 1977. part.2, p.130.

JUVA, K. \& PROCKOP, D.J. Hydroxylation of proline and the intracellular accumulation of a polypeptide precursor of collagen. Science, 152:92-4, 1966.

KIRSCH, R.E.; BROCK, J.F.; SAUNDERS, S.J. Experimental protein-calorie malnutrition. Am. J. clin. Nutr., 21:820-6, 1968. 
KIVIRIKKO, K.I. Urinary excretion of hydroxyproline in health and disease. Int. Rev. Connect. Tissue Res., 5: 93-163, 1970.

KREBS, H.A. Rate control of tricarboxilic acid cicle. Adv. Enzyme Regul. , 8:335-53, 1969.

KUMAR, V.; DEO, M.G.; RAMALINGASWAMI, V. Mechanism of fatty liver in protein deficiency; an experimental study in the rhesus monkey. Gastroenterology, 62:445-51, 1972 .

LAITINEM, O.; NIKKILA, E.A.; KIVIRIKKO, K.I. Hydroxyproline in the serum and urine; normal values and clinical significance. Acta med. Scand., 179:275-84, 1966.

LEHNINGER, A.L. Adjustments of metabolism to stress. In:Biochemistry. New York, worth Publ., 1975. cap. 30, part. 3, p. 840-9.

LINDSTEDT, S. \& PROCKOP, D.J. Isotopic studies on urinary hydroxyproline as evidence for rapidly catabolized forms of collagen in the young rat. J. biol. chem., 236:1399-403, 1961.

MCCANCE, R.A. \& WIDDOWSON, E.M. Protein deficiencies and calorie deficiencies. Lancet, 2:158-9, 1966.

MADI, K.; JERVIS, H.R.; ANDERSON, P.R.; ZIMMERMAN, M.R. A protein deficient diet; effect on the Iiver, pancreas, stomach, and small intestine of the rat. Arch. Path., 89:38-52, 1970.

MAFFEI, H.V.L.; RODRIGUES, M.A.M.; CAMARGO, J.L.V.; CAMPANA, A.O. Intraepithelial lymphocytes in the jejunal mucosa of malnourished rats. GUT, 21:32-6, 1980 .

MAYES, P.A. Metabolism of lipids. In: HARPER, H.A., ed. et alii. Review of physiological chemistry. 16.ed. Los Altos, Lange Medical Publications, 1977. cap. 20, p.308. 
MEYER, F.A. \& SILBERBERG, A. Aging and the interstitial content of loose connective tissue. Mech. Ageing \& Develop., ㅁ:437-42, 1976.

MILNER, J.A. Mechanism for fatty liver induction in rats fed arginine deficient diets. J. Nutr., 109:663-70, 1979.

MILNER, J.A. \& PERKINS, E.G. Liver lipid alterations in rats fed arginine deficiency diets. Lipids, 13:563-5, 1978.

MILNER, J.A. \& VISEK, W.J. Urinary metabolites characteristics of urea cycle amino acid deficiency. Metabolism, 24:643-51, 1975.

MORRISON, D.F. Multivariate statistical methos. New York, MCGraw Hill, 1967. 338p.

NDIKA, L.I.L. Protein malnutrition and gastrointestinal histamine in the rat. Brit. J. Nutr., 28:153-65, 1972.

NEUBERGER, A. \& RICHARDS, F.F. In: MUNRO, H.N. \& ALLISON, J.B., ed. Mammalian protein metabolism. New York, Academic Press, 1964. v.1, p. 243.

NEUBERGER, A. \& SLACK, H.G.B. The metabolism of collagen from liver, bone, skin and tendon in the normal rat. Biochem. J.' $53: 47-52,1953$.

NEUBERGER, A.; PERRONE, J.C.; SLACK, H.G.B. The relative metabolic inertia of tendon collagen in the rat. Biochem. J., 49:199-204, 1951.

NEUMAN, R.E. \& LONGAN, M.A. The determination of hydroxyproline. J. biol. chem., 184:299-306, 1950 .

NOLEN, G.A. Effect of various restricted dietary regimens on the growth, health and longevity of albino rats. J. Nutr., 102: $1477-94,1972$. 
NUSGENS, B. \& LAPIERE, C.H.M. The relationship between proline and hydroxyproline urinary excretion in human as an index of collagen catabolism. Clin. chim. Acta, 48:203-11, 1973.

OUTA, A.Y.; ANGELELI, W.A. ; BURINI, R.C.; CAMPANA, A.O. Carência protéica experimental do rato. IV. Teor de gordura da carcaça e de órgãos. In: JORNADA CIENTIFICA DE BOTUCATU, 5, Botucatu, 1975. Anais... Botucatu, Faculdade de Ciências Médicas e Biológicas de Botucatu, 1975. p.126.

PICOU, D. \& PHILLIPS, M. Urea metabolism in malnourished and recovered children receiving a high or low protein diet. Amer. J. clin. Nutr., 25:1261-66, 1972.

PICOU, D. \& TAYLOR-ROBERTS, T. The measurement of total protein synthesis and catabolism and nitrogen turnover in infants in different nutritional states and receiving different amounts of dietary protein. Clin. Sci., 36:283-96, 1969.

PICOU, D.; HALLIDAY, D.; GARROW, J.S. Total body protein, collagen and non collagen protein in infatile protein malnutrition. Clin. Sci., 30:345-51, 1966.

PORTA, E.A. \& HARTROFT, W.S. Protein deficiency and liver injury. Am. J. clin. Nutr., 23:447-61, 1970 .

PROCKOP, D.J. \& GUZMAN, N.A. Collagen diseases and the biosynthesis of collagen. Hosp. Pract., dec.: 61-68, 1977.

PROCKOP, D.J. \& KIVIRIKKO, K.I. Relationship of hydroxyproline excretion in urine to collagen metabolism; biochemistry and clinical applications. An. Int. Med., 66:1243-66, 1967.

RAMALINGASWAMI, V. Perspectives in protein malnutrition. Nature, Lond., 201:546-51, 1964.

REZENDE, T.A. Estudo do estômago do rato na carência protêica experimental. Alterações anátomo-patológicas. Teor de proteina: e atividade da $\beta$-glicuronidase no suco gástrico e na mucosa gástrica. Botucatu, 1973. 143p. (Tese - Doutoramento Faculdade de Ciências Médicas e Biológicas de Botucatu) 
RODWELL, V.W. Catabolism of amino acids. In: HARPER, H.A., ed. et alii. Review of physiological chemistry. 16.ed. Los Altos, Lange Medical Publications, 1977. Cap.22, p.356.

SCHIMKE, R.T. Adaptative characteristics of urea cycle enzymes in the rat. J. biol. chem., 237:459-68, 1962a.

SCHIMKE, R.T. Differential effects of fasting and protein-free diets on levels of urea cycle enzymes in rat liver. J. biol. chem. , 237:1921-4, 1962b.

SHAMBAUGH III, G.E. Urea biosynthesis. I. The urea cycle and relationship to the citric acid cycle. Am. J. clin. Nutr.' 30: $2083-7,1977$.

SHAMBAUGH III, G.E. Urea biosynthesis. II. Normal and abnormal regulation. Am. J. clin. Nutr., 31:126-33, 1978.

SJOERDSMA, A.; UDENFRIEND, S.; KEISER, H.; LE ROY, E.C. Hydroxyproline and collagen metabolism; clinical implications. Ann. int. Med., 63:672-94, 1965.

SMITH JR., J.G.; WEHR, R.F.; BADGER, N.L.; PIRKLE, D.E. Urinary hydroxyproline: source of increase after thermal burns. Proc. Soc. exp. Biol. Med., 145:897-900, 1974 .

SNODGRASS, P.J. \& LIN, R.C. Induction of urea cycle enzymes of rat liver by amino acids. J. Nutr., 111:586-601, 1981.

STANDERFER, S.B. \& HANDLER, P. Fatty liver induced by orotic acid feeding. Proc. Soc. exp. Biol. Med., 90:270-1, 1955.

TAYLOR, Y.M.; SCRIMSHAW, N.S.; YOUNG, V.R. The relationship between serum urea levels and dietary nitrogen utilization in young men. Brit. J. Nutr., 32:407-11, 1974.

UAUY, R.; WINTERER, J.C.; BILMAZES, C.; HAVERBERG, L.N.; SCRIMSHAW, N.S.; MUNRO, H.N.; YOUNG, V.R. The changing pattern of whole body protein metabolism in aging humans. J. Geront., 33: 663-71, 1978 . 
VASANTHA, L.; SRIKANTIA, S.G.; GOPALAN, C. Biochemical changes in the skin in kwashiorkor. Am. J. clin. Nutr., 23:78-82, 1970.

VUUST, J. \& PIEZ, K.A. A kinetic study of collagen biosynthesis. J. biol. chem., 247:856-62, 1972 .

WALLIN, J.D. The kidney and the urine. In: HARPER, H.A., ed. et alii. Review of physiological chemistry. 16.ed. Los Altos, Lange Medical Publication, 1977. cap.35, p.609-32.

WATERLOW, J.C. Evolution of kwashiorkor and marasmus. Lancet, $21: 712,1974$.

WATERLOW, J.C. Use of creatine metabolism in relation to homeostasis. In: GREENE, H.L., ed. et alii. Clinical nutrition update; amino acids. Chicago, American Medical Association, 1977. part. 2, p.108-111.

WATERLOW, J.C. \& ALLEYNE, G.A.O. Protein malnutrition in children: advances in knowledge in the last ten years. Adv. Protein chem., 25:117-241, 1971.

WATERLOW, J.C. \& STEPHEN, J.M.L. Adaptation of the rat to a low-protein diet: the effect of a reduced protein intake on the pattern of incorporation of $\mathrm{L}-\left[{ }^{14} \mathrm{C}\right]$ lysine. Brit. J. Nutr., 20:461-84, 1966.

WEISS, P.H. \& KLEIN, L. The quantitative relationship of urinary peptide hydroxyproline excretion to collagen degradation. J. clin. Invest., 48:1-10, 1969.

WHITEHEAD, R.G. Biochemical testes for assessing subclinical nutritional deficiency. Clin. Pediat., 6 6 :516-8, 1967.

WIDDOWSON, E.M. Changes in the extracellular compartment of muscle and skin during normal and retarded development. Biblthca "Nutr. Dieta", 13:60-8, 1969. 
82.

WIDDOWSON, E.M. \& WHITEHEAD, R.G. Plasma amino-acid ratios and urinary hydroxyproline excretions in rats deficient in protein and calories. Nature, Lond., 212:683-6, 1966.

WILEY, E.R.; MCCLAIN, P.E.; BEECHER, G.R. Influence of dietary protein on collagen synthesis and cross-linking. Fedn. Proc. Fedn. Am. Soc. exp. Biol., 32:922, 1973.

WINICK, M. \& NOBLE, A. Cellular response in rats during malnutrition at various ages. J.Nutx., 89:300-6, 1966.

WOLF, G.; HECK, W.W.; LEAK, J.C. The metabolism of hydroxyproline $-\alpha-{ }^{14} \mathrm{C}$ in the intact rat; radivactivity in amino acids from proteins. J. biol. chem., 223:95-105, 1956.

ZIFF, M.; KIBRICK, A.; DRESNER, E.; GRIBERTZ, H.J. Excretion of hydroxyproline in patients with rheumatic and non-rheumatic diseases. J. clin. Invest., 35:579-87, 1956. 
83.

$\underline{A} \underline{P} \underline{\mathrm{N}} \underline{\mathrm{D}} \underline{\mathrm{I}} \underline{\mathrm{C}}$ 
TABELA 14 - Peso semana1 (em gramas) dos animais dos grupos controles, duran te o período experimental.

\begin{tabular}{|c|c|c|c|c|c|c|c|c|c|}
\hline \multirow{2}{*}{ GRUPOS } & & \multirow{2}{*}{$\begin{array}{l}\text { PESO } \\
\text { INICIAL }\end{array}$} & \multicolumn{2}{|r|}{$\mathrm{T}$} & $\mathrm{E}$ & $P$ & \multicolumn{2}{|c|}{ (dias) } & \multirow[b]{2}{*}{42} \\
\hline & & & 6 & $12:$ & 18 & 24 & 30 & 36 & \\
\hline $\mathrm{J}$ & & 84,0 & 117,0 & 158,0 & 193,0 & 223,0 & 240,0 & 252,0 & 254,0 \\
\hline 0 & & 78,0 & 108,0 & 139,0 & 168,0 & 201,0 & 222,0 & 238,0 & 264,0 \\
\hline $\begin{array}{l}\text { V } \\
E\end{array}$ & & 79,0 & 109,0 & 140,0 & 163,0 & 189,0 & 210,0 & 226,0 & 249,0 \\
\hline \multirow[t]{5}{*}{ M } & & 83,0 & 106,0 & 132,0 & 150,0 & 178,0 & 206,0 & 224,0 & 246,0 \\
\hline & & 86,0 & 126,0 & 166,0 & 201,0 & 234,0 & 253,0 & 273,0 & 280,0 \\
\hline & $\bar{x}$ & 82,0 & 113,0 & 147,0 & 175,0 & 205,0 & 226,0 & 243,0 & 259,0 \\
\hline & S & 3,7 & 8,3 & 14,3 & 21,3 & 23,2 & 20,0 & 20,3 & 13,8 \\
\hline & $\mathrm{CV}$ & 4,5 & 7,3 & 9,5 & 12,2 & 11,3 & 8,8 & 8,4 & 5,3 \\
\hline
\end{tabular}

\begin{tabular}{|c|c|c|c|c|c|c|c|c|}
\hline 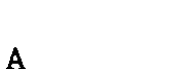 & 236,0 & 267,0 & 279,0 & 290,0 & 300,0 & 308,0 & 315,0 & 327,0 \\
\hline D & 229,0 & 244,0 & 249,0 & 261,0 & 256,0 & 257,0 & 256,0 & 262,0 \\
\hline U & 242,0 & 265,0 & 268,0 & 279,0 & 290,0 & 303,0 & 308,0 & 321,0 \\
\hline[ & 238,0 & 264,0 & 281,0 & 294,0 & 303,0 & 314,0 & 321,0 & 330,0 \\
\hline 0 & 215,0 & 237,0 & 245,0 & 252,0 & 266,0 & 274,0 & 280,0 & 289,0 \\
\hline $\bar{x}$ & 232,0 & 255,0 & 264,0 & 275,0 & 283,0 & 291,0 & 296,0 & 306,0 \\
\hline$S$ & 10,6 & 13,9 & 16,7 & 18,2 & 21,0 & 24,5 & 27,3 & 29,4 \\
\hline $\mathrm{CV}$ & 4,6 & 5,5 & 6,3 & 6,6 & 7,4 & 8,4 & 9,2 & 9,6 \\
\hline
\end{tabular}

\begin{tabular}{|c|c|c|c|c|c|c|c|c|}
\hline$v$ & 458,0 & 460,0 & 475,0 & 468,0 & 466,0 & 461,0 & 463,0 & 467,0 \\
\hline $\mathrm{E}$ & 382,0 & 392,0 & 401,0 & 393,0 & 394,0 & 371,0 & 378,0 & 484,0 \\
\hline $\begin{array}{l}\mathrm{L} \\
\mathrm{H}\end{array}$ & 464,0 & 475,0 & 483,0 & 486,0 & 480,0 & 484,0 & 483,0 & 478,0 \\
\hline 0 & 493,0 & 482,0 & 515,0 & 524,0 & 520,0 & 502,0 & 522,0 & 527,0 \\
\hline & 473,0 & 483,0 & 505,0 & 505,0 & 516,0 & 508,0 & 513,0 & 520,0 \\
\hline $\bar{x}$ & 454,0 & 458,0 & 476,0 & 475,0 & 475,0 & 465,0 & 472,0 & 495,0 \\
\hline 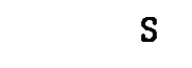 & 42,3 & 38,2 & 44,8 & 50,5 & 50,9 & 55,7 & 57,5 & 26,7 \\
\hline $\mathrm{CV}$ & 9,3 & 8,3 & 9,4 & 10,6 & 10,7 & 12,0 & 12,2 & 5,4 \\
\hline
\end{tabular}


85.

TABELA 15 - Peso semanal (em gramas) dos animais dos grupos hipoprotéicos du rante o período experimental.

\begin{tabular}{|c|c|c|c|c|c|c|c|c|c|}
\hline \multirow{2}{*}{ GRUPOS } & \multirow{2}{*}{\multicolumn{2}{|c|}{$\begin{array}{l}\text { PESO } \\
\text { INICIAL }\end{array}$}} & \multicolumn{2}{|r|}{$T$} & E $\quad$ M & $\begin{array}{ll}P & 0\end{array}$ & \multicolumn{2}{|c|}{ (dias) } & \multirow[b]{2}{*}{42} \\
\hline & & & 6 & 12 & 18 & 24 & 30 & 36 & \\
\hline \multirow{8}{*}{$\begin{array}{l}\mathrm{J} \\
0 \\
\mathrm{~V} \\
\mathrm{E} \\
\mathrm{M}\end{array}$} & & 81,0 & 74,0 & 68,0 & 65,0 & 62,0 & 61,0 & 58,0 & 51,0 \\
\hline & & 85,0 & 75,0 & 76,0 & 69,0 & 63,0 & 69,0 & 68,0 & 67,0 \\
\hline & & 80,0 & 75,0 & 69,0 & 66,0 & 65,0 & 65,0 & 63,0 & 63,0 \\
\hline & & 77,0 & 75,0 & 69,0 & 65,0 & 62,0 & 63,0 & 58,0 & 58,0 \\
\hline & & 84,0 & 83,0 & 78,0 & 73,0 & 73,0 & 75,0 & 69,0 & 67,0 \\
\hline & $\bar{x}$ & 81,0 & 76,0 & 72,0 & 68,0 & 65,0 & 67,0 & 63,0 & 61,0 \\
\hline & $\mathrm{s}$ & 3,2 & 3,7 & 4,6 & 3,4 & 4,6 & 5,5 & 5,3 & 6,8 \\
\hline & $\mathrm{CV}$ & 4,0 & 4,9 & 6,4 & 5,1 & 7,1 & 8,3 & 8,4 & 11,1 \\
\hline
\end{tabular}

\begin{tabular}{|c|c|c|c|c|c|c|c|c|c|}
\hline$A$ & & 232,0 & 228,0 & 218,0 & 216,0 & 214,0 & 218,0 & 215,0 & 214,0 \\
\hline D & & 224,0 & 216,0 & 209,0 & 208,0 & 201,0 & 211,0 & 211,0 & 209,0 \\
\hline $\mathrm{U}$ & & 227,0 & 214,0 & 203,0 & 203,0 & 199,0 & 202,0 & 199,0 & 199,0 \\
\hline & & 241,0 & 237,0 & 226,0 & 221,0 & 218,0 & 220,0 & 222,0 & 225,0 \\
\hline 0 & & 240,0 & 232,0 & 223,0 & 225,0 & 229,0 & 231,0 & 232,0 & 236,0 \\
\hline & $\bar{x}$ & 233,0 & 225,0 & 216,0 & 215,0 & 212,0 & 216,0 & 216,0 & 217,0 \\
\hline & $S$ & 7,6 & 10,0 & 9,6 & 9,1 & 12,4 & 10,8 & 12,3 & 14,3 \\
\hline & $\mathrm{CV}$ & 3,3 & 4,4 & 4,5 & 4,2 & 5,9 & 5,0 & 5,7 & 6,6 \\
\hline
\end{tabular}

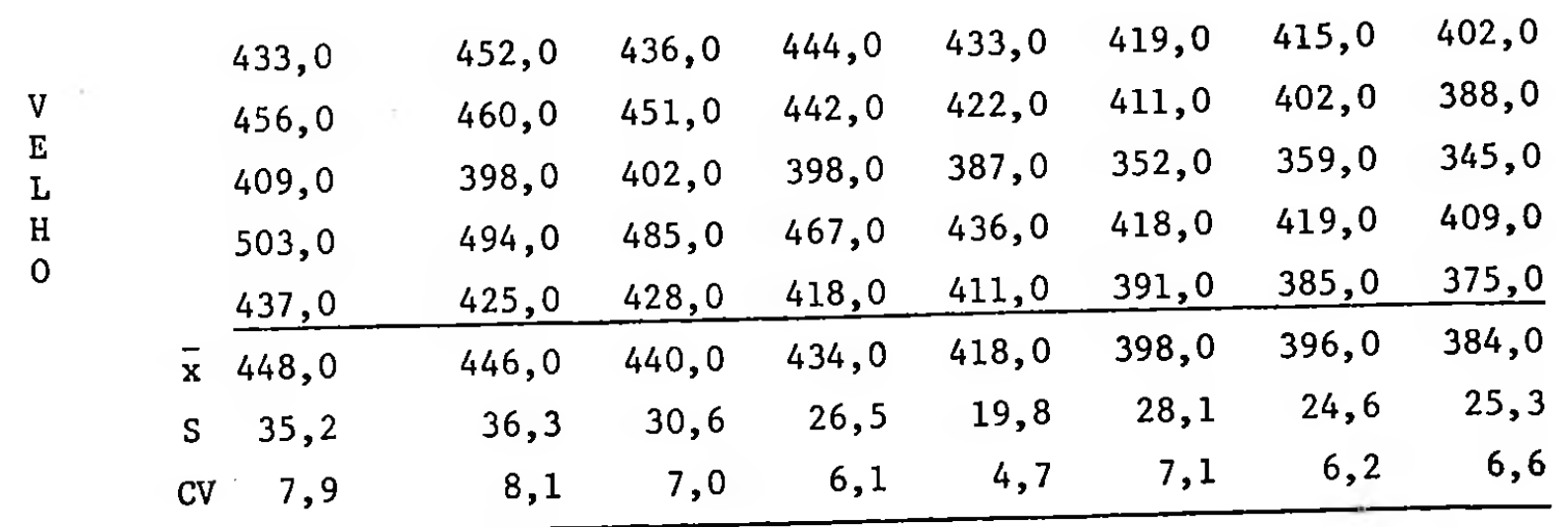




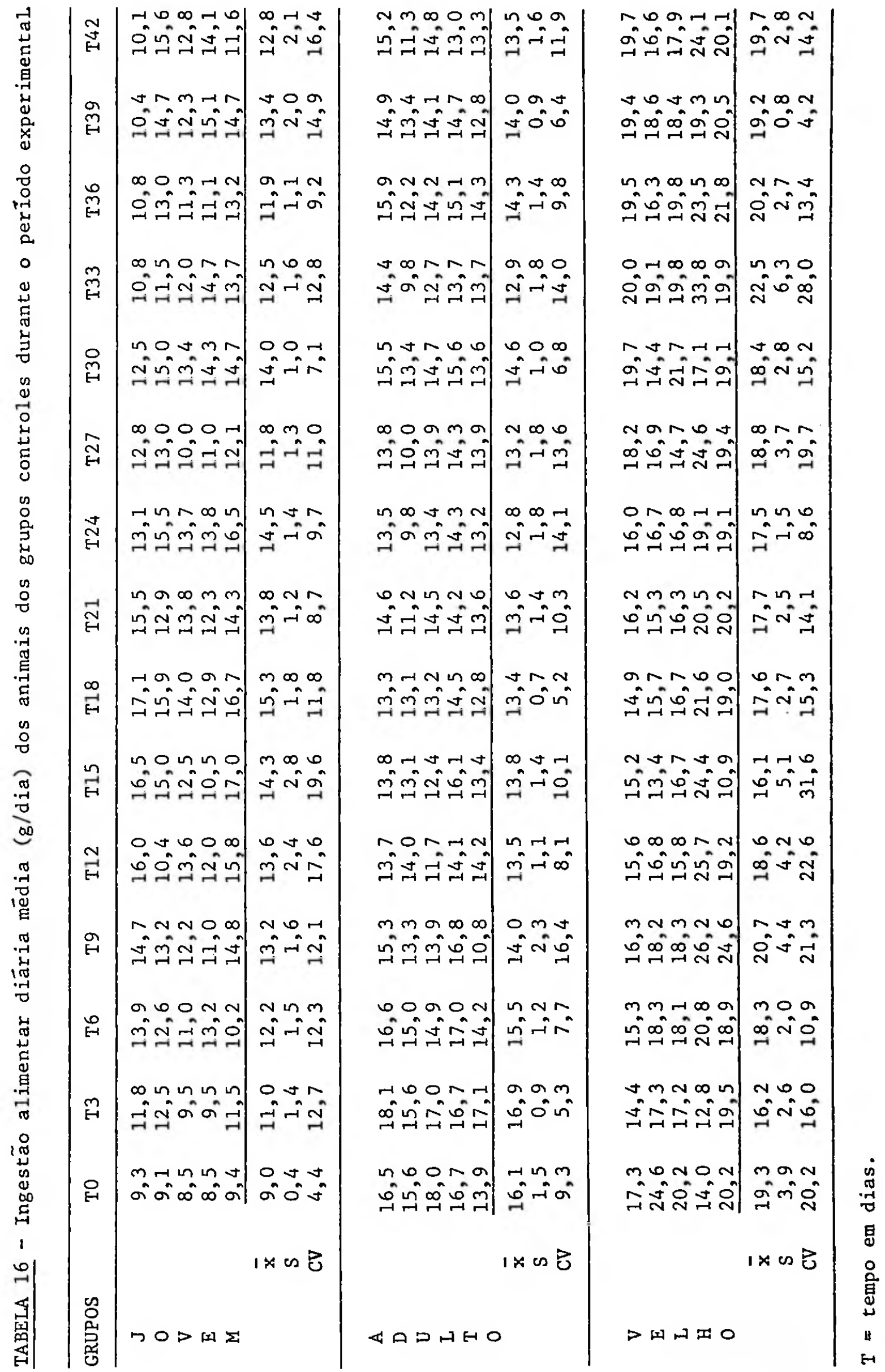




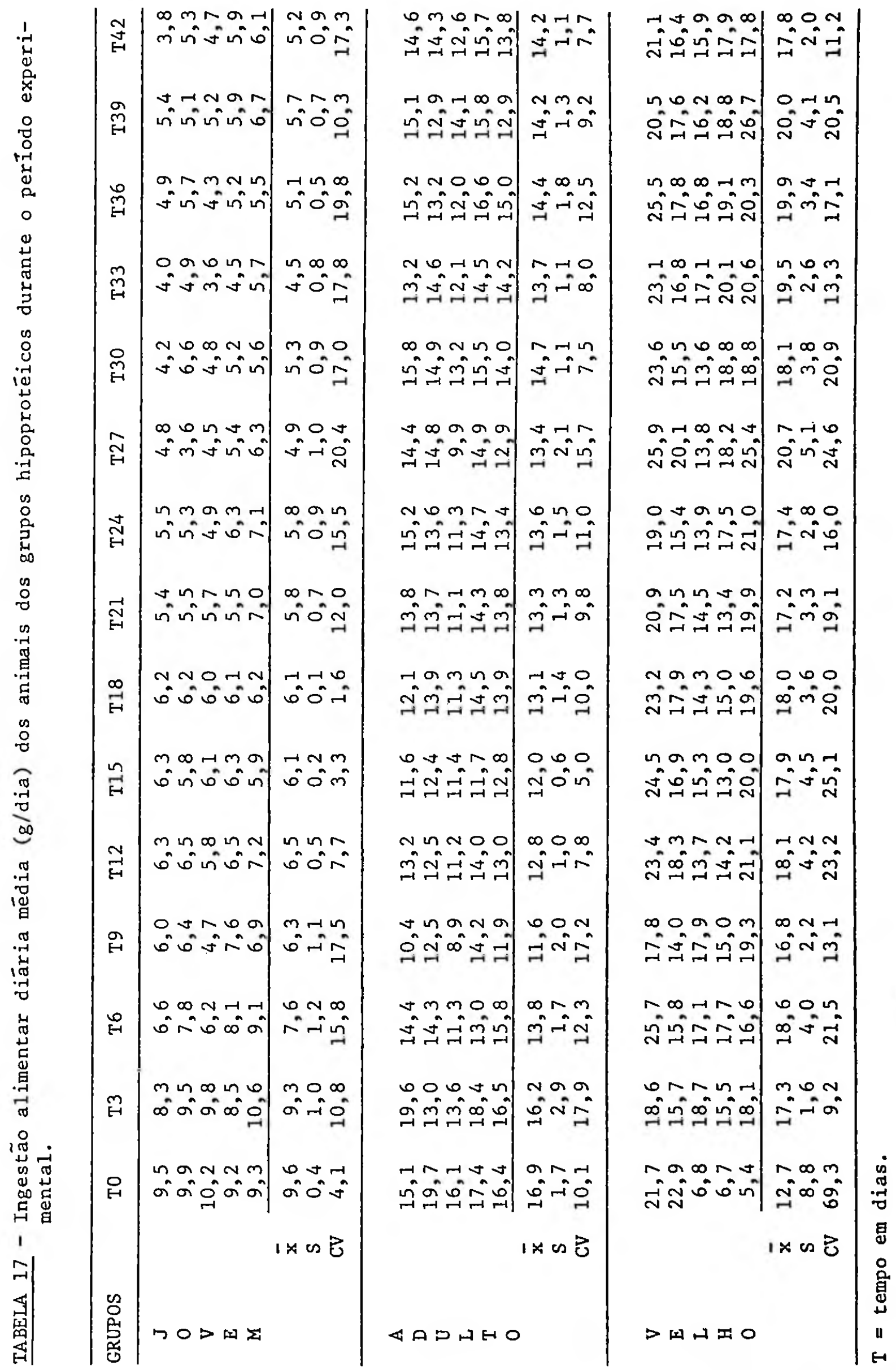




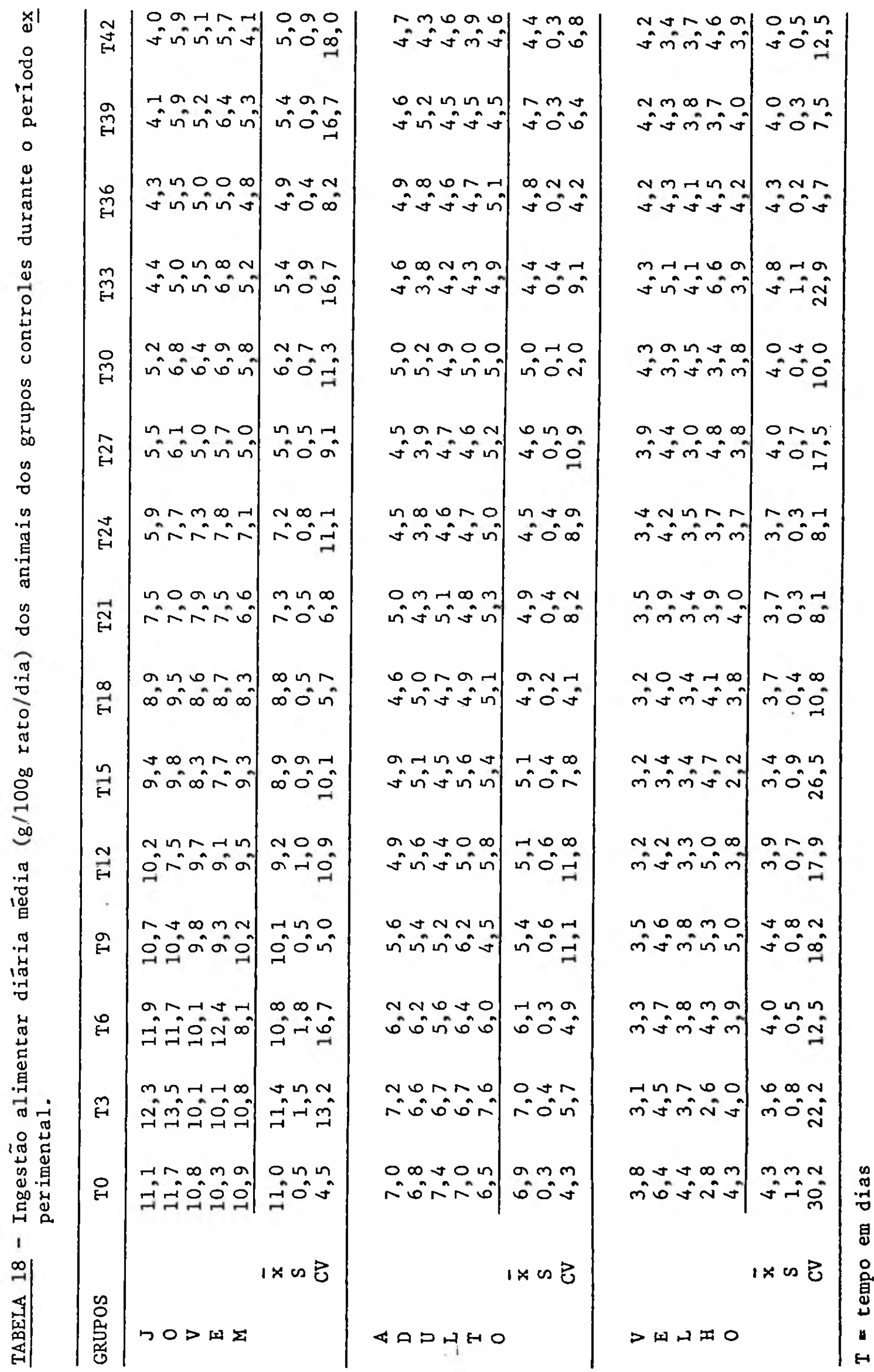




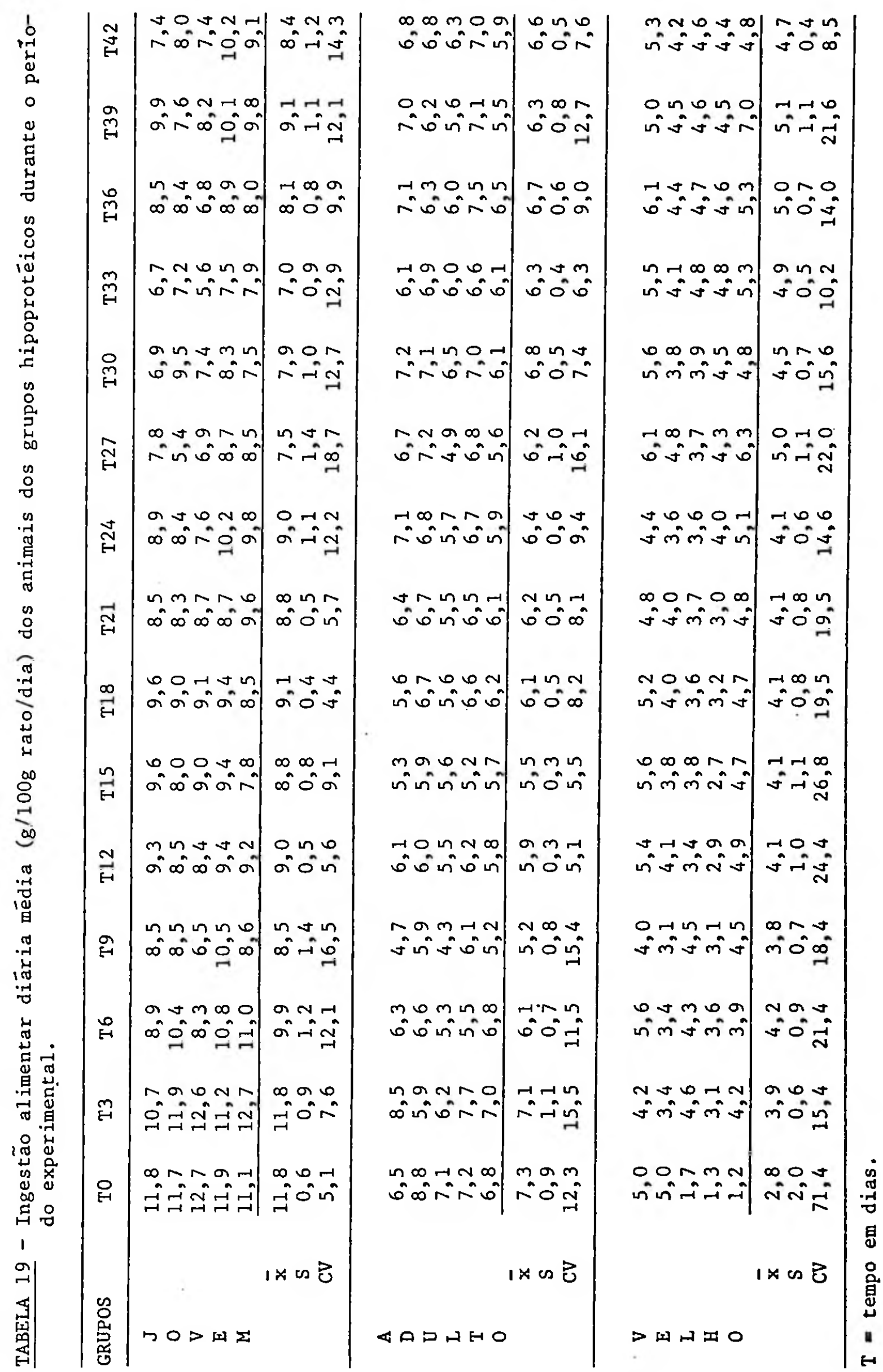




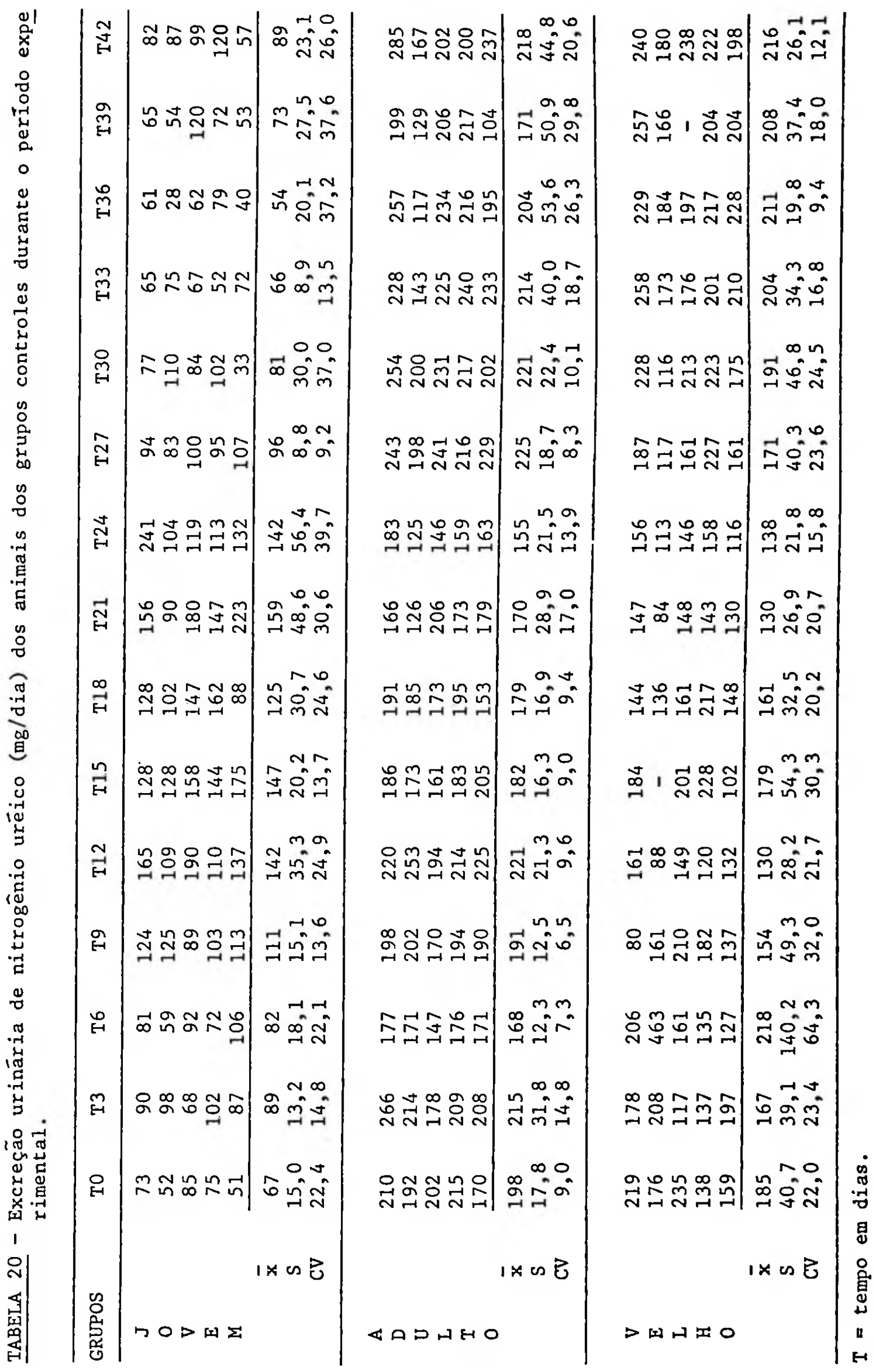




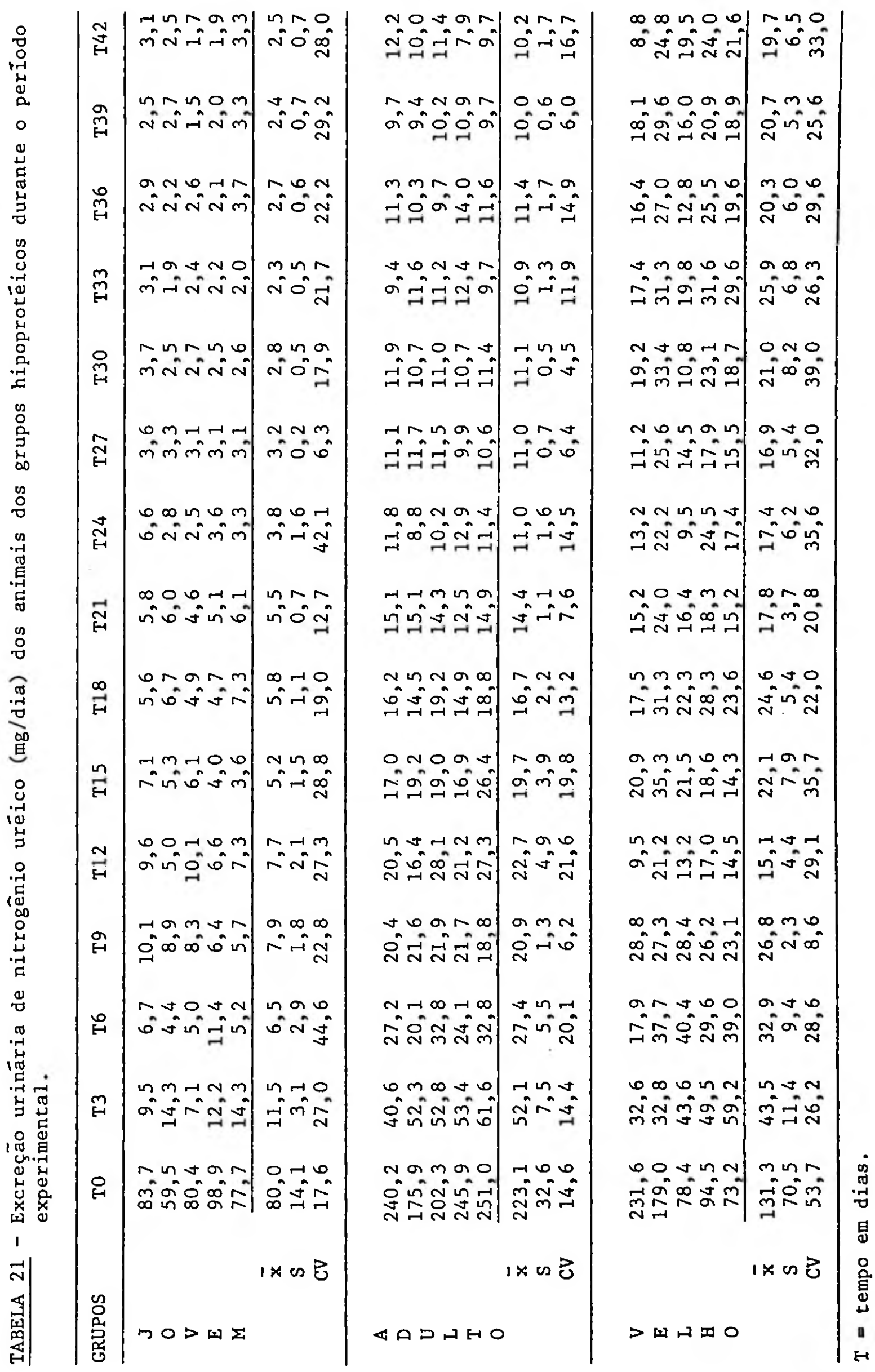




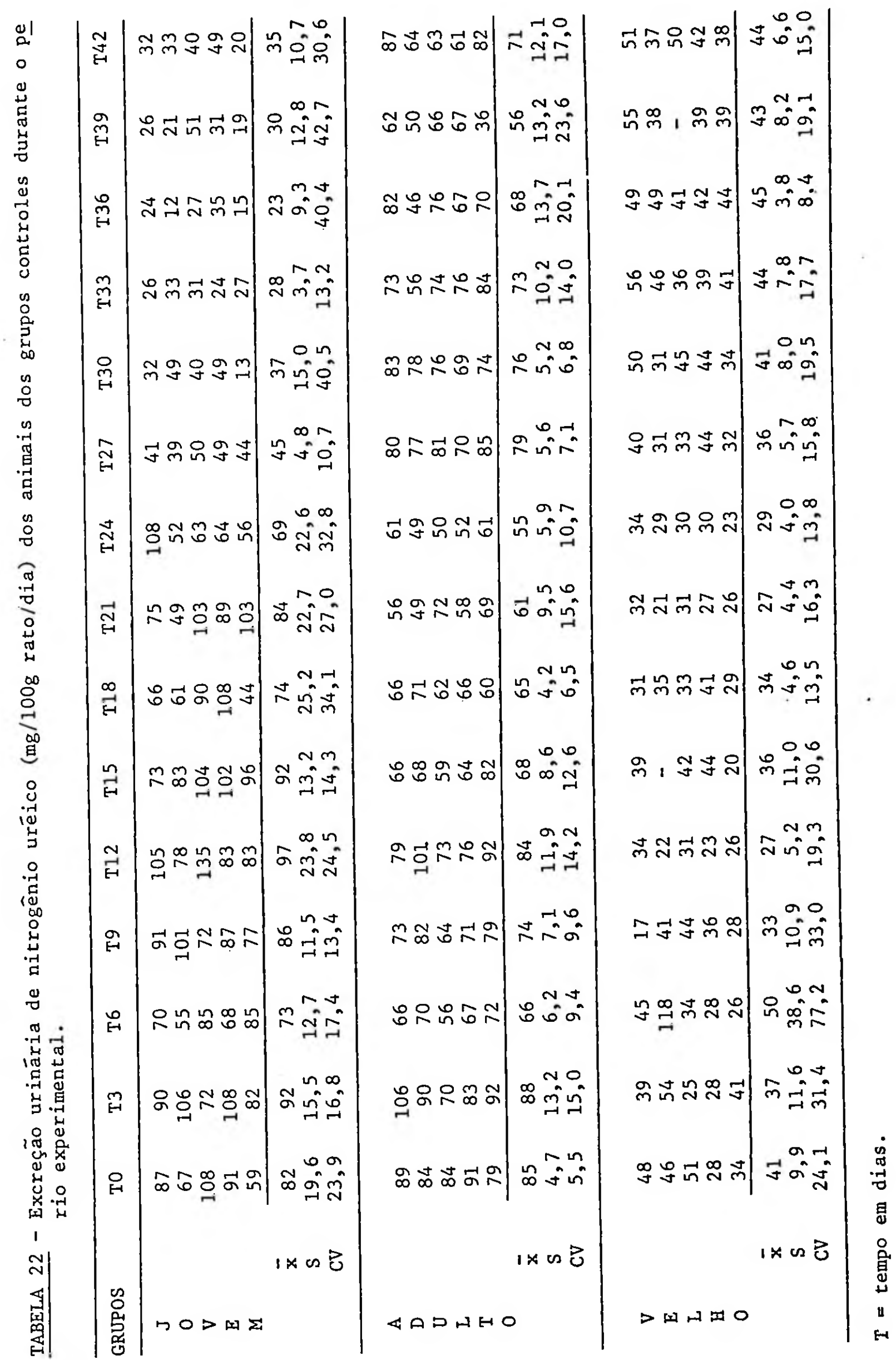




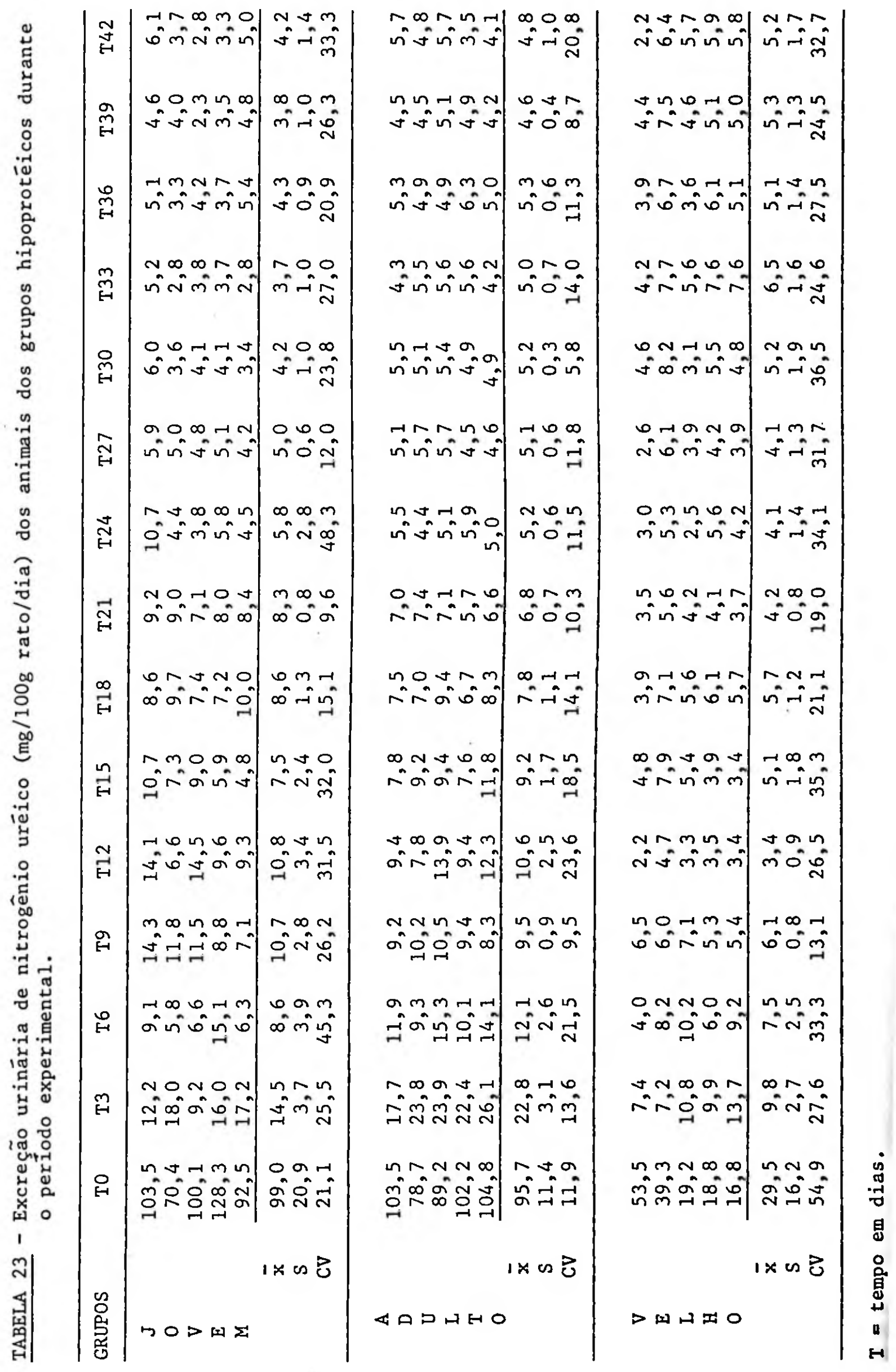


TABELA 24 - Concentração plasmática de proteínas totais e frações (albumina e globulina), em $\mathrm{g} \%$, dos animais dos grupos controles e hipoprotéicos após 42 dias de perỉodo experimental.

\begin{tabular}{|c|c|c|c|c|c|c|c|}
\hline \multirow{2}{*}{ PROTEINAS } & \multirow{2}{*}{$\begin{array}{l}\text { RATO } \\
\text { No }\end{array}$} & \multicolumn{2}{|c|}{ GRUPO JOVEM } & \multicolumn{2}{|c|}{ GRUPO ADULTO } & \multicolumn{2}{|c|}{ GRUPO VELHO } \\
\hline & & $\begin{array}{l}\text { CON- } \\
\text { TROLE }\end{array}$ & $\begin{array}{l}\text { HIPO- } \\
\text { PROTEICO }\end{array}$ & $\begin{array}{l}\text { CON- } \\
\text { TROLE }\end{array}$ & $\begin{array}{l}\text { HIPO- } \\
\text { PROTEICO }\end{array}$ & $\begin{array}{l}\text { CON- } \\
\text { TROLE }\end{array}$ & $\begin{array}{l}\text { HIPO- } \\
\text { PROTEICO }\end{array}$ \\
\hline & 1 & 6,8 & 5,0 & 7,5 & 6,1 & 7,7 & 6,5 \\
\hline$T$ & 2 & 7,0 & 4,7 & 7,3 & 5,8 & 7,7 & 6,0 \\
\hline 0 & 3 & 6,8 & 4,4 & 6,7 & 6,2 & 6,7 & 6,9 \\
\hline $\mathrm{T}$ & 4 & 6,7 & 4,7 & 6,3 & 5,2 & 7,5 & 6,2 \\
\hline A & 5 & 6,7 & 4,5 & 7,0 & 6,2 & 5,9 & 5,8 \\
\hline I & $\overline{\mathbf{x}}$ & 6,8 & 4,7 & 7,0 & 5,9 & 7,1 & 6,3 \\
\hline$S$ & sd & 0,12 & 0,23 & 0,48 & 0,42 & 0,79 & 0,43 \\
\hline
\end{tabular}

\begin{tabular}{|c|c|c|c|c|c|c|c|}
\hline & 1 & 4,2 & 2,5 & 4,2 & 3,1 & 4,1 & 2,9 \\
\hline $\begin{array}{l}\text { A } \\
\text { L }\end{array}$ & 2 & 4,1 & 2,6 & 3,6 & 3,0 & 3,5 & 2,5 \\
\hline B & 3 & 3,9 & 2,2 & 3,8 & 3,0 & 3,4 & 3,1 \\
\hline $\begin{array}{l}\text { U } \\
\text { M }\end{array}$ & 4 & 3,7 & 1,6 & 3,8 & 3,1 & 4,2 & 2,8 \\
\hline I & 5 & 4,1 & 2,0 & 3,8 & 3,0 & 3,2 & 3,0 \\
\hline A & $\bar{x}$ & 4,0 & 2,2 & 3,9 & 3,0 & 3,7 & 2,9 \\
\hline$S$ & sd & 0,20 & 0,40 & 0,22 & 0,05 & 0,44 & 0,23 \\
\hline $\mathrm{G}$ & 1 & 2,6 & 2,5 & 3,3 & 3,0 & 3,6 & 3,6 \\
\hline $\begin{array}{l}\mathrm{L} \\
0\end{array}$ & 2 & 2,9 & 2,1 & 3,7 & 2,8 & 4,2 & 3,5 \\
\hline B & 3 & 2,9 & 2,2 & 2,9 & 3,2 & 3,3 & 3,8 \\
\hline $\begin{array}{l}\text { U } \\
\text { L }\end{array}$ & 4 & 3,0 & 3,1 & 2,5 & 2,1 & 3,3 & 3,4 \\
\hline I & 5 & 2,6 & 2,5 & 3,2 & 3,2 & 2,7 & 2,8 \\
\hline $\begin{array}{l}\mathrm{N} \\
\mathrm{A}\end{array}$ & $\overline{\mathbf{x}}$ & 2,8 & 2,5 & 3,1 & 2,9 & 3,4 & 3,4 \\
\hline$S$ & sd & 0,19 & 0,39 & 0,45 & 0,46 & 0,54 & 0,38 \\
\hline
\end{tabular}




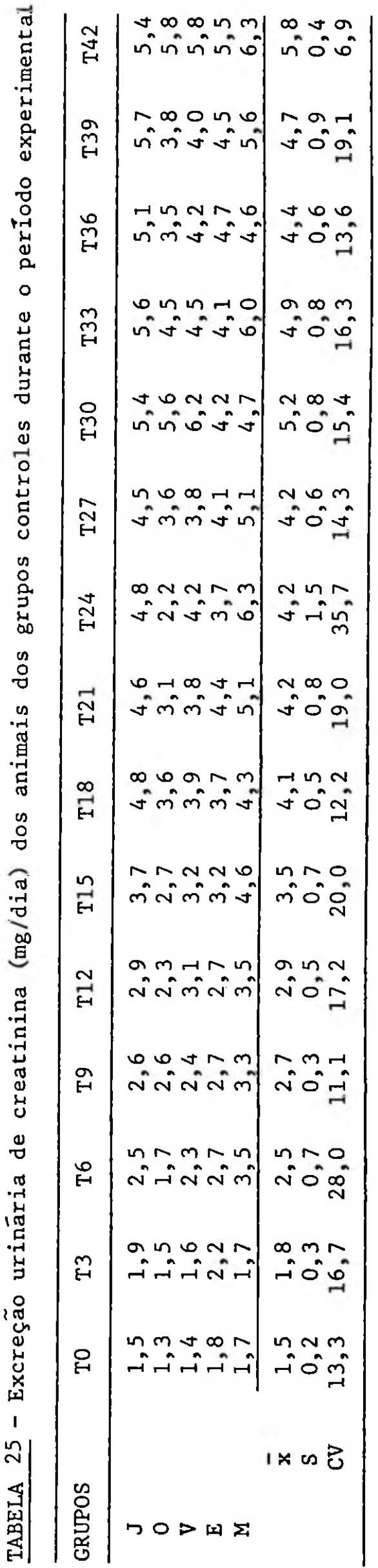

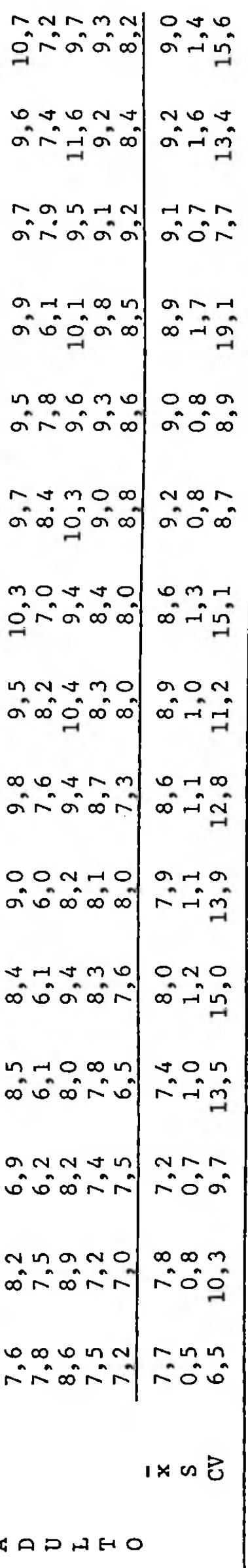

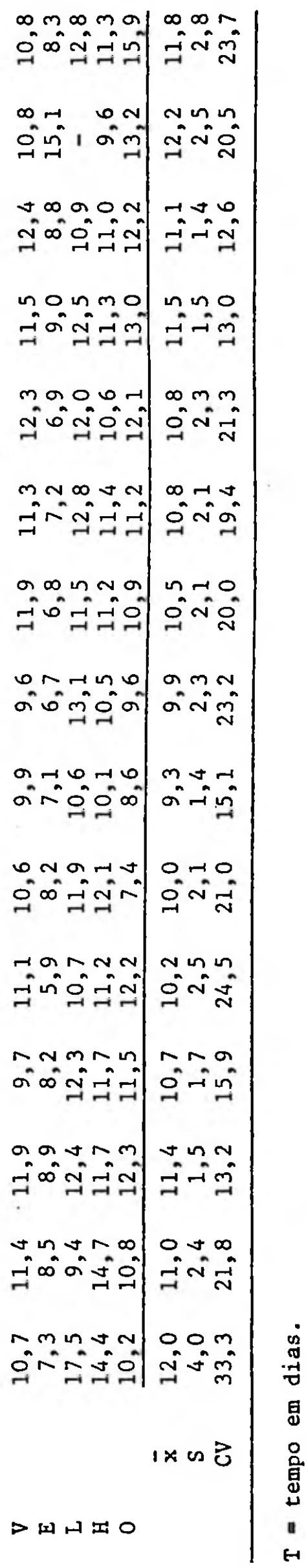




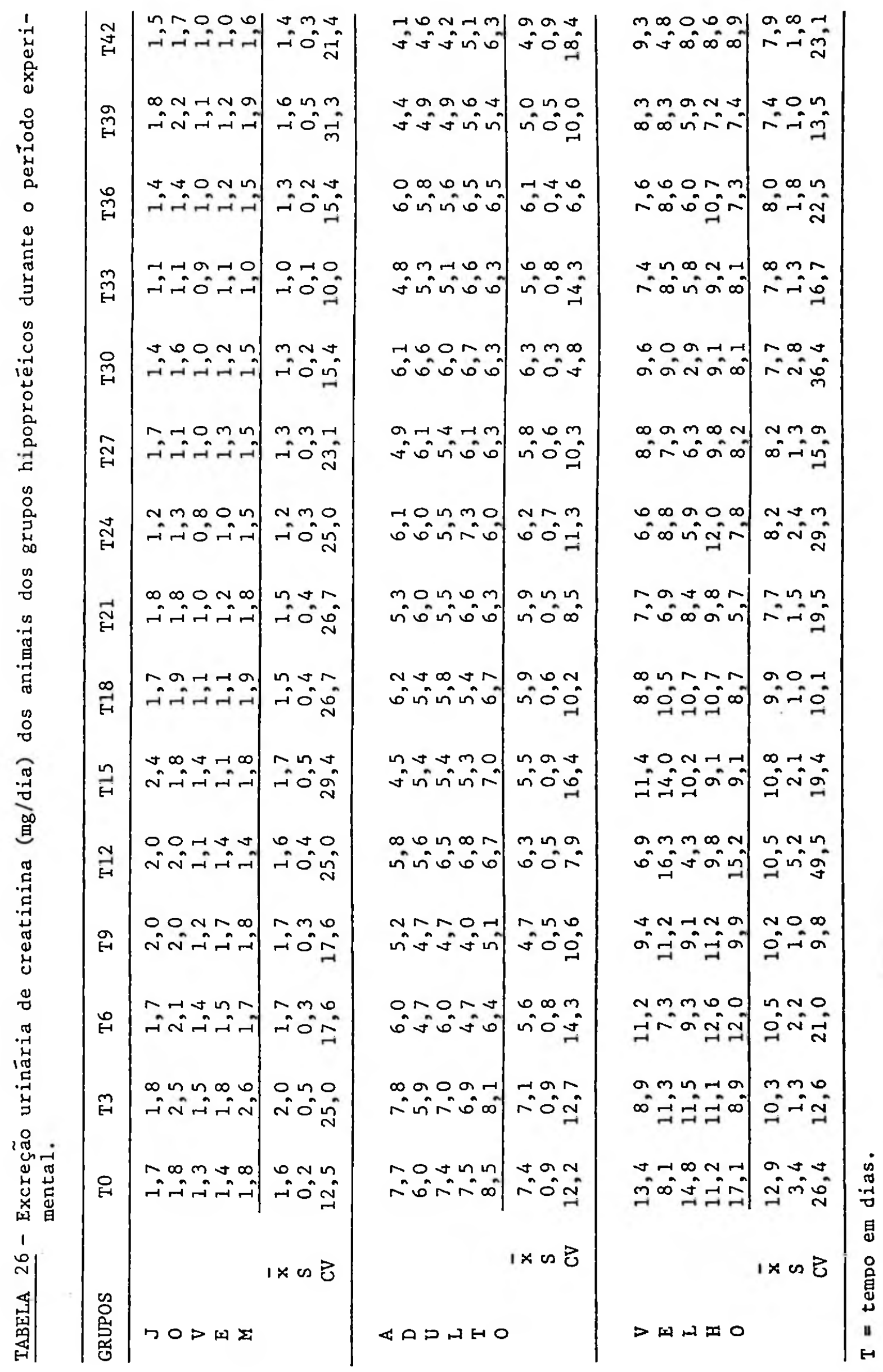




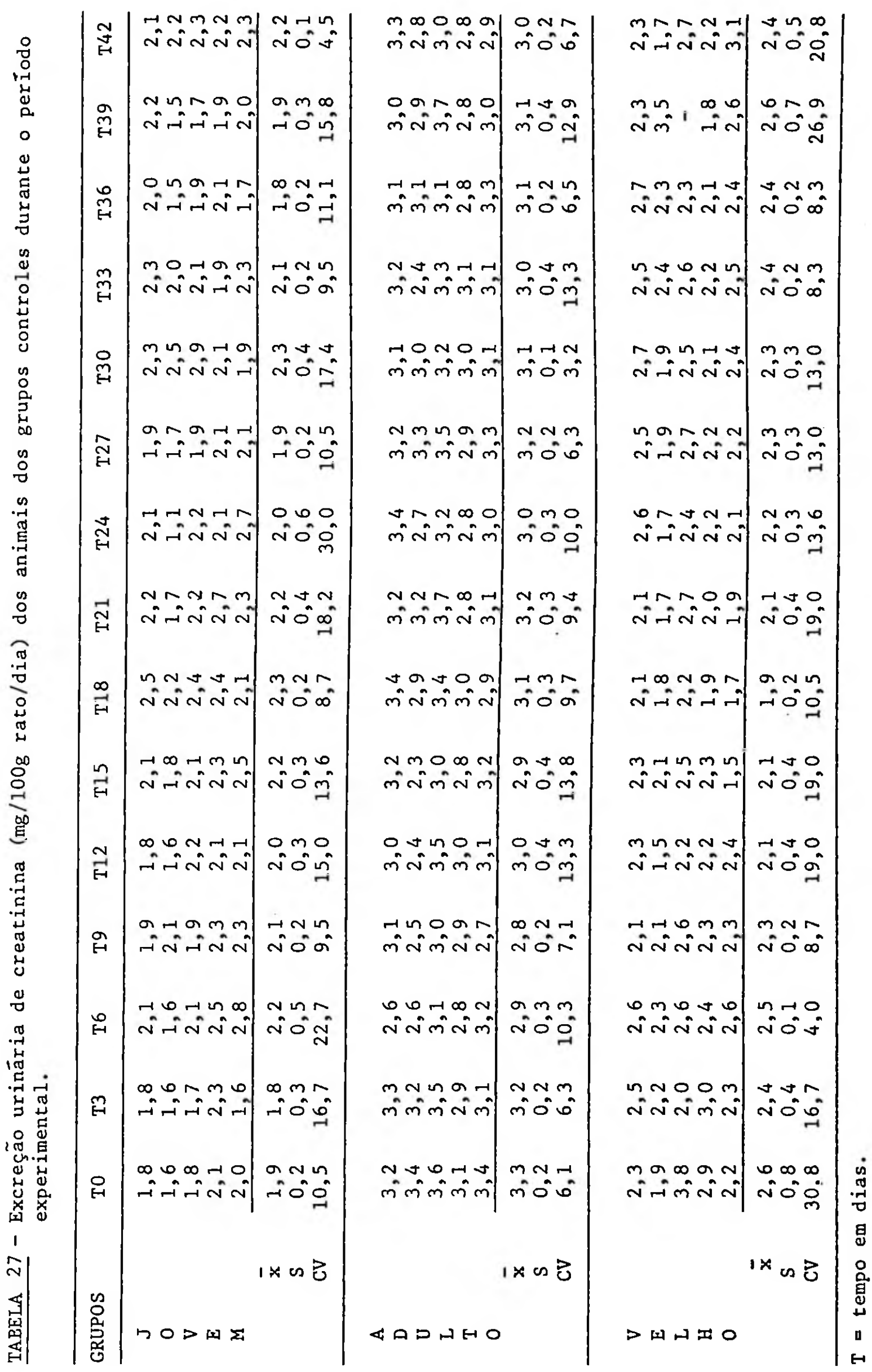




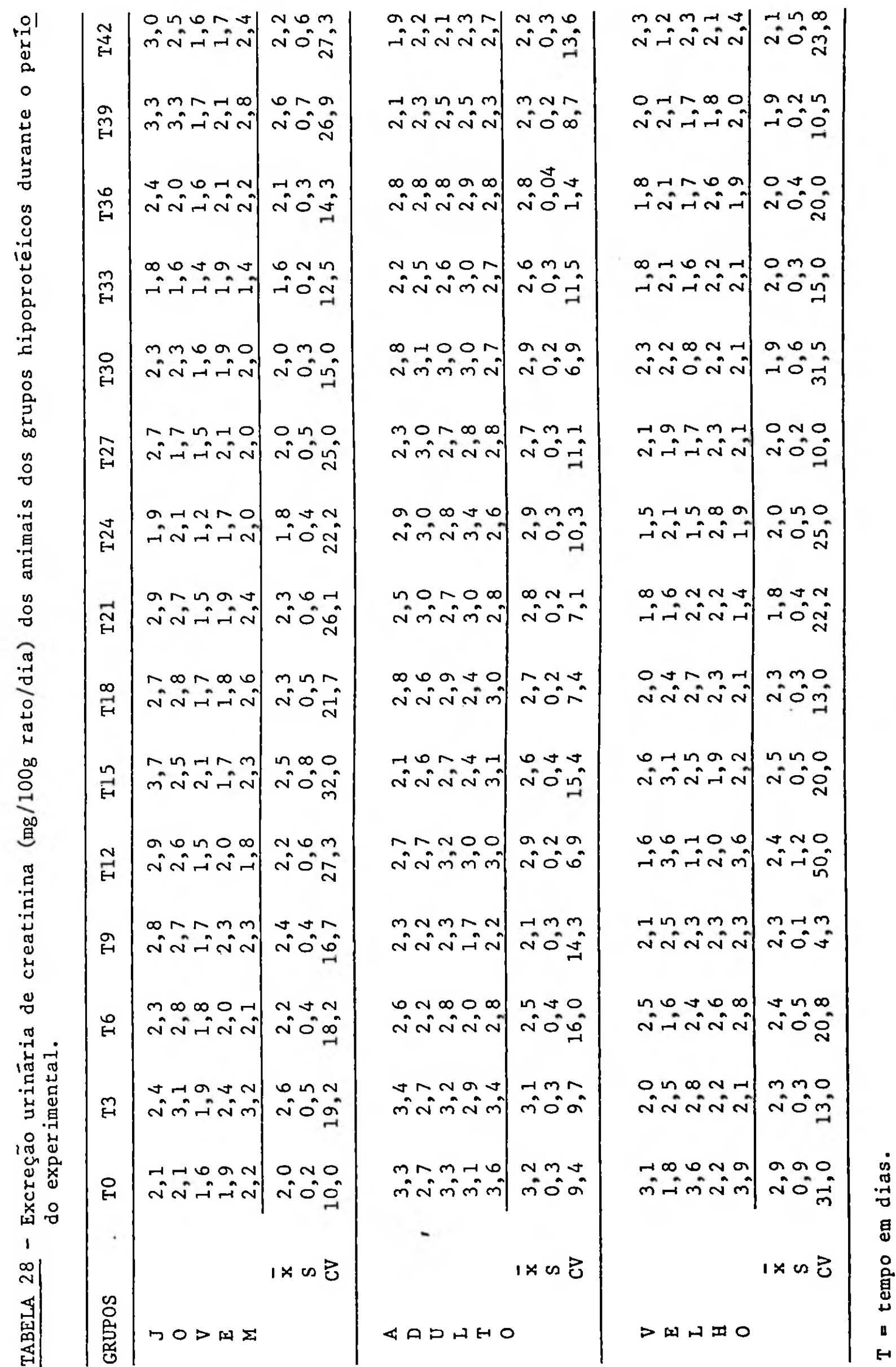




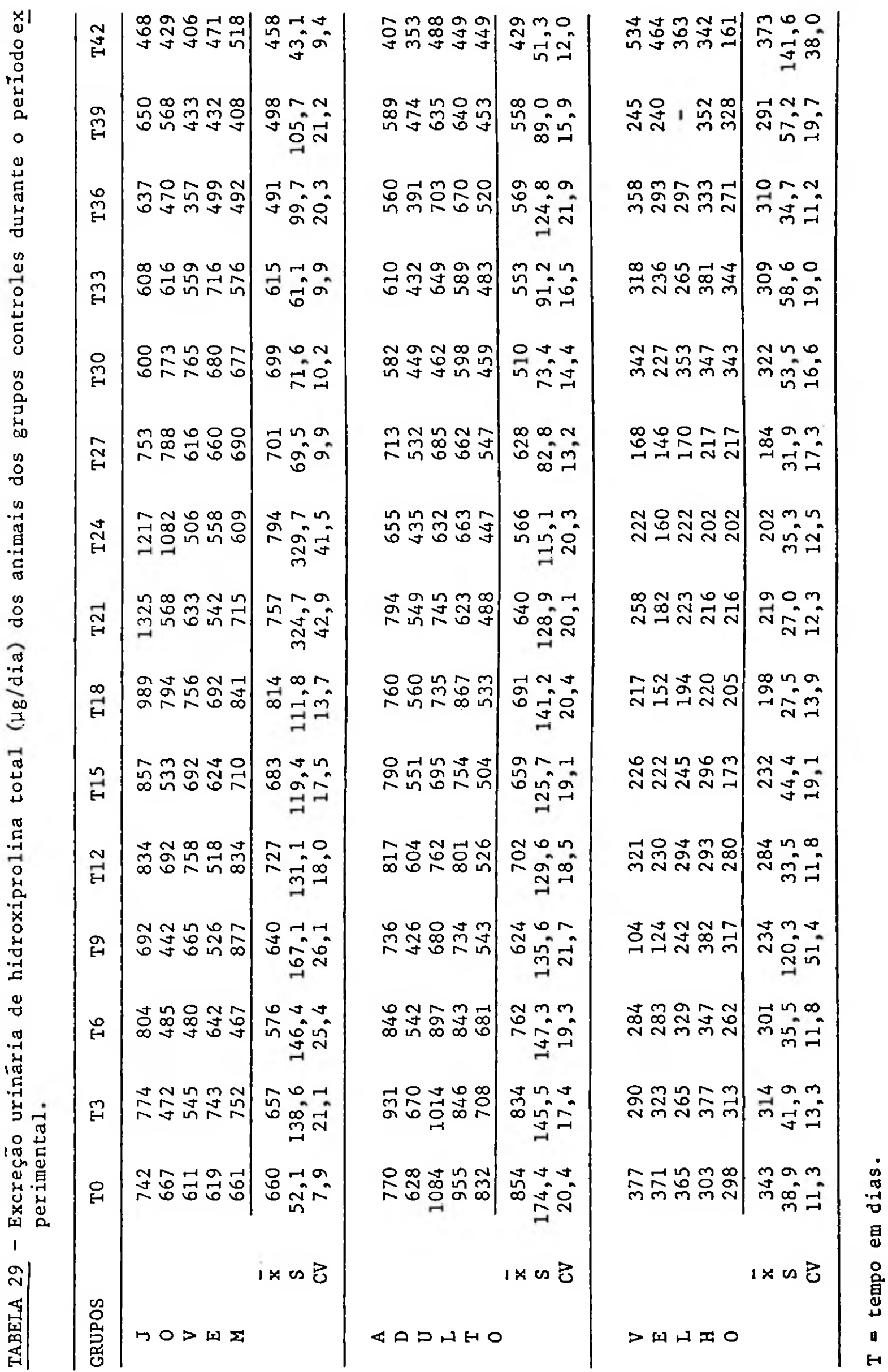




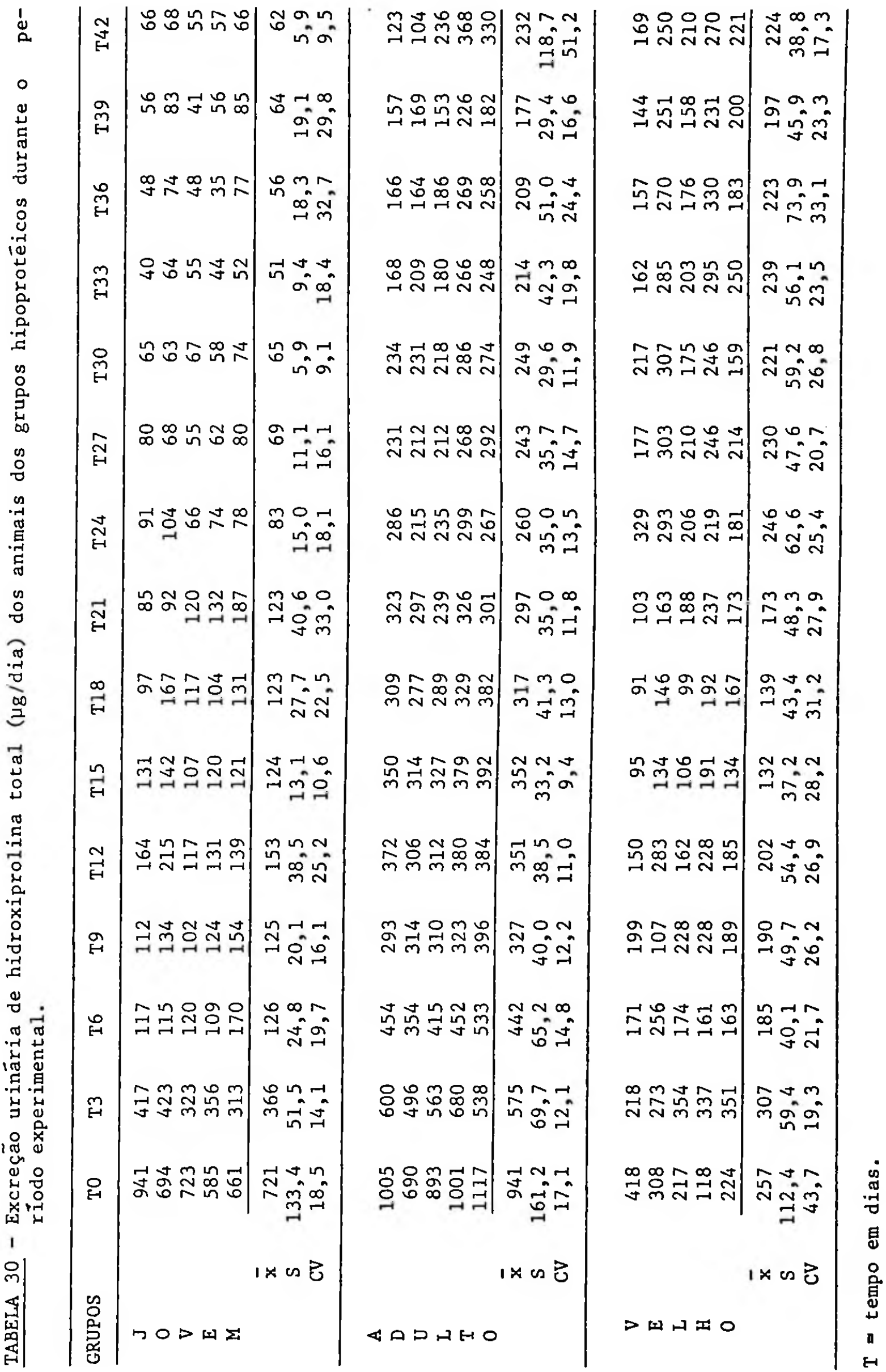




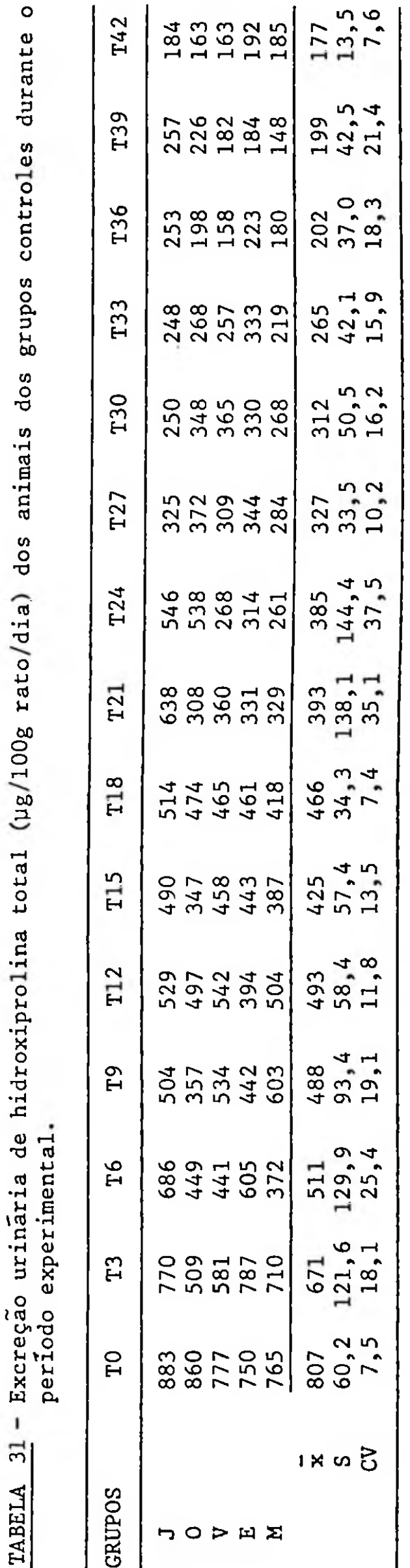

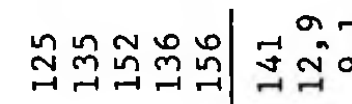

๘ Nता $\rightarrow=1$

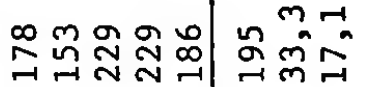

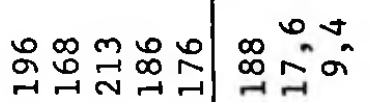

ฌำตั่

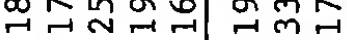

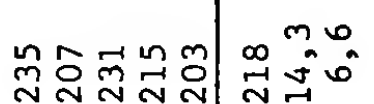

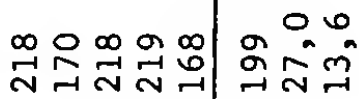

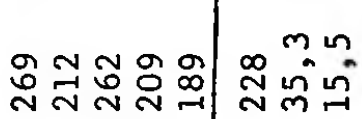

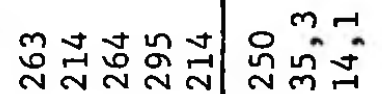

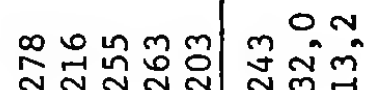

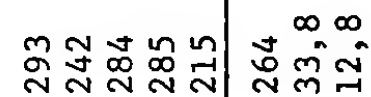

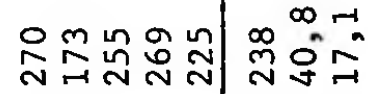

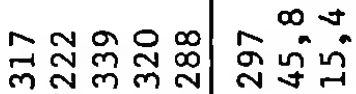

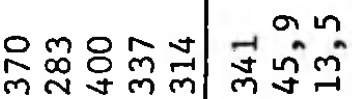

तิ

$1 x \cos$

凹ロ カHO

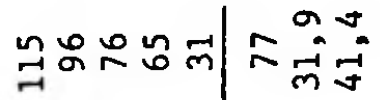

กำ

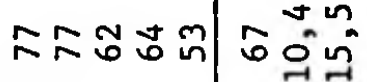

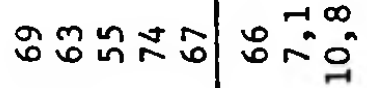

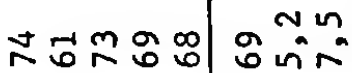

mั

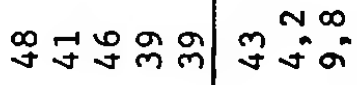

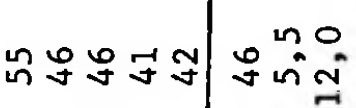

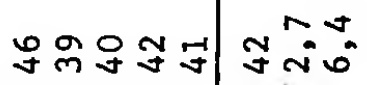

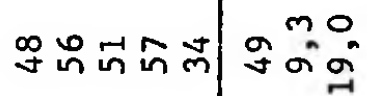

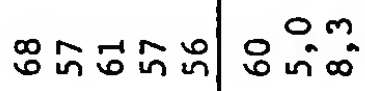

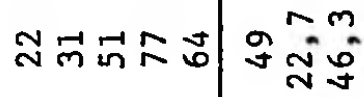

ชูก์ำง

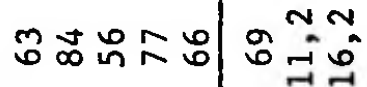

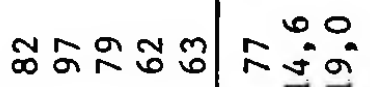

$1 x \cos$

>ツル田 


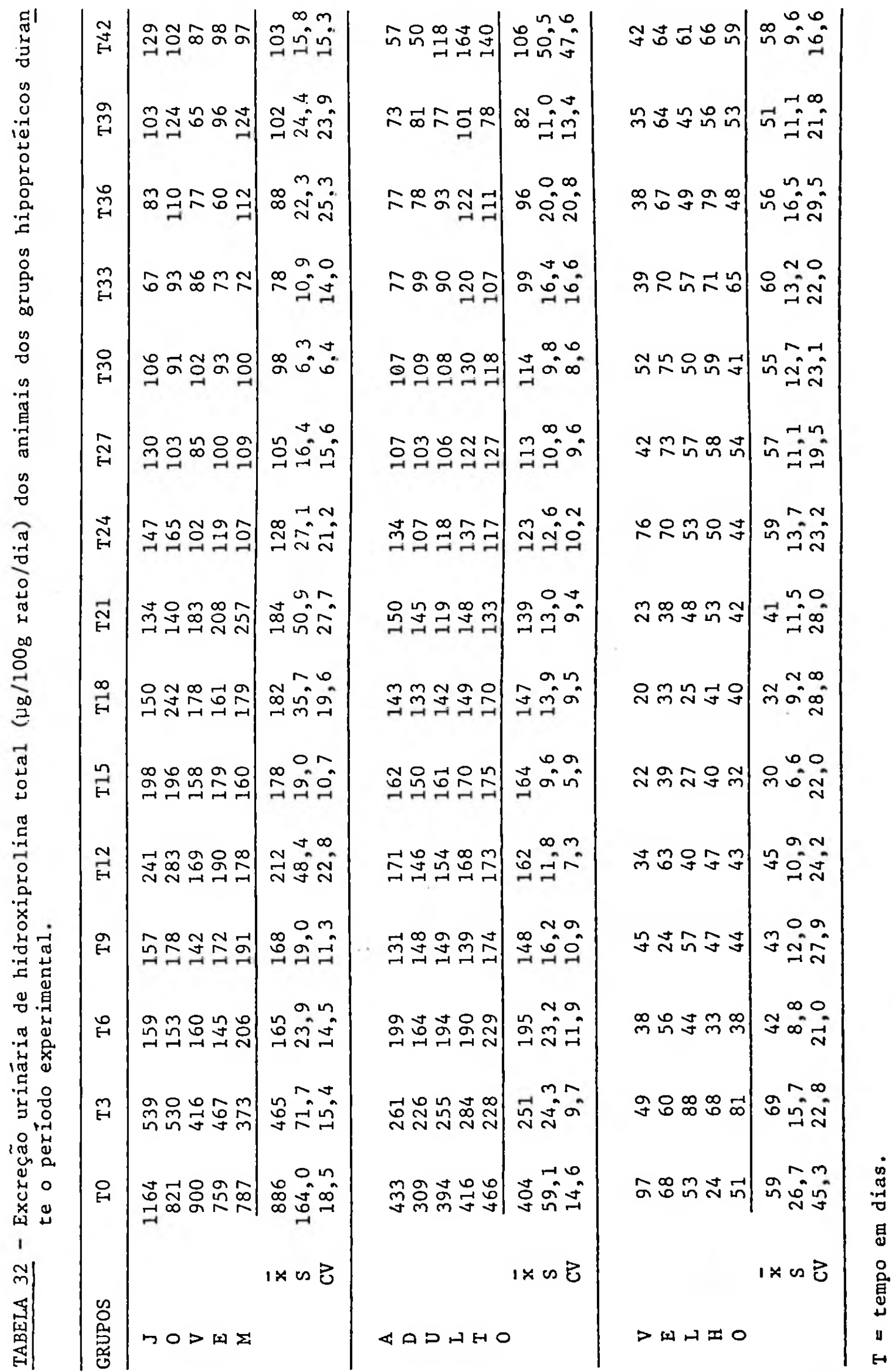




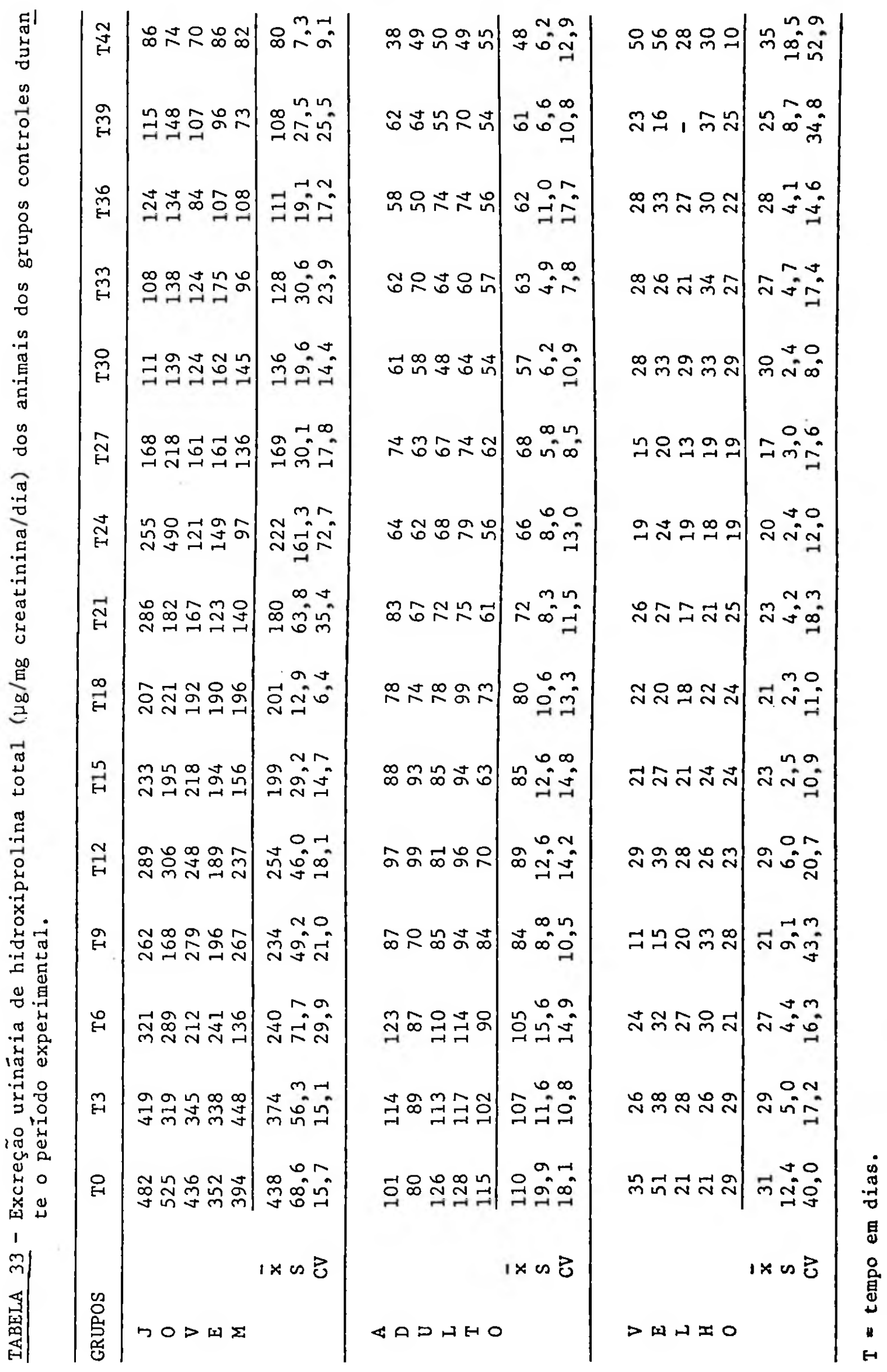




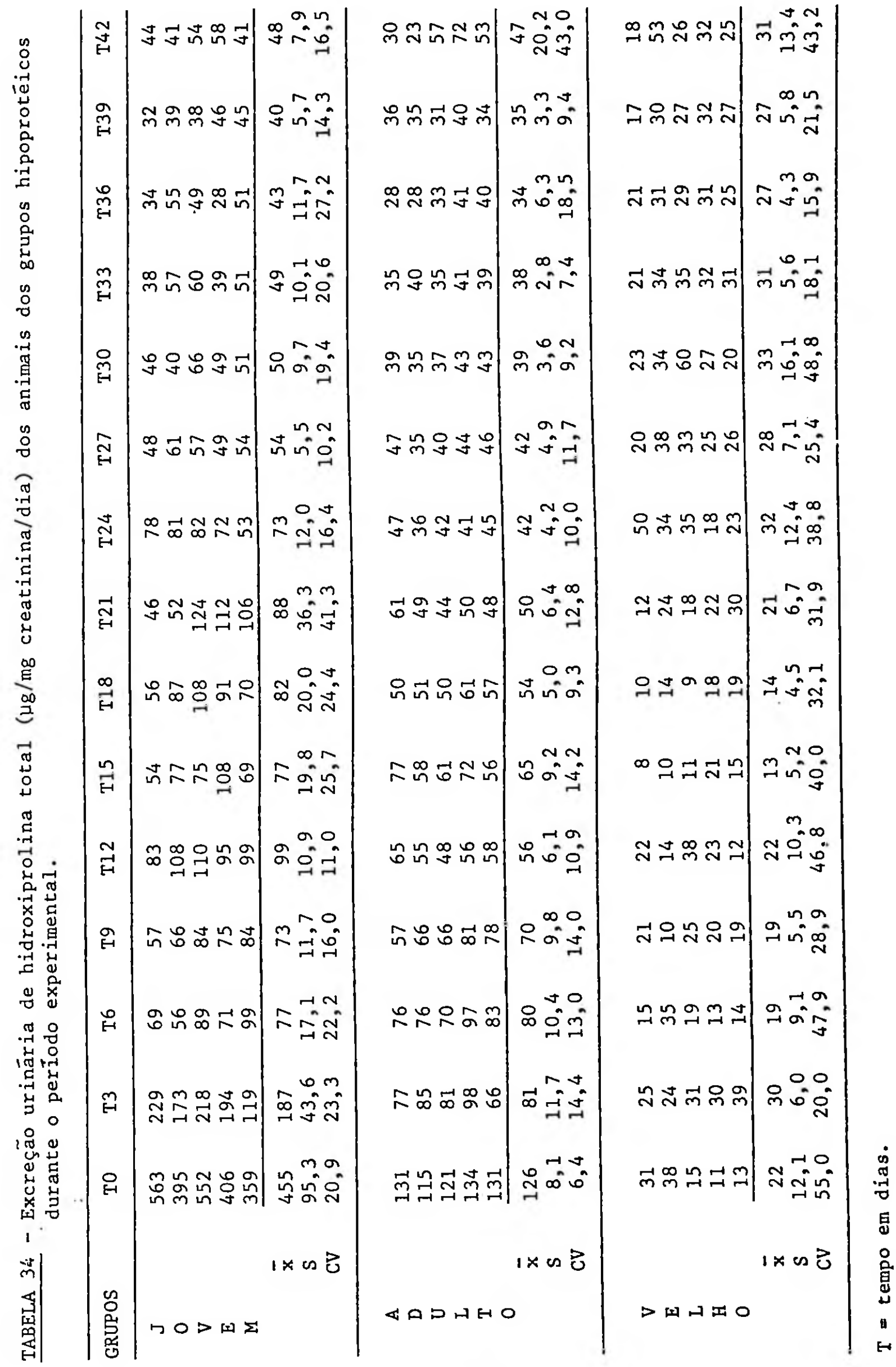

